Cochrane Database of Systematic Reviews

\title{
Exercise for pregnant women with gestational diabetes for improving maternal and fetal outcomes (Review)
}

Brown J, Ceysens G, Boulvain M

Brown J, Ceysens G, Boulvain M.

Exercise for pregnant women with gestational diabetes for improving maternal and fetal outcomes.

Cochrane Database of Systematic Reviews 2017, Issue 6. Art. No.: CD012202.

DOI: 10.1002/14651858.CD012202.pub2.

www.cochranelibrary.com 
TABLE OF CONTENTS

HEADER

ABSTRACT

PLAIN LANGUAGE SUMMARY

SUMMARY OF FINDINGS

2

BACKGROUND

OBJECTIVES

METHODS

Figure 1.

RESULTS

Figure 2.

Figure 3.

DISCUSSION

AUTHORS' CONCLUSIONS

ACKNOWLEDGEMENTS

REFERENCES

CHARACTERISTICS OF STUDIES

DATA AND ANALYSES

Analysis 1.1. Comparison 1 Exercise versus control, Outcome 1 Hypertensive disorders of pregnancy (pre-eclampsia).

Analysis 1.2. Comparison 1 Exercise versus control, Outcome 2 Caesarean section.

Analysis 1.3. Comparison 1 Exercise versus control, Outcome 3 Perinatal mortality (stillbirth and neonatal mortality).

Analysis 1.4. Comparison 1 Exercise versus control, Outcome 4 Mortality and morbidity composite (variously defined by trials, e.g. perinatal or infant death, shoulder dystocia, bone fracture or nerve palsy).

Analysis 1.5. Comparison 1 Exercise versus control, Outcome 5 Use of additional pharmacotherapy.

Analysis 1.6. Comparison 1 Exercise versus control, Outcome 6 Maternal hypoglycaemia.

Analysis 1.7. Comparison 1 Exercise versus control, Outcome 7 Glycaemic control end of treatment (Mean).

Analysis 1.8. Comparison 1 Exercise versus control, Outcome 8 Glycaemic control end of treatment (Fasting blood glucose concentration).

Analysis 1.9. Comparison 1 Exercise versus control, Outcome 9 Glycaemic control end of treatment (Postprandial blood glucose concentration).

Analysis 1.10. Comparison 1 Exercise versus control, Outcome 10 Glycaemic control end of treatment (HbA1c).

Analysis 1.11. Comparison 1 Exercise versus control, Outcome 11 Glycaemic control end of treatment (Glucose tolerance test).

Analysis 1.12. Comparison 1 Exercise versus control, Outcome 12 Weight gain in pregnancy.

Analysis 1.13. Comparison 1 Exercise versus control, Outcome 13 Weight gain in pregnancy (Excessive).

Analysis 1.14. Comparison 1 Exercise versus control, Outcome 14 Adherence to the intervention.

Analysis 1.15. Comparison 1 Exercise versus control, Outcome 15 Induction of labour.

Analysis 1.16. Comparison 1 Exercise versus control, Outcome 16 Maternal mortality.

Analysis 1.17. Comparison 1 Exercise versus control, Outcome 17 Views of the intervention (favourable).

Analysis 1.18. Comparison 1 Exercise versus control, Outcome 18 Postnatal weight retention or return to pre-pregnancy weight.

Analysis 1.19. Comparison 1 Exercise versus control, Outcome 19 Stillbirth.

Analysis 1.20. Comparison 1 Exercise versus control, Outcome 20 Macrosomia.

Analysis 1.21. Comparison 1 Exercise versus control, Outcome 21 Gestational age at birth.

Analysis 1.22. Comparison 1 Exercise versus control, Outcome 22 Preterm birth.

Analysis 1.23. Comparison 1 Exercise versus control, Outcome 23 Five-minute Apgar $<$ seven.

Analysis 1.24. Comparison 1 Exercise versus control, Outcome 24 Birthweight.

Analysis 1.25. Comparison 1 Exercise versus control, Outcome 25 Length (cm) (at birth).

Analysis 1.26. Comparison 1 Exercise versus control, Outcome 26 Neonatal hypoglycaemia.

Analysis 1.27. Comparison 1 Exercise versus control, Outcome 27 Respiratory distress syndrome.

Analysis 1.28. Comparison 1 Exercise versus control, Outcome 28 Neonatal jaundice (hyperbilirubinaemia).

Analysis 1.29. Comparison 1 Exercise versus control, Outcome 29 Hypocalcaemia. 
[Intervention Review]

\section{Exercise for pregnant women with gestational diabetes for improving maternal and fetal outcomes}

Julie Brown ${ }^{1}$, Gilles Ceysens², Michel Boulvain 3

1Liggins Institute, The University of Auckland, Auckland, New Zealand. 2Department of Obstetrics and Gynaecology, Ambroise Pare hospital, Mons, Belgium. ${ }^{3}$ Département de Gynécologie et d'Obstétrique, Unité de Développement en Obstétrique, Maternité Hôpitaux Universitaires de Genève, Genève 14, Switzerland

Contact address: Julie Brown, Liggins Institute, The University of Auckland, Park Rd, Grafton, Auckland, 1142, New Zealand. j.brown@auckland.ac.nz.

Editorial group: Cochrane Pregnancy and Childbirth Group.

Publication status and date: New, published in Issue 6, 2017.

Citation: Brown J, Ceysens G, Boulvain M. Exercise for pregnant women with gestational diabetes for improving maternal and fetal outcomes. Cochrane Database of Systematic Reviews 2017, Issue 6. Art. No.: CD012202. DOI: 10.1002/14651858.CD012202.pub2.

Copyright ( 2017 The Cochrane Collaboration. Published by John Wiley \& Sons, Ltd.

\section{A B S T R A C T}

\section{Background}

Gestational diabetes mellitus (GDM) is associated with both short- and long-term complications for the mother and her baby. Exercise interventions may be useful in helping with glycaemic control and improve maternal and infant outcomes.

The original review on Exercise for diabetic pregnant women has been split into two new review titles reflecting the role of exercise for pregnant women with gestational diabetes and for pregnant women with pre-existing diabetes.

Exercise for pregnant women with gestational diabetes for improving maternal and fetal outcomes (this review)

Exercise for pregnant women with pre-existing diabetes for improving maternal and fetal outcomes

\section{Objectives}

To evaluate the effects of exercise interventions for improving maternal and fetal outcomes in women with GDM.

\section{Search methods}

We searched the Cochrane Pregnancy and Childbirth Group's Trials Register (27 August 2016), ClinicalTrials.gov, the WHO International Clinical Trials Registry Platform (ICTRP) (18th August 2016), and reference lists of retrieved studies.

\section{Selection criteria}

We included randomised controlled trials (RCTs) comparing an exercise intervention with standard care or another intervention in pregnant women diagnosed with gestational diabetes. Quasi-randomised and cross-over studies, and studies including women with pre-existing type 1 or type 2 diabetes were not eligible for inclusion.

\section{Data collection and analysis}

All selection of studies, assessment of trial quality and data extraction was conducted independently by two review authors. Data were checked for accuracy. 


\section{Main results}

We included 11 randomised trials, involving 638 women. The overall risk of bias was judged to be unclear due to lack of methodological detail in the included studies.

For the mother, there was no clear evidence of a difference between women in the exercise group and those in the control group for the risk of pre-eclampsia as the measure of hypertensive disorders of pregnancy (risk ratio (RR) $0.31,95 \%$ confidence interval (Cl) 0.01 to 7.09 ; two RCTs, 48 women; low-quality evidence), birth by caesarean section (RR 0.86, 95\% Cl 0.63 to 1.16; five RCTs, 316 women; I2 = $0 \%$; moderatequality evidence), the risk of induction of labour (RR 1.38, 95\% Cl 0.71 to 2.68 ; one RCT, 40 women; low-quality evidence) or maternal body mass index at follow-up (postnatal weight retention or return to pre-pregnancy weight) (mean difference (MD) $0.11 \mathrm{~kg} / \mathrm{m}^{2}, 95 \% \mathrm{Cl}-1.04$ to 1.26; three RCTs, 254 women; $\mathrm{I}^{2}=0 \%$; high-quality evidence). Development of type 2 diabetes, perineal trauma/tearing and postnatal depression were not reported as outcomes in the included studies.

For the infant/child/adult, a single small $(n=19)$ trial reported no perinatal mortality (stillbirth and neonatal mortality) events in either the exercise intervention or control group (low-quality evidence). There was no clear evidence of a difference between groups for a mortality and morbidity composite (variously defined by trials, e.g. perinatal or infant death, shoulder dystocia, bone fracture or nerve palsy) (RR $0.56,95 \% \mathrm{Cl} 0.12$ to 2.61 ; two RCTs, 169 infants; $\left.\right|^{2}=0 \%$; moderate-quality evidence) or neonatal hypoglycaemia (RR $2.00,95 \% \mathrm{Cl} 0.20$ to 20.04; one RCT, 34 infants; low-quality evidence). None of the included trials pre-specified large-for-gestational age, adiposity (neonatal/ infant, childhood or adulthood), diabetes (childhood or adulthood) or neurosensory disability (neonatal/infant) as trial outcomes.

Other maternal outcomes of interest: exercise interventions were associated with both reduced fasting blood glucose concentrations (average standardised mean difference (SMD) $-0.59,95 \% \mathrm{Cl}-1.07$ to -0.11 ; four RCTs, 363 women; $\mathrm{I}^{2}=73 \%$; $\mathrm{T}^{2}=0.19$ ) and a reduced postprandial blood glucose concentration compared with control interventions (average SMD $-0.85,95 \% \mathrm{Cl}-1.15$ to -0.55 ; three RCTs, 344 women; $1^{2}=34 \% ; T^{2}=0.03$ ).

\section{Authors' conclusions}

Short- and long-term outcomes of interest for this review were poorly reported. Current evidence is confounded by the large variety of exercise interventions. There was insufficient high-quality evidence to be able to determine any differences between exercise and control groups for our outcomes of interest. For the woman, both fasting and postprandial blood glucose concentrations were reduced compared with the control groups. There are currently insufficient data for us to determine if there are also benefits for the infant. The quality of the evidence in this review ranged from high to low quality and the main reason for downgrading was for risk of bias and imprecision (wide Cls, low event rates and small sample size). Development of type 2 diabetes, perineal trauma/tearing, postnatal depression, largefor-gestational age, adiposity (neonate/infant, childhood or adulthood), diabetes (childhood or adulthood) or neurosensory disability (neonate/infant) were not reported as outcomes in the included studies.

Further research is required comparing different types of exercise interventions with control groups or with another exercise intervention that reports on both the short- and long-term outcomes (for both the mother and infant/child) as listed in this review.

\section{PLAIN LANGUAGE SUMMARY}

\section{Can exercise, for women with gestational diabetes, improve outcomes for mother and her baby?}

\section{What is the issue?}

A previous Cochrane review on Exercise for diabetic pregnant women included women with pre-existing diabetes and women with gestational diabetes. That review has now been split into two new reviews on: exercise for pregnant women with gestational diabetes (this review) and exercise for pregnant women with pre-existing diabetes (the subject of another new review).

There will be similarities in the background, methods and outcomes between these two systematic reviews.

Gestational diabetes mellitus (GDM), or diabetes during pregnancy, has both short- and long-term complications for the mother and her baby. Women with GDM are at an increased chance of developing high blood pressure or pre-eclampsia during pregnancy, having their labour induced, giving birth by caesarean section, and experiencing perineal trauma. In the long term, up to half of women with GDM are likely to develop type 2 diabetes. Their babies are at increased risk of being born large-for-gestational age, experiencing a birth injury and being admitted to the neonatal intensive care unit. They are also more likely to develop metabolic syndrome in childhood and later life.

\section{Why is this important?}

Exercise may help to control blood sugar levels and improve outcomes for the mother and her baby, possibly leading to long-term health benefits. Physical activity for this review is planned, structured and repetitive body movements undertaken to improve physical fitness.

\section{What evidence did we find?}


We searched for evidence from randomised controlled trials in August 2016. We identified 11 trials that involved 638 pregnant women. They were conducted in middle-or high-income countries. We judged the overall risk of bias in the trials as unclear because of a lack of information about how the trials were conducted. Using GRADE, the quality of the evidence from the trials ranged from high to low quality. The main reasons for downgrading the quality were for risk of bias in the trials and imprecise effect sizes, low event rates and small numbers of participants.

For the mothers, exercising did not appear to reduce the risk of pre-eclampsia as the measure of hypertensive disorders of pregnancy (two trials, 48 women, low-quality evidence), birth by caesarean section (five trials, 316 women, moderate-quality evidence), or the risk of induction of labour (one trial, 40 women, low-quality evidence). The mothers had similar body mass index at follow-up in the exercise and control groups (three trials, 254 women, high-quality evidence). Exercising was associated with lower fasting blood glucose levels (four trials) and blood glucose levels after a meal (three trials) but with variations in effect sizes between the different trials. The exercise programmes varied between trials as did their duration and whether or not they were supervised. None of the included trials reported on perineal trauma, postnatal depression or development of type 2 diabetes.

For the babies, no deaths occurred around the time of birth in (one trial, 19 babies, low-quality evidence) and there was no evidence of any difference in the risk of ill-health (two trials, 169 babies, moderate-quality evidence) or low blood sugar levels (one trial, 34 babies, lowquality evidence). None of the trials reported on the number of large-for-gestational-age babies or babies that went on to develop diabetes in childhood or adulthood or neurosensory disability that became apparent during childhood.

\section{What does this mean?}

Although exercise appeared to be able to lower fasting blood sugar levels and sugar levels after a meal, we did not find any differences in other outcomes for pregnant women with GDM. The present evidence is insufficient to advise for or against women enrolling in exercise programmes. Even if exercise does not provide any benefit during pregnancy, this change in lifestyle may persist after birth and may help prevent the onset of type 2 diabetes and its long-term complications. Pregnant women with GDM who wish to enrol in an exercise programme may wish to discuss their choice with a health professional. Further research is needed comparing one exercise intervention with another (or with a control) and reporting on both the short- and long-term outcomes (for both the mother and infant/child/adult) as listed in this review. 


\section{SUMMARY OF FINDINGS}

Summary of findings for the main comparison. Exercise compared to control for pregnant women with gestational diabetes for improving maternal outcomes

\section{Exercise compared to control for pregnant women with gestational diabetes for improving maternal outcomes}

Patient or population: pregnant women with gestational diabetes

Setting: USA, Italy, Brazil, Australia

Intervention: exercise

Comparison: control

\begin{tabular}{|c|c|c|c|c|c|c|}
\hline \multirow[t]{2}{*}{ Outcomes } & \multicolumn{2}{|c|}{$\begin{array}{l}\text { Anticipated absolute effects }{ }^{*} \\
(95 \% \mathrm{CI})\end{array}$} & \multirow[t]{2}{*}{$\begin{array}{l}\text { Relative effect } \\
(95 \% \mathrm{Cl})\end{array}$} & \multirow{2}{*}{$\begin{array}{l}\text { № of partici- } \\
\text { pants } \\
\text { (studies) }\end{array}$} & \multirow{2}{*}{$\begin{array}{l}\text { Quality of the } \\
\text { evidence } \\
\text { (GRADE) }\end{array}$} & \multirow[t]{2}{*}{ Comments } \\
\hline & $\begin{array}{l}\text { Risk with con- } \\
\text { trol }\end{array}$ & $\begin{array}{l}\text { Risk with exer- } \\
\text { cise }\end{array}$ & & & & \\
\hline $\begin{array}{l}\text { Hypertensive disorders of } \\
\text { pregnancy (pre-eclampsia) }\end{array}$ & 43 per 1000 & $\begin{array}{l}13 \text { per } 1000 \\
(0 \text { to } 308)\end{array}$ & $\begin{array}{l}\text { RR } 0.31 \\
\text { (0.01 to } 7.09)\end{array}$ & $\begin{array}{l}48 \\
(2 \mathrm{RCTS})\end{array}$ & $\begin{array}{l}\oplus \oplus \ominus \ominus \\
\text { LOW } 12\end{array}$ & $\begin{array}{l}\text { Event rates were very low with } 0 / 25 \text { in the } \\
\text { exercise group and } 1 / 23 \text { in the control } \\
\text { group. }\end{array}$ \\
\hline & & & & & & $\begin{array}{l}\text { No data were reported for pregnancy-in- } \\
\text { duced hypertension or eclampsia. }\end{array}$ \\
\hline Caesarean section & 319 per 1000 & $\begin{array}{l}274 \text { per } 1000 \\
\text { (201 to } 370)\end{array}$ & $\begin{array}{l}\text { RR } 0.86 \\
\text { (0.63 to } 1.16)\end{array}$ & $\begin{array}{l}316 \\
(5 \mathrm{RCTs})\end{array}$ & $\begin{array}{l}\oplus \oplus \oplus \ominus \\
\text { MODERATE } 1\end{array}$ & \\
\hline $\begin{array}{l}\text { Development of type } 2 \text { dia- } \\
\text { betes - not measured }\end{array}$ & - & - & - & - & - & $\begin{array}{l}\text { This outcome was not measured in any of } \\
\text { the included studies in this review. }\end{array}$ \\
\hline $\begin{array}{l}\text { Postnatal weight retention } \\
\text { or return to pre-pregnancy } \\
\text { weight (maternal BMI (fol- } \\
\text { low-up) } \mathrm{kg} / \mathrm{m}^{2} \text { ) }\end{array}$ & $\begin{array}{l}\text { The mean ma- } \\
\text { ternal BMI (fol- } \\
\text { low-up) } \mathrm{kg} / \mathrm{m} 2 \\
\text { was } 0\end{array}$ & $\begin{array}{l}\text { MD } 0.11 \text { higher } \\
\text { (1.04 lower to } \\
1.26 \text { higher) }\end{array}$ & - & $\begin{array}{l}254 \\
\text { (3 RCTs) }\end{array}$ & $\begin{array}{l}\oplus \oplus \oplus \oplus \\
\mathrm{HIGH}\end{array}$ & \\
\hline $\begin{array}{l}\text { Postnatal depression - not } \\
\text { measured }\end{array}$ & - & - & - & - & - & $\begin{array}{l}\text { This outcome was not measured in any of } \\
\text { the included studies in this review. }\end{array}$ \\
\hline Induction of labour & 400 per 1000 & $\begin{array}{l}552 \text { per } 1000 \\
\text { ( } 284 \text { to } 1,000)\end{array}$ & $\begin{array}{l}\text { RR } 1.38 \\
\text { (0.71 to } 2.68)\end{array}$ & $\begin{array}{l}40 \\
(1 \mathrm{RCT})\end{array}$ & $\oplus \oplus \ominus \ominus$ & $\begin{array}{l}\text { Event rates and sample size were low } 11 / 20 \\
\text { in exercise group and } 8 / 20 \text { in control group. }\end{array}$ \\
\hline
\end{tabular}


${ }^{*}$ The risk in the intervention group (and its $95 \%$ confidence interval) is based on the assumed risk in the comparison group and the relative effect of the intervention (and its $95 \% \mathrm{Cl})$.

Cl: Confidence interval; RR: Risk ratio

\section{GRADE Working Group grades of evidence}

High quality: We are very confident that the true effect lies close to that of the estimate of the effect

Moderate quality: We are moderately confident in the effect estimate: The true effect is likely to be close to the estimate of the effect, but there is a possibility that it is sub-

stantially different

Low quality: Our confidence in the effect estimate is limited: The true effect may be substantially different from the estimate of the effect

Very low quality: We have very little confidence in the effect estimate: The true effect is likely to be substantially different from the estimate of effect

1 Lack of clarity for most items related to risk of bias - downgraded one level.

2 Wide confidence intervals crossing the line of no effect and low event rates with a small sample size are suggestive of imprecision - downgraded one level.

3 Imprecision - low event rates and small sample size - downgraded one level.

\section{Summary of findings 2 . Exercise compared to control for pregnant women with gestational diabetes for improving fetal outcomes}

Exercise compared to control for pregnant women with gestational diabetes for improving maternal and fetal outcomes

Patient or population: pregnant women with gestational diabetes

Setting: USA, Italy

Intervention: exercise

Comparison: control

\begin{tabular}{|c|c|c|c|c|c|c|}
\hline \multirow[t]{2}{*}{ Outcomes } & \multicolumn{2}{|c|}{$\begin{array}{l}\text { Anticipated absolute effects }{ }^{*} \\
(95 \% \mathrm{CI})\end{array}$} & \multirow[t]{2}{*}{$\begin{array}{l}\text { Relative effect } \\
(95 \% \mathrm{CI})\end{array}$} & \multirow{2}{*}{$\begin{array}{l}\text { № of partici- } \\
\text { pants } \\
\text { (studies) }\end{array}$} & \multirow{2}{*}{$\begin{array}{l}\text { Quality of the } \\
\text { evidence } \\
\text { (GRADE) }\end{array}$} & \multirow[t]{2}{*}{ Comments } \\
\hline & $\begin{array}{l}\text { Risk with con- } \\
\text { trol }\end{array}$ & $\begin{array}{l}\text { Risk with exer- } \\
\text { cise }\end{array}$ & & & & \\
\hline $\begin{array}{l}\text { Large-for-gestational age - } \\
\text { not reported }\end{array}$ & - & - & - & - & - & $\begin{array}{l}\text { None of the included studies in this review re- } \\
\text { ported data for this outcome. }\end{array}$ \\
\hline
\end{tabular}




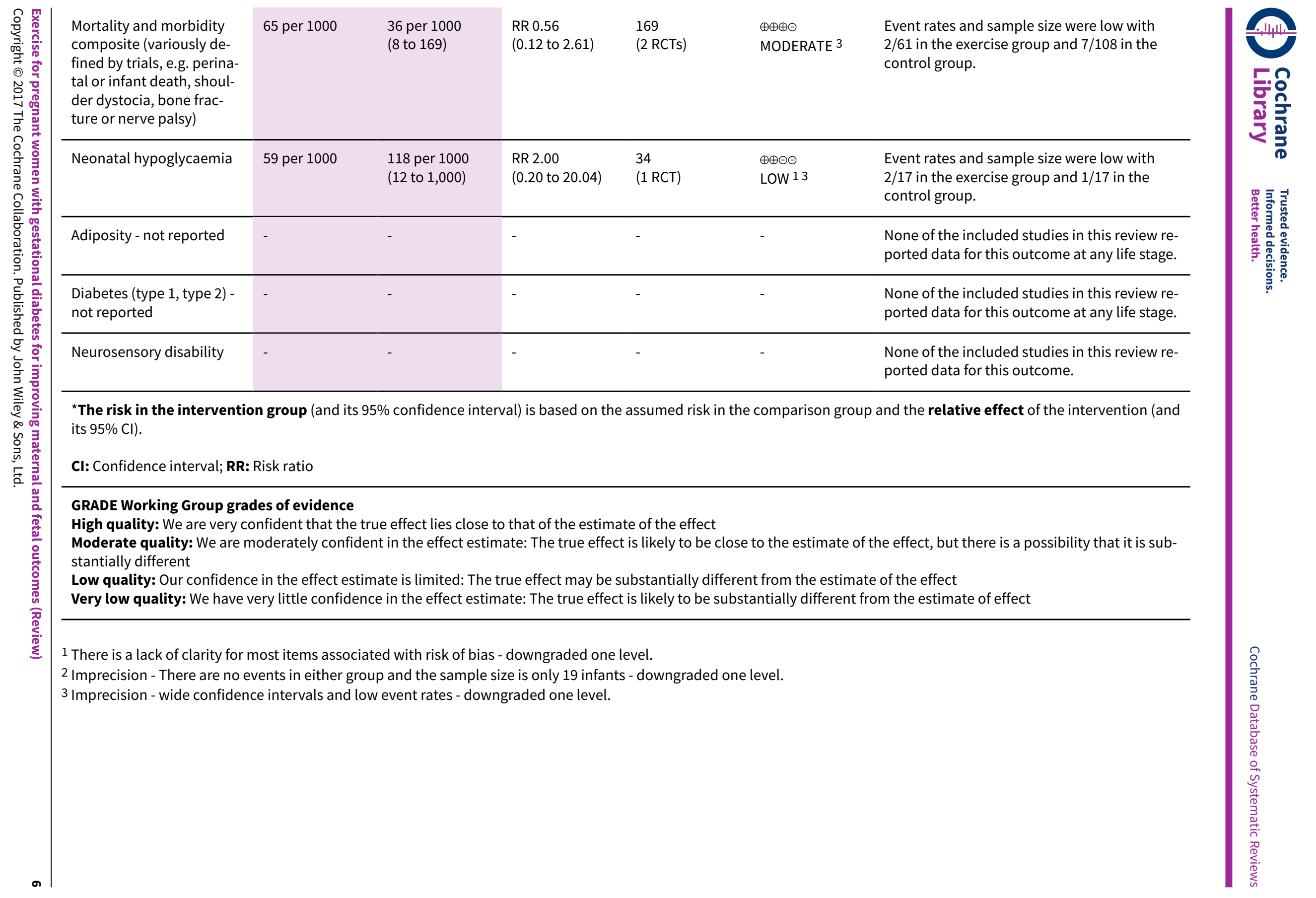




\section{B A C K G R O U N D}

The original review by Ceysens and colleagues Exercise for diabetic pregnant women (Ceysens 2006) has been split into two new review titles reflecting the role of exercise for pregnant women with gestational diabetes and for pregnant women with pre-existing diabetes.

Exercise for pregnant women with gestational diabetes for improving maternal and fetal outcomes (this review)

Exercise for pregnant women with pre-existing diabetes for improving maternal and fetal outcomes

There will be similarities in the background, methods and outcomes between these two systematic reviews. Portions of the methods section of this review are based on a standard template used by the Cochrane Pregnancy and Childbirth Review Group.

\section{Description of the condition}

Gestational diabetes mellitus (GDM) is defined as "glucose intolerance or hyperglycaemia (high blood glucose concentration) with onset or first recognition during pregnancy" (WHO 1999) that usually resolves around the time of birth. Diagnosis is usually made following an oral glucose tolerance test (OGTT) although various definitions of glucose intolerance and subsequently classification of GDM exist (ACOG 2013; Coustan 2010; HAPO 2008; IADPSG 2010; NICE 2015). Recent definitions of GDM exclude overt diabetes which may be detected for the first time during pregnancy (IADPSG 2010; WHO 2014)

Rates of GDM are increasing globally, and up to one third of pregnancies are now thought to be affected (Cundy 2014; Duran 2014; Ferrara 2007; NICE 2015; Tran 2013). The incidence of GDM is likely to increase in parallel with increasing rates of maternal obesity and associated type 2 diabetes (Bottalico 2007; Petry 2010), and between different diagnostic criteria (Cundy 2014).

Non-modifiable risk factors associated with an increased chance of being diagnosed with GDM include: having a previous macrosomic infant (birthweight $4000 \mathrm{~g}$ or more) or having been diagnosed with GDM in a previous pregnancy (Petry 2010); older maternal age (Chamberlain 2013), ethnicity (e.g. South Asian, Middle Eastern), high parity, or having a first-degree relative with a history of type 2 diabetes or polycystic ovarian syndrome (Cypryk 2008; Petry 2010). Maternal overweight/obesity (Kim 2010), physically inactivity (Chasan-Taber 2008) and excessive gestational weight gain (Hedderson 2010) are modifiable risk factors that are associated with an increased chance of being diagnosed with GDM.

Throughout pregnancy maternal metabolism is altered (Lain 2007). The first trimester is associated with an increase in insulin secretion that enhances maternal nutrient storage for later fetal growth. During this stage of early pregnancy insulin sensitivity is stable or may even increase. The physiological demands of later pregnancy means that insulin sensitivity gradually decreases (Barbour 2007), and as a result, the fetus is able to increase glucose uptake for fetal growth. In non-diabetic women, normal blood glucose levels are maintained through a process of increasing insulin secretion (Barbour 2007; Lain 2007). Reductions in insulin signalling in women with GDM result in glucose intolerance, which promotes fetal glucose uptake (Barbour 2007).

\section{Adverse outcomes for women associated with gestational diabetes}

Women with GDM are at an increased chance of developing hypertensive disorders of pregnancy, having their labour induced (Crowther 2005; Landon 2009), giving birth by caesarean section (Landon 2009), and having perineal trauma (Jastrow 2010). In the long term, up to half of women with GDM are likely to proceed to be diagnosed with type 2 diabetes (Kim 2002).

\section{Short- and long-term adverse outcomes for the neonate associated with gestational diabetes}

Infants of mothers diagnosed with GDM are at an increased risk of being born large-for-gestational age (LGA) or macrosomic (Crowther 2005; Landon 2009), have respiratory distress syndrome, neonatal hypoglycaemia, hyperbilirubinaemia and being admitted to the neonatal intensive care unit (Metzger 2008; Reece 2009). These infants are also more likely to have a birth injury, including shoulder dystocia, bone fractures and/or nerve palsy (Esakoff 2009; Henriksen 2008), are more likely to have increased adiposity (Catalano 2003; Pettitt 1985; Pettitt 1993), and are more likely to develop metabolic syndrome in childhood and later life (Guerrero-Romero 2010; Harder 2009). These inter-generational health problems remain an important issue for public health policy.

\section{Description of the intervention}

The American College of Sports Medicine defines physical activity as any bodily movement that is produced as a result of the contraction of skeletal muscle and defines exercise as physical activity comprising planned, structured and repetitive body movements which are undertaken to improve one or more components of physical fitness (ACSM 2014).

Physical activity in pregnancy (in non-diabetic women) has been shown to be beneficial, has not been shown to be harmful to the fetus, and can potentially lead to long-term health benefits for the mother (Nascimento 2012). Benefits observed include cardiorespiratory fitness, prevention of stress urinary incontinence, prevention of lumbar pain, decreased depression and control of weight gain during pregnancy (Nascimento 2012).

In women with type 2 diabetes, who were not pregnant, physical activity combined with diet and hypoglycaemic medication has been shown to be effective in maintaining glycaemic control (Tuomilehto 2001).

This evidence may not be generalisable to pregnant women with GDM, but it does suggest that mild exercise during pregnancy may have the potential to reduce the risk of complications associated with GDM.

The American College of Obstetricians and Gynecologists (ACOG) notes that physical activity in pregnancy appears to have benefits for most women and has few risks associated with it, although some adaptation may be required due to usual anatomical and physiological changes in pregnancy (ACOG 2015). ACOG 2015 also recommends that a clinical evaluation is conducted prior to undertaking an exercise programme during pregnancy to ensure that there are no medical contraindications to participation and that participation in aerobic and strength-conditioning exercises should be encouraged in women before, during and after uncomplicated pregnancies. 
Aerobic exercise during pregnancy is contraindicated in a number of medical conditions, including:

1. cardiac disease;

2. restrictive lung disease;

3. incompetent cervix/cerclage;

4. multiple gestation at risk of preterm birth;

5. persistent second or third trimester bleeding;

6. placenta praevia after 26 weeks' gestation;

7. preterm labour (current pregnancy);

8. ruptured membranes;

9. pre-eclampsia or pregnancy-induced hypertension;

10.severe anaemia (ACOG 2015).

Safe physical activities that are considered acceptable to continue with or initiate during an uncomplicated pregnancy, following medical advice include:

1. walking;

2. swimming;

3. stationary cycling;

4. low-impact aerobics;

5. modified yoga (avoiding positions that result in decreased venous return);

6. modified Pilates;

7. racquet sports;

8. running or jogging;

9. strength training (ACOG 2015).

The latter two activities in the list above should be undertaken following consultation with an obstetric care provider (ACOG 2015). During pregnancy the duration, frequency and intensity of physical activity may have to be modified (Nascimento 2012)

A number of activities are recommended to be avoided during pregnancy, including:

1. contact sports (e.g. ice hockey, soccer, boxing);

2. activities with a high risk of falling (e.g. skiing, surfing, off-road cycling);

3. scuba diving;

4. sky diving;

5. 'hot yoga' or 'hot Pilates' (ACOG 2015).

\section{How the intervention might work}

Glycaemic control may be improved in those with diabetes (type 1 , type 2 or GDM) by the amount of physical activity as a result of the interaction between insulin sensitivity and uptake of glucose by skeletal muscle (Asano 2014). Skeletal muscles use a process of diffusion to take up glucose using a glucose transporter type 4 (GLUT4). Increases in insulin receptor substrate, insulin receptor and phosphatidylinositol 3-kinase (Chibalin 2000; Dela 1993; Hjeltnes 1998) following regular physical activity are associated with improvements in insulin sensitivity.

\section{Why it is important to do this review}

Rates of GDM continue to increase globally (NICE 2015) and are associated with both short- (Crowther 2005; Landon 2009; Reece
2009) and long-term (Guerrero-Romero 2010; Harder 2009) adverse effects for the woman and her infant. Identifying interventions for improving health outcomes for women with GDM and their infants is a priority. Exercise has been shown to have benefits for women without GDM (Tuomilehto 2001); the benefits and safety for women with GDM remains unclear.

\section{O B JECTIVES}

To evaluate the effects of exercise interventions for improving maternal and fetal outcomes in women with gestational diabetes mellitus (GDM).

\section{METHODS}

\section{Criteria for considering studies for this review}

\section{Types of studies}

We included published or unpublished randomised controlled trials in full-text or abstract format. Cluster-randomised trials were eligible for inclusion but none were identified. Quasi-randomised and cross-over trials were not eligible for inclusion. Conference abstracts were handled in the same way as full-text publications.

\section{Types of participants}

Pregnant women diagnosed with gestational diabetes mellitus (GDM) (as defined by trialist).

Women with known pre-gestational diabetes (type 1 or type 2 diabetes) were excluded as this will be covered in a different Cochrane review on Exercise for pregnant women with pre-existing diabetes for improving maternal and fetal outcomes.

\section{Types of interventions}

We included any type of exercise programme (+/- standard care) targeted at women with GDM at any stage of pregnancy compared with 1) standard care or 2) another intervention.

\section{Types of outcome measures}

\section{Primary outcomes}

Mother

1. Hypertensive disorders of pregnancy (as reported by trialists, including pre-eclampsia, pregnancy-induced hypertension, eclampsia)

2. Caesarean section

3. Development of type 2 diabetes

\section{Neonatal/infant}

1. Large-for-gestational age ( $\geq 4 \mathrm{~kg}$ )

2. Perinatal mortality (stillbirth and neonatal mortality)

3. Mortality or morbidity composite (variously defined by trials, e.g. perinatal or infant death, shoulder dystocia, bone fracture or nerve palsy)

4. Neurosensory disability

\section{Secondary outcomes}

Mother

1. Use of additional pharmacotherapy 
2. Maternal hypoglycaemia (as defined by trialists)

3. Glycaemic control during/end of treatment (as defined by trialists)

4. Weight gain in pregnancy

5. Adherence to the intervention

6. Induction of labour

7. Placental abruption

8. Postpartum haemorrhage (as defined by trialists)

9. Postpartum infection

10.Perineal trauma/tearing

11. Breastfeeding at discharge, six weeks postpartum, six months or longer

12. Maternal mortality

13.Sense of well-being and quality of life

14. Behavioural changes associated with the intervention

15.Views of the intervention

16. Relevant biomarker changes associated with the intervention (including adiponectin, free fatty acids, triglycerides, highdensity lipoproteins, low-density lipoproteins, insulin)

Long-term maternal outcomes

1. Postnatal depression

2. Postnatal weight retention or return to pre-pregnancy weight

3. Body mass index (BMI)

4. GDM in a subsequent pregnancy

5. Type 2 diabetes

6. Impaired glucose tolerance

7. Cardiovascular health (as defined by trialists, including blood pressure, hypertension, cardiovascular disease, metabolic syndrome)

\section{Neonatal/infant}

1. Stillbirth

2. Neonatal death

3. Macrosomia (greater than $4000 \mathrm{~g}$; or as defined by individual study)

4. Small-for-gestational age (as defined by trialists)

5. Birth trauma (shoulder dystocia, bone fracture, nerve palsy)

6. Gestational age at birth

7. Preterm birth ( $<37$ weeks' gestation; and $<32$ weeks' gestation)

8. Five-minute Apgar < seven

9. Birthweight and $z$ score

10. Head circumference and $z$ score

11. Length and $z$ score

12.Ponderal index

13.Adiposity (including skinfold thickness measurements ( $\mathrm{mm}$ ), fat mass)

14. Neonatal hypoglycaemia (as defined by trialists)

15. Respiratory distress syndrome

16. Neonatal jaundice (hyperbilirubinaemia) (as defined by trialists)

17. Hypocalcaemia (as defined by trialists)

18. Polycythaemia (as defined by trialists)

19. Relevant biomarker changes associated with the intervention (including insulin, cord c-peptide)

\section{Later infant and childhood secondary outcomes}

1. Weight and $z$ scores

2. Height and $z$ scores

3. Head circumference and $z$ scores

4. Adiposity (including BMI, skinfold thickness, fat mass)

5. Educational attainment

6. Blood pressure

7. Type I diabetes

8. Type 2 diabetes

9. Impaired glucose tolerance

10.Dyslipidaemia or metabolic syndrome

Child as an adult

1. Weight

2. Height

3. Adiposity (including BMI, skinfold thickness)

4. Cardiovascular health (as defined by trialists, including blood pressure, hypertension, cardiovascular disease, metabolic syndrome)

5. Employment, education and social status/achievement

6. Type 1 diabetes

7. Type 2 diabetes

8. Impaired glucose tolerance

\section{Health service use}

1. Number of antenatal visits or admissions

2. Number of hospital or health professional visits (including midwife, obstetrician, physician, dietician, diabetic nurse)

3. Admission to neonatal intensive care unit/nursery

4. Cost of maternal care

5. Cost of offspring care

6. Costs associated with the intervention

7. Costs to families associated with the management provided

8. Cost of dietary monitoring (e.g. diet journals, dietician, nurse visits, etc)

9. Costs to families - change of diet, extra antenatal visits

10. Extra use of healthcare services (consultations, blood glucose monitoring, length and number of antenatal visits)

11.Women's view of treatment advice

12.Duration of stay in neonatal intensive care unit or special care baby unit

13.Duration of maternal and neonatal hospital stay (antenatal, neonatal, postnatal)

\section{Search methods for identification of studies}

The following methods section of this review is based on a standard template used by Cochrane Pregnancy and Childbirth.

\section{Electronic searches}

We searched the Cochrane Pregnancy and Childbirth Group's Trials Register by contacting their Information Specialist (27 August 2016).

The Register is a database containing over 23,000 reports of controlled trials in the field of pregnancy and childbirth. For full 
search methods used to populate Pregnancy and Childbirth's Trials Register including the detailed search strategies for CENTRAL, MEDLINE, Embase and CINAHL; the list of handsearched journals and conference proceedings, and the list of journals reviewed via the current awareness service, please follow this link to the editorial information about the Cochrane Pregnancy and Childbirth in the Cochrane Library and select the 'Specialized Register' section from the options on the left side of the screen.

Briefly, the Cochrane Pregnancy and Childbirth's Trials Register is maintained by their Information Specialist and contains trials identified from:

1. monthly searches of the Cochrane Central Register of Controlled Trials (CENTRAL);

2. weekly searches of MEDLINE (Ovid);

3. weekly searches of Embase (Ovid);

4. monthly searches of CINAHL (EBSCO);

5. handsearches of 30 journals and the proceedings of major conferences;

6. weekly current awareness alerts for a further 44 journals plus monthly BioMed Central email alerts.

Search results are screened by two people and the full text of all relevant trial reports identified through the searching activities described above is reviewed. Based on the intervention described, each trial report is assigned a number that corresponds to a specific Pregnancy and Childbirth review topic (or topics), and is then added to the Register. The Information Specialist searches the Register for each review using this topic number rather than keywords. This results in a more specific search set which has been fully accounted for in the relevant review sections (Included studies; Excluded studies; Studies awaiting classification; Ongoing studies)

In addition, we searched ClinicalTrials.gov and the WHO International Clinical Trials Registry Platform (ICTRP) (18th August 2016) for unpublished, planned and ongoing trial reports. The search terms we used are given in Appendix 1.

\section{Searching other resources}

We searched the reference lists of retrieved studies. We did not apply any language or date restrictions.

\section{Data collection and analysis}

The following methods section of this review is based on a standard template used by Cochrane Pregnancy and Childbirth.

\section{Selection of studies}

Two review authors independently assessed for inclusion all the potential studies we identified as a result of the search strategy. We resolved any disagreement through discussion or, if required, we consulted a third person.

We created a study flow diagram to map out the number of records identified, included and excluded (Figure 1). 
Figure 1. Study flow diagram.

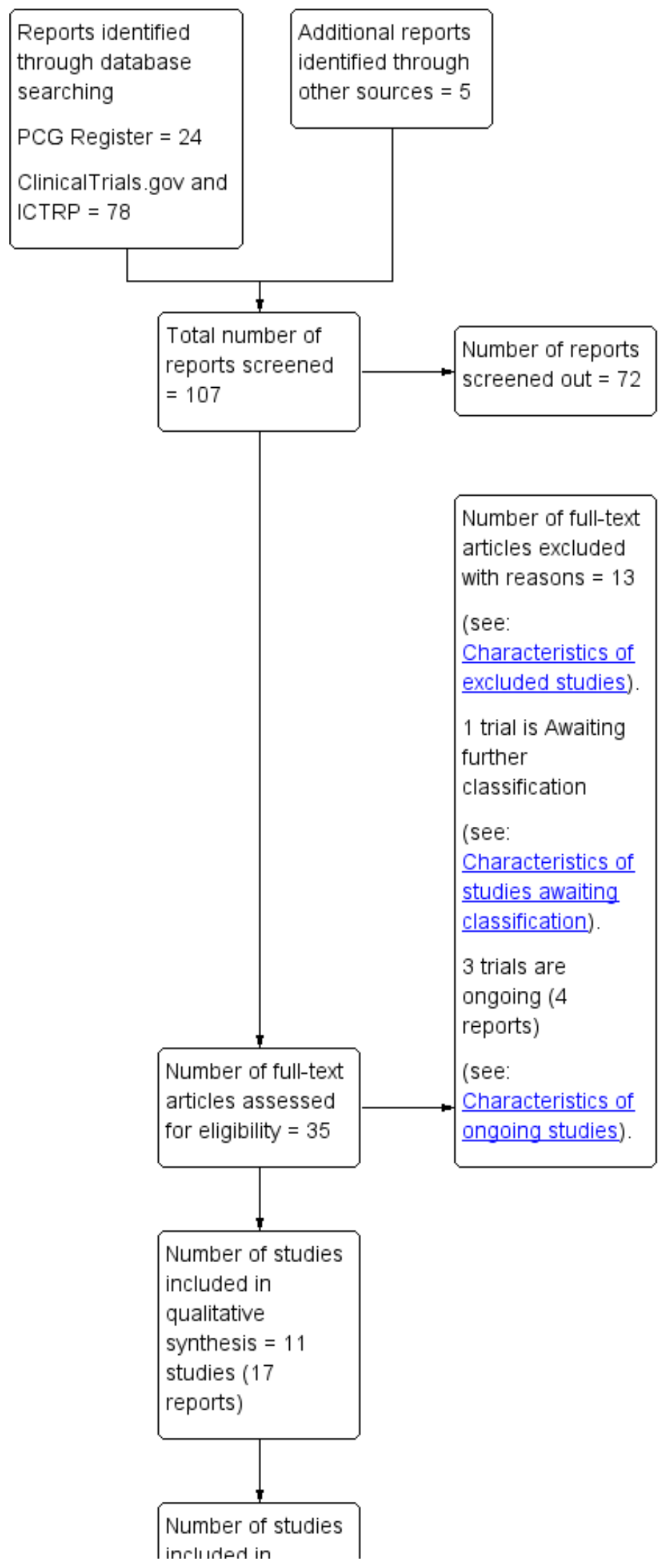


Figure 1. (Continued)

Number of studies
included in
qualitative
synthesis = 11

\section{Data extraction and management}

We designed a form to extract data. For eligible studies, two review authors extracted the data using the agreed form. We resolved discrepancies through discussion or, if required, we consulted a third person. We entered data into Review Manager software (RevMan 2014) and checked for accuracy. When information regarding any of the above was unclear, we attempted to contact authors of the original reports to provide further details.

\section{Assessment of risk of bias in included studies}

Two review authors independently assessed risk of bias for each study using the criteria outlined in the Cochrane Handbook for Systematic Reviews of Interventions (Higgins 2011). We resolved any disagreement by discussion or by involving a third person.

The following sections refer to individually-randomised trials.

\section{(1) Random sequence generation (checking for possible selection bias)}

We described for each included study the method used to generate the allocation sequence in sufficient detail to allow an assessment of whether it should produce comparable groups.

We assessed the method as:

- low risk of bias (any truly random process, e.g. random number table; computer random number generator);

- high risk of bias (any non-random process, e.g. odd or even date of birth; hospital or clinic record number);

- unclear risk of bias.

\section{(2) Allocation concealment (checking for possible selection bias)}

We described for each included study the method used to conceal allocation to interventions prior to assignment and assessed whether intervention allocation could have been foreseen in advance of, or during recruitment, or changed after assignment.

We assessed the methods as:

- low risk of bias (e.g. telephone or central randomisation; consecutively numbered sealed opaque envelopes);

- high risk of bias (open random allocation; unsealed or nonopaque envelopes, alternation; date of birth);

- unclear risk of bias.

\section{(3.1) Blinding of participants and personnel (checking for} possible performance bias)

We described for each included study the methods used, if any, to blind study participants and personnel from knowledge of which intervention a participant received. We considered that studies were at low risk of bias if they were blinded, or if we judged that the lack of blinding would be unlikely to affect results. We assessed blinding separately for different outcomes or classes of outcomes.

We assessed the methods as:

- low, high or unclear risk of bias for participants;

- low, high or unclear risk of bias for personnel.

\section{(3.2) Blinding of outcome assessment (checking for possible detection bias)}

We described for each included study the methods used, if any, to blind outcome assessors from knowledge of which intervention a participant received. We assessed blinding separately for different outcomes or classes of outcomes.

We assessed the methods used to blind outcome assessment as:

- low, high or unclear risk of bias.

(4) Incomplete outcome data (checking for possible attrition bias due to the amount, nature and handling of incomplete outcome data)

We described for each included study, and for each outcome or class of outcomes, the completeness of data including attrition and exclusions from the analysis. We stated whether attrition and exclusions were reported and the numbers included in the analysis at each stage (compared with the total randomised participants), reasons for attrition or exclusion where reported, and whether missing data were balanced across groups or were related to outcomes. Where sufficient information was reported, or could be supplied by the trial authors, we re-included missing data in the analyses.

We assessed the methods as:

- low risk of bias (e.g. no missing outcome data; missing outcome data balanced across groups);

- high risk of bias (e.g. numbers or reasons for missing data imbalanced across groups; 'as treated' analysis done with substantial departure of intervention received from that assigned at randomisation);

- unclear risk of bias.

\section{(5) Selective reporting (checking for reporting bias)}

We described for each included study how we investigated the possibility of selective outcome reporting bias and what we found.

We assessed the methods as:

- low risk of bias (where it is clear that all of the study's prespecified outcomes and all expected outcomes of interest to the review have been reported); 
- high risk of bias (where not all the study's pre-specified outcomes have been reported; one or more reported primary outcomes were not pre-specified; outcomes of interest were reported incompletely and so cannot be used; study fails to include results of a key outcome that would have been expected to have been reported);

- unclear risk of bias.

\section{(6) Other bias (checking for bias due to problems not covered by} (1) to (5) above)

We described for each included study any important concerns we have about other possible sources of bias.

We assessed whether each study was free of other problems that could put it at risk of bias:

- low risk of other bias;

- high risk of other bias;

- unclear whether there is risk of other bias.

\section{(7) Overall risk of bias}

We made explicit judgements about whether studies were at high risk of bias, according to the criteria given in the Handbook (Higgins 2011). With reference to (1) to (6) above, we assessed the likely magnitude and direction of the bias and whether we considered it is likely to impact on the findings. We explored the impact of the level of bias through undertaking sensitivity analyses - see Sensitivity analysis.

\section{Assessment of the quality of the evidence using the GRADE approach}

We assessed the quality of the evidence using the GRADE approach as outlined in the GRADE handbook in order to assess the quality of the body of evidence relating to the following outcomes for the mother and for the infant for the main comparisons of 1) exercise versus standard care and 2 ) exercise versus another intervention.

\section{Maternal}

1. Hypertensive disorders of pregnancy (as reported by trialists, including pre-eclampsia, pregnancy-induced hypertension, eclampsia)

2. Caesarean section

3. Development of type 2 diabetes

4. Perineal trauma/tearing

5. Postnatal weight retention or return to pre-pregnancy weight

6. Postnatal depression

7. Induction of labour

\section{Child (as a fetus, neonate, child, adult)}

1. Large-for-gestational age

2. Perinatal mortality (stillbirth and neonatal mortality)

3. Mortality and morbidity composite (variously defined by trials, e.g. perinatal or infant death, shoulder dystocia, bone fracture or nerve palsy)

4. Neonatal hypoglycaemia

5. Adiposity ${ }^{\star}$

6. Diabetes (type 1 , type 2$)^{\star}$

7. Neurosensory disability
We used the GRADEpro Guideline Development Tool to import data from Review Manager 5.3 (RevMan 2014) in order to create 'Summary of findings' tables. A summary of the intervention effect and a measure of quality for each of the above outcomes was produced using the GRADE approach. The GRADE approach uses five considerations (study limitations, consistency of effect, imprecision, indirectness and publication bias) to assess the quality of the body of evidence for each outcome. The evidence can be downgraded from 'high quality' by one level for serious (or by two levels for very serious) limitations, depending on assessments for risk of bias, indirectness of evidence, serious inconsistency, imprecision of effect estimates or potential publication bias.

*These outcomes will be reported for each stage of life where data are reported.

\section{Measures of treatment effect \\ Dichotomous data}

For dichotomous data, we presented results as summary risk ratio with $95 \%$ confidence intervals.

\section{Continuous data}

For continuous data, we used the mean difference if outcomes were measured in the same way between trials. We used the standardised mean difference (SMD) to combine trials that measured the same outcome, but used different methods.

\section{Unit of analysis issues}

\section{Cluster-randomised trials}

We did not identify any cluster-randomised trials for inclusion in this review. In future updates, if cluster-randomised trials are identified we will include them in the analyses along with individually-randomised trials. We will make adjustments using the methods described in the Handbook [Section 16.3.4 or 16.3.6] using an estimate of the intra-cluster correlation co-efficient (ICC) derived from the trial (if possible), from a similar trial or from a study of a similar population. If we use ICCs from other sources, we will report this and conduct sensitivity analyses to investigate the effect of variation in the ICC. We will consider it reasonable to combine the results from both cluster-randomised trials and individuallyrandomised trials if there is little heterogeneity between the study designs and the interaction between the effect of intervention and the choice of randomisation unit is considered to be unlikely. If cluster-randomised trials are included, we will seek statistical advice on appropriate analysis to enable inclusion of data in the meta-analyses.

\section{Other unit of analysis issues}

\section{Multiple pregnancy}

There may be unit of analysis issues that arise when the women randomised have a multiple pregnancy. We presented maternal data as per woman randomised and neonatal data per infant.

\section{Multiple-arm studies}

We identified one trial with multiple intervention arms (Bo 2014). We split the 'shared' group into two or more groups with smaller sample size and include two or more (reasonably independent) comparisons. 


\section{Dealing with missing data}

For included studies, we noted levels of attrition. We explored the impact of including studies with high levels of missing data in the overall assessment of treatment effect by using sensitivity analysis.

For all outcomes, we carried out analyses, as far as possible, on an intention-to-treat basis, i.e. we attempted to include all participants randomised to each group in the analyses, and all participants were analysed in the group to which they were allocated, regardless of whether or not they received the allocated intervention. The denominator for each outcome in each trial was the number randomised minus any participants whose outcomes are known to be missing.

\section{Assessment of heterogeneity}

We assessed statistical heterogeneity in each meta-analysis using the $\mathrm{Tau}^{2}, \mathrm{I}^{2}$ and $\mathrm{Chi}^{2}$ statistics. We regarded heterogeneity as substantial if an $\mathrm{I}^{2}$ was greater than $30 \%$ and either the $\mathrm{Tau}^{2}$ was greater than zero, or there was a low $P$ value (less than 0.10 ) in the $\mathrm{Chi}^{2}$ test for heterogeneity.

\section{Assessment of reporting biases}

In future updates, if there are 10 or more studies in the metaanalysis, we will investigate reporting biases (such as publication bias) using funnel plots. We will assess funnel plot asymmetry visually. If asymmetry is suggested by a visual assessment, we will perform exploratory analyses to investigate it.

\section{Data synthesis}

We carried out statistical analysis using the Review Manager software (RevMan 2014). We used fixed-effect meta-analysis for combining data where it was reasonable to assume that studies were estimating the same underlying treatment effect: i.e. where trials were examining the same intervention, and the trials' populations and methods were judged sufficiently similar. If there was clinical heterogeneity sufficient to expect that the underlying treatment effects differed between trials, or if substantial statistical heterogeneity was detected, we used random-effects meta-analysis to produce an overall summary, if an average treatment effect across trials was considered clinically meaningful. The random-effects summary was treated as the average of the range of possible treatment effects and we discussed the clinical implications of treatment effects differing between trials. If the average treatment effect was not clinically meaningful, we did not combine trials.

Where we used random-effects analyses, the results were presented as the average treatment effect with 95\% confidence intervals, and the estimates of $\mathrm{Tau}^{2}$ and $\mathrm{I}^{2}$.

\section{Subgroup analysis and investigation of heterogeneity}

Had we identified substantial heterogeneity, we planned to investigate it using subgroup analyses and sensitivity analyses. We considered whether an overall summary was meaningful, and if it was, used random-effects analysis to produce it.

We planned to carry out the following subgroup analyses.

1. Group exercise versus individual exercise.
2. Low-level exercise (cumulative duration of exercise at $50 \%$ $\mathrm{VO}_{2} \mathrm{max}$ (maximal oxygen consumption) of less than 180 minutes) versus high-level exercise (cumulative duration of exercise at $50 \% \mathrm{VO}_{2}$ max of more than 180 minutes) intensity exercise.

The following outcomes were planned to be used in subgroup analysis where there were sufficient data.

\section{Maternal outcomes}

1. Hypertensive disorders of pregnancy (as reported by trialists, including pre-eclampsia, pregnancy-induced hypertension, eclampsia)

2. Caesarean section

3. Development of type 2 diabetes

\section{Neonatal outcomes}

1. Large-for-gestational age

2. Perinatal mortality (stillbirth and neonatal mortality)

3. Mortality or morbidity composite (variously defined by trials, e.g. perinatal or infant death, shoulder dystocia, bone fracture or nerve palsy)

4. Neurosensory disability

We were unable to conduct these subgroup analyses in the current review due to insufficient data. If sufficient data are included in future updates of this review, we will assess subgroup differences by interaction tests available within RevMan (RevMan 2014). We will report the results of subgroup analyses quoting the $\mathrm{Chi}^{2}$ statistic and $P$ value, and the interaction test $I^{2}$ value.

\section{Sensitivity analysis}

If there was evidence of significant heterogeneity, we planned to explore this by using the quality of the included trials for the primary outcomes. We planned to compare trials that had low risk of bias for allocation concealment with those judged to be of unclear or high risk of bias, and to exclude conference abstracts from the meta-analysis.

We also planned to investigate the effect of the randomisation unit (i.e. where we include cluster-randomised trials along with individually-randomised trials) but no cluster-randomised trials were identified.

As there was no statistical heterogeneity observed for the primary outcomes of this review, we did not conduct any sensitivity analyses.

\section{RES U L T S}

\section{Description of studies}

\section{Results of the search}

The search of the Cochrane Pregnancy and Childbirth Group's Trials Register retrieved 24 records, we found 78 records in ClinicalTrials.gov and the WHO International Clinical Trials Registry Platform (ICTRP) and also five potential studies from other sources. See: Figure 1.

We included 11 trials (17 reports) (Adam 2014; Avery 1997; Bambicini 2012; Bo 2014; Brankston 2004; Bung 1991; de 
Barros 2010; Halse 2014; Jovanovic-Peterson 1989; Ramos 2015; Youngwanichsetha 2014) (Characteristics of included studies). One study is awaiting classification (Frias 2012) (Characteristics of studies awaiting classification). There are three ongoing studies (da Silva 2013; Kokic 2014; Shaw 2005).

\section{Included studies}

We included 11 trials (Adam 2014; Avery 1997; Bambicini 2012; Bo 2014; Brankston 2004; Bung 1991; de Barros 2010; Halse 2014; Jovanovic-Peterson 1989; Ramos 2015; Youngwanichsetha 2014).

\section{Design}

All of the included trials were parallel randomised controlled trials (RCTs).

\section{Sample sizes}

Sample sizes ranged from a minimum of six women (Ramos 2015) to a maximum of 180 women (Youngwanichsetha 2014). Only the Youngwanichsetha 2014 trial had a sample size of more than 100 women.

\section{Setting}

All trials were conducted in middle- or high-income countries. Three trials were conducted in the USA (Avery 1997; Bung 1991; Jovanovic-Peterson 1989) and in Brazil (Bambicini 2012; de Barros 2010; Ramos 2015), two trials in Canada (Adam 2014; Brankston 2004), and one trial each in Italy (Bo 2014), Australia (Halse 2014) and Thailand (Youngwanichsetha 2014). One trial was conducted in the 1990s (Bung 1991) and two trials in the 2000s (Bo 2014; de Barros 2010). For the remaining trials (Adam 2014; Avery 1997; Bambicini 2012; Brankston 2004; Halse 2014; JovanovicPeterson 1989; Ramos 2015; Youngwanichsetha 2014), no details were provided regarding timing of the trial.

\section{Participants}

All trials recruited pregnant women with a diagnosis of gestational diabetes mellitus (GDM).

\section{Interventions and comparisons}

The exercise interventions and comparisons were very varied and included the following.

1. A supervised, individualised follow-up with a kinesiologist versus standard counselling for physical activity (Adam 2014).

2. Exercise using a cycle ergometer for 30 minutes duration, three to four times per week including both supervised and unsupervised sessions versus standard care with no additional exercise programme (Avery 1997). No details on the duration of the programme.

3. Aerobic activity (30 minutes brisk walking) or resistance exercises (30-minutes circuit workout with elastic-band exercises) versus a control group who remained seated for 30 minutes listening to explanations about Shantala exercises for the baby (Bambicini 2012).

4. All women were given an individually-prescribed diet (carbohydrates $48 \%$ to $50 \%$, proteins $18 \%$ to $20 \%$, fats $30 \%$ to $35 \%$, fibre $20 \%$ to $25 \mathrm{~g} /$ day, no alcohol). Women in the exercise intervention group were advised to walk briskly at least 20 minutes/day. Women in the behaviour group were given individual oral/written recommendations for helping with healthy dietary choices (i.e. lowering carbohydrate intake, strategies for out-of-home eating, healthy cooking and food shopping and related behavioural suggestions), and debunking false myths about diet in pregnancy and women in the control group who were given individually-prescribed dietary recommendations only $(n=50)$ (Bo 2014). This study also included a combined behaviour and exercise group that was not included in this review.

5. The intervention group undertook a progressive physical conditioning program involving three supervised introductory sessions, and weekly contact with supervisor. Women were instructed to perform resistance training circuit-type exercises three times per week. Women were instructed to exercise at a level that felt "somewhat hard", and were taught to monitor their heart rate to ensure that it did not rise above 140 beats/ min during exercise. All exercise sessions were recorded in a log book $(n=16)$. The control group received standard diabetic diet advice: $40 \%$ carbohydrate, $20 \%$ protein, $40 \%$ fat, calculated at $24 \mathrm{kcal} / \mathrm{kg}$ to $30 \mathrm{kcal} / \mathrm{kg}$ per day on the basis of the woman's ideal pre-pregnant body weight. Women were asked not to begin a structured exercise program for the remainder of the pregnancy (Brankston 2004).

6. The intervention group was provided with dietary advice and instructed to conduct a non-sedentary lifestyle, and attend the exercise laboratory three times a week to exercise under medical supervision. Exercise was 45 minutes with two, fiveminute breaks, on a recumbent bicycle, at $50 \%$ of their last determined maximum aerobic capacity (classed as moderate exercise) versus standard care insulin therapy and diet (Bung 1991).

7. All women received dietary advice from a nutritionist. The program consisted of a circuit of eight resistance training exercises using an elastic band to work the main muscle groups (chest, back, biceps, triceps, deltoid, quadriceps, thigh and calf muscles). Women were instructed to perform 15 repetitions of each exercise three times a week (once a week under supervision in the clinic, and twice a week at home) from recruitment (between 24 and 34 weeks) until the end of gestation. Women were instructed to exercise at a "somewhat heavy" intensity. Women were contacted by telephone at least once a week to verify adherence to the program $(n=32)$. The control group received usual care, and were questioned as to whether they had started some type of physical activity $(\mathrm{N}=32)$ (de Barros 2010).

8. In addition to usual care, the intervention group took part in five sessions per week of a home-based exercise program (three supervised and two unsupervised) on an upright stationary cycle ergometer (continuous moderate intensity cycling, with intervals of varying intensity consisting of 15 to 60 seconds of higher intensity bouts every two minutes, interspersed with lower-intensity recovery pedalling in between, tailored to a percentage of the woman's age-predicted maximum heart rate). The intervention commenced at recruitment (between 26 and 30 weeks' gestation) until 34 weeks of gestation $(n=20)$. The comparison group had usual care $(n=20)$, which consisted of assessment of glycaemic control and counselling by a diabetes educator and dietician, and self-monitoring of fasting and 120minute postprandial glucose levels $(n=20)$ (Halse 2014).

9. In addition to usual care, women in the intervention group participated in a six-week exercise program that consisted of 20 
minutes of supervised aerobic training on an arm ergometer, sufficient to maintain target heart rate in a training range $(n=10)$. The control group was managed with a standard diet consisting of $40 \%$ carbohydrate, $20 \%$ protein, and $40 \%$ fat calculated at $24 \mathrm{kcal} / \mathrm{kg}$ to $30 \mathrm{kcal} / \mathrm{kg} / 24$ hours of present pregnant weight, divided into three meals and three snacks. Women in the control group did not participate in any structured exercise program (n = 9) (Jovanovic-Peterson 1989).

10.A 10-week program of regular aerobic exercise of three 50minute sessions per week (no further details) $(n=2)$, versus 10 weeks of a 50-minute stretching and relaxation session once a week $(n=4)$ (Ramos 2015).

11.Training in mindfulness eating, and yoga exercise in two 50minute sessions. Participants were provided with manuals and encouraged to continue mindfulness eating and yoga exercise at home five times a week for eight weeks $(n=90)$ versus standard diabetes care $(n=90)$ (Youngwanichsetha 2014).

\section{Outcomes}

Two trials reported hypertensive disorders of pregnancy (preeclampsia) - Avery 1997; Jovanovic-Peterson 1989.

Five trials reported caesarean section - Avery 1997; Bo 2014; Bung 1991; de Barros 2010; Halse 2014.

One trial reported perinatal mortality (stillbirth and neonatal mortality) - Jovanovic-Peterson 1989.

Two trials reported a mortality or morbidity composite - Bo 2014; Jovanovic-Peterson 1989.

Seven trials reported the use of additional pharmacotherapy Adam 2014; Avery 1997; Bo 2014; Brankston 2004; de Barros 2010; Halse 2014; Jovanovic-Peterson 1989.

One trial reported maternal hypoglycaemia - Bung 1991.

Five trials reported glycaemic control during/end of treatment Bo 2014; Bung 1991; Brankston 2004; Jovanovic-Peterson 1989; Youngwanichsetha 2014.

Three trials reported weight gain in pregnancy - Adam 2014; de Barros 2010; Halse 2014.

One trial reported adherence to the intervention - JovanovicPeterson 1989.

One trial reported induction of labour - Halse 2014.

Two trials reported maternal mortality - Avery 1997; JovanovicPeterson 1989.

One trial reported on views of the intervention - Halse 2014.

Three trials reported postnatal weight retention or return to prepregnancy weight (maternal BMI at follow-up) - Bo 2014; de Barros 2010; Halse 2014.

One trial reported stillbirth - Avery 1997.

Five trials reported macrosomia - Avery 1997; Bo 2014; Bung 1991; de Barros 2010; Jovanovic-Peterson 1989.
Four trials reported gestational age at birth - Avery 1997; Bung 1991; de Barros 2010; Halse 2014.

Five trials reported preterm birth - Avery 1997; Bo 2014; de Barros 2010; Halse 2014; Jovanovic-Peterson 1989.

One trial reported five-minute Apgar < seven - Bung 1991.

Six trials reported birthweight - Avery 1997; Bung 1991; de Barros 2010; Halse 2014; Jovanovic-Peterson 1989; Ramos 2015.

One trial reported length at birth - Bung 1991.

One trial reported neonatal hypoglycaemia - Bung 1991.

One trial reported respiratory distress syndrome - Bung 1991.

One trial reported hyperbilirubinaemia - Bung 1991.

One trial reported hypocalcaemia - Bung 1991.

No data were reported in the included trials for any of the other prespecified outcomes for this review listed below.

For the mother: placental abruption, postpartum haemorrhage, postpartum infection, perineal trauma/tearing, breastfeeding at discharge, six weeks postpartum, six months or longer, sense of well-being and quality of life, behavioural changes associated with the intervention, relevant biomarker changes associated with the intervention, postnatal depression, postnatal weight retention or return to pre-pregnancy weight, BMI, GDM in a subsequent pregnancy, type 2 diabetes, impaired glucose tolerance, cardiovascular health.

For the infant: neurosensory disability, small-for-gestational age, birth trauma (shoulder dystocia, bone fracture, nerve palsy), birthweight z score, head circumference and z score, length and $z$ score, ponderal index, neonatal adiposity, polycythaemia, relevant biomarker changes associated with the intervention, childhood weight and $z$ scores, height and $z$ scores, head circumference and $z$ scores, adiposity, educational attainment, blood pressure, type 1 diabetes, type 2 diabetes, impaired glucose tolerance, dyslipidaemia or metabolic syndrome.

For the child as an adult: weight, height, adiposity, cardiovascular health, employment, education and social status/achievement, type 1 diabetes, type 2 diabetes, impaired glucose tolerance.

Health service outcomes: number of antenatal visits or admissions, number of hospital or health professional visits, admission to neonatal intensive care unit/nursery, cost of maternal care, cost of offspring care, costs associated with the intervention, costs to families associated with the management provided, cost of dietary monitoring, costs to families, extra use of healthcare services, women's view of treatment advice, duration of stay in neonatal intensive care unit or special care baby unit and duration of maternal and neonatal hospital stay.

\section{Declarations of interest in the trial reports}

Four publications clearly stated that there were no conflicts of interest (Adam 2014; Bo 2014; Halse 2014; Ramos 2015). Seven publications did not provide details on conflicts of interest (Avery 1997; Bambicini 2012; Brankston 2004; Bung 1991; de Barros 2010; Jovanovic-Peterson 1989; Youngwanichsetha 2014). 


\section{Sources of trial funding}

Three publications declared funding sources, none of which were associated with the pharmaceutical industry (Bo 2014; de Barros 2010; Halse 2014). One trial (Avery 1997) reported funding sources from multiple sources (academic, governmental and other) that also included funding from Boehringer Manheim Corporation. The type of funding from Boehringer Manheim Corporation was unclear. No details on sources of funding were provided by seven publications (Adam 2014; Bambicini 2012; Brankston 2004; Bung 1991; Jovanovic-Peterson 1989; Ramos 2015; Youngwanichsetha 2014).

\section{Excluded studies}

Thirteen studies were excluded (Characteristics of excluded studies). Seven trials were excluded due to ineligible population
(Barakat 2013; Chen 1997; Deshpande 2013; Fieril 2015; Melo 2008; Nobles 2015; Ong 2009). Five trials were of an ineligible trial design (Ehrlich 2016; Garcia-Patterson 2001; Lesser 1996; Moholdt 2013; Yin 2014), and in one trial (Berry 2013), the intervention was ineligible.

\section{Studies awaiting classification}

One study remains in Characteristics of studies awaiting classification (Frias 2012). ClinicalTrials.gov stated this trial has been terminated due to recruitment issues. We will attempt to contact the responsible party for further information.

\section{Risk of bias in included studies}

See Figure 2 and Figure 3.

Figure 2. 'Risk of bias' graph: review authors' judgements about each risk of bias item presented as percentages across all included studies.

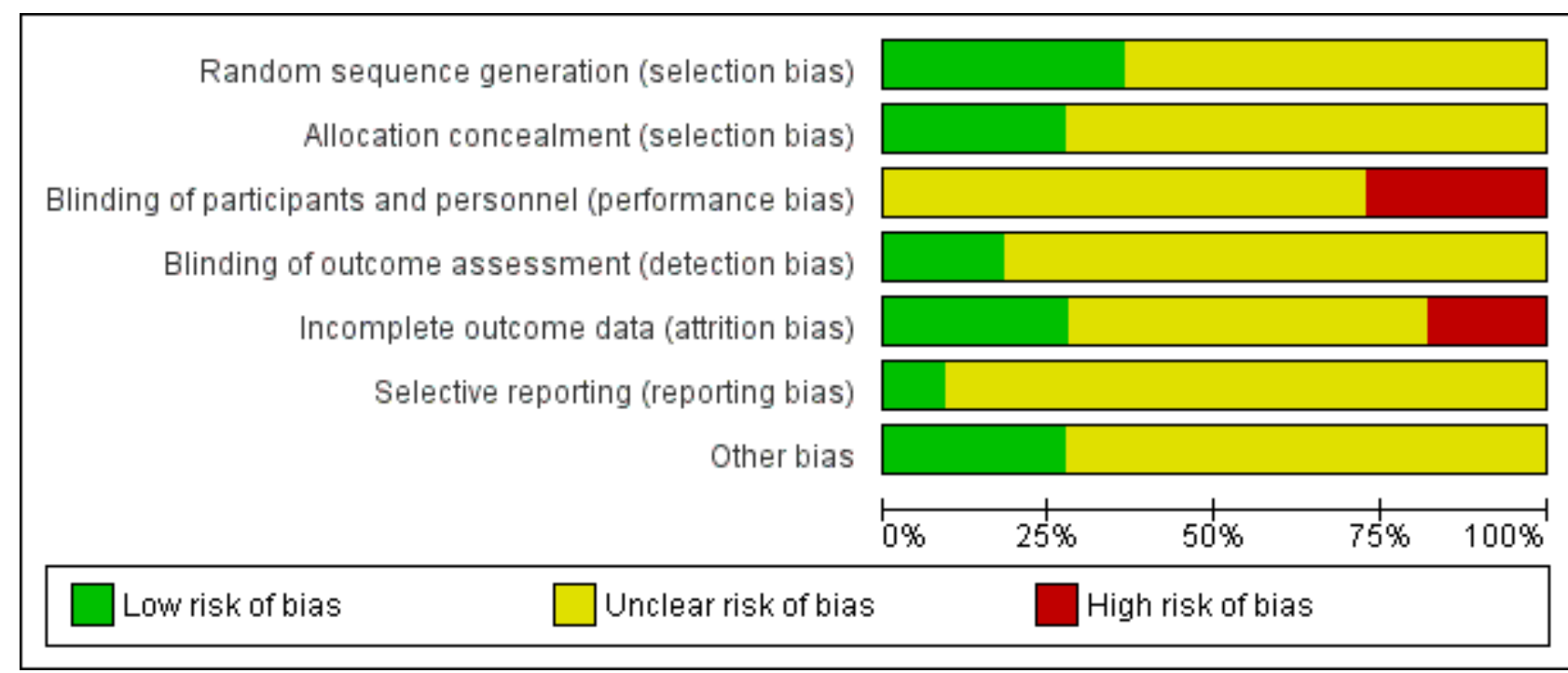


Figure 3. 'Risk of bias' summary: review authors' judgements about each risk of bias item for each included study.

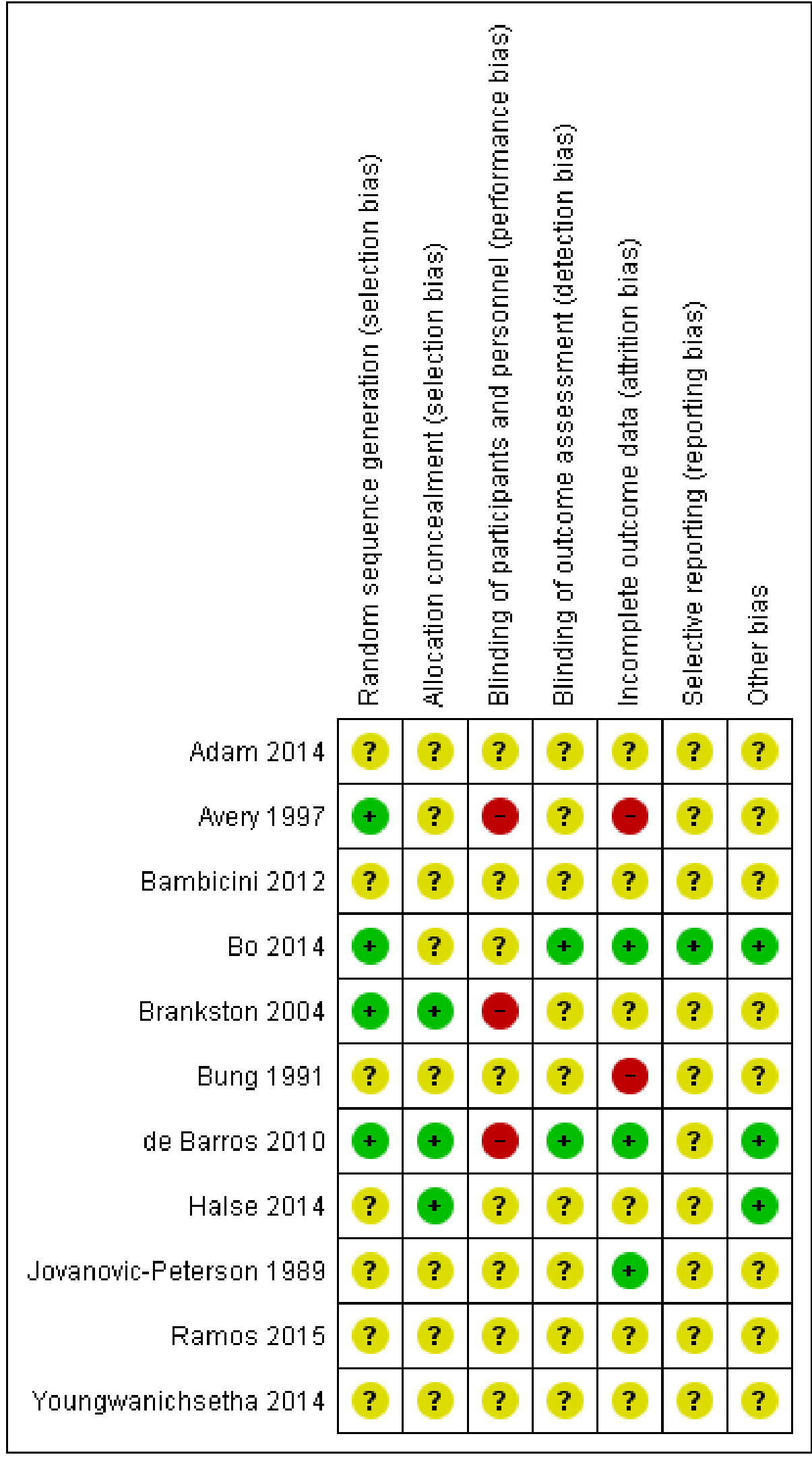

Exercise for pregnant women with gestational diabetes for improving maternal and fetal outcomes (Review) 


\section{Allocation}

\section{Random sequence generation}

Four trials were judged to be of low risk of bias. Avery 1997, Bo 2014, Brankston 2004 and de Barros 2010 reported using computergenerated random number tables.

Seven trials were judged as unclear risk of bias due to lack of methodological details (Adam 2014; Bambicini 2012; Bung 1991; Halse 2014; Jovanovic-Peterson 1989; Ramos 2015; Youngwanichsetha 2014).

\section{Allocation concealment}

Three trials were judged to be of low risk of bias. Brankston 2004, de Barros 2010 and Halse 2014 reported using sequentially numbered, opaque envelopes.

Eight trials were judged as unclear risk of bias due to lack of methodological details (Adam 2014; Avery 1997; Bambicini 2012; Bo 2014; Bung 1991; Jovanovic-Peterson 1989; Ramos 2015; Youngwanichsetha 2014).

\section{Blinding}

\section{Performance bias}

Eight trials were judged as unclear risk of bias due to lack of methodological details (Adam 2014; Bambicini 2012; Bo 2014; Bung 1991; Halse 2014; Jovanovic-Peterson 1989; Ramos 2015; Youngwanichsetha 2014). Bo 2014 reported that women were not blinded but dieticians and obstetricians who reported maternal/ neonatal complications, and the laboratory personnel were blinded to the group assignment.

Three trials were judged as high risk of bias as they stated that the participants were not blinded (Avery 1997; Brankston 2004; de Barros 2010).

\section{Detection bias}

Two trials were judged to be of low risk of bias. Bo 2014 reported that outcome assessors including dietitians, obstetricians and laboratory personnel were blinded to allocation. de Barros 2010 also stated that obstetricians recording data were blinded to group allocation.

Nine trials were judged as unclear risk of bias due to lack of methodological details (Adam 2014; Avery 1997; Bambicini 2012; Brankston 2004; Bung 1991; Halse 2014; Jovanovic-Peterson 1989; Ramos 2015; Youngwanichsetha 2014).

\section{Incomplete outcome data}

Three trials were judged to be of low risk of bias. Bo 2014, de Barros 2010, and Jovanovic-Peterson 1989 reported that all women were analysed.

Five trials were judged as unclear risk of bias due to lack of methodological detail (Adam 2014; Bambicini 2012; Halse 2014; Ramos 2015; Youngwanichsetha 2014). Brankston 2004 was judged to be of unclear risk of bias as they had data missing for some women who did not record blood glucose concentrations.

Two trials were judged to be high risk of bias. Avery 1997 reported that "several subjects gave birth before the follow-up exercise test", however the number of women included in the measures at the end is unclear and home blood glucose levels were reported for $10 / 15$ women in the exercise group, and 12/14 women in the control group. It is unclear why the other women are missing. Seven of 41 women in the Bung 1991 were not analysed and some of these may be attributed to the intervention.

\section{Selective reporting}

One trial was judged to be of low risk of bias. Bo 2014 had a trial protocol available and all pre-specified outcomes were reported with the exception of birthweight.

Ten trials were judged as unclear risk of bias. Three due to the study being assessed from a brief conference abstract, without access to the study protocol (Adam 2014; Bambicini 2012; Ramos 2015). Six studies were assessed from a published report, without a protocol available (Avery 1997; Bung 1991; de Barros 2010; Halse 2014; Jovanovic-Peterson 1989; Youngwanichsetha 2014), and Brankston 2004 reported that on results without providing absolute values for women in the treatment and control groups.

\section{Other potential sources of bias}

Three trials were judged to be of low risk of bias. Bo 2014 reported no evidence of differences at baseline between intervention and control groups. de Barros 2010 has no evidence of other bias. For Halse 2014, the sample size was calculated to detect differences in blood glucose based on previous study and pilot data.

Eight trials were judged as unclear risk of bias. Three were published as a conference abstract and lacked methodological detail (Adam 2014; Bambicini 2012; Ramos 2015). Some imbalances were detected between groups at baseline (Avery 1997). Brankston 2004 reported that analysis was done by intention-to-treat, but not all women were included in all analyses and there were some differences between groups at baseline. In the Bung 1991 trial, there were small discrepancies in the reporting of data, for example birthweight and number of babies with Apgar less than seven at five minutes. There was insufficient methodological detail provided in Jovanovic-Peterson 1989 and Youngwanichsetha 2014 and these were judged as having an unclear risk of other bias.

\section{Effects of interventions}

See: Summary of findings for the main comparison Exercise compared to control for pregnant women with gestational diabetes for improving maternal outcomes; Summary of findings 2 Exercise compared to control for pregnant women with gestational diabetes for improving fetal outcomes

\section{Exercise versus control}

\section{Primary outcomes}

\section{Mother}

1.1 Hypertensive disorders of pregnancy (as reported by trialists, including pre-eclampsia, pregnancy-induced hypertension, eclampsia)

There was no clear evidence of a difference between women in the exercise group (0/25) and those in the control group (1/25) for the risk of pre-eclampsia (risk ratio (RR) $0.31,95 \%$ confidence interval (CI) 0.01 to 7.09 ; two RCTs, 48 women; low-quality evidence). Data should be interpreted with caution due to low event rates and small 
sample size suggesting imprecision (Analysis 1.1). No data were reported for pregnancy-induced hypertension or eclampsia.

\subsection{Caesarean section}

There was no clear evidence of a difference between women in the exercise and control groups for the risk of birth by caesarean section (RR $0.86,95 \% \mathrm{Cl} 0.63$ to 1.16; five RCTs, 316 women; 12 = 0\%; moderate-quality evidence) (Analysis 1.2).

None of the included trials pre-specified development of type 2 diabetes as a trial outcome.

\section{Neonatal/infant}

\subsection{Perinatal mortality (stillbirth and neonatal mortality)}

A single small trial (Jovanovic-Peterson 1989) including only 19 women reported data for perinatal mortality. There were no events in either the exercise intervention or control group (low-quality evidence) (Analysis 1.3).

1.4 Mortality or morbidity composite (variously defined by trials, e.g. perinatal or infant death, shoulder dystocia, bone fracture or nerve palsy)

There was no clear evidence of a difference between groups for the risk of a mortality or morbidity composite outcome (RR 0.56, 95\% $\mathrm{Cl} 0.12$ to 2.61; two RCTs, 169 infants; $\mathrm{I}^{2}=0 \%$; moderate-quality evidence) (Analysis 1.4).

None of the included trials pre-specified large-for-gestational age, or neurosensory disability (childhood) as trial outcomes.

\section{Secondary outcomes}

\section{Mother}

\subsection{Use of additional pharmacotherapy}

There was no clear evidence of a difference between groups found between exercise and control groups for the use of additional pharmacotherapy (RR $0.76,95 \% \mathrm{Cl} 0.54$ to 1.08; seven RCTs, 413 women; ${ }^{2}=5 \%$ ) (Analysis 1.5).

\subsection{Maternal hypoglycaemia}

One small trial of 34 women (Bung 1991) reported no events of maternal hypoglycaemia in either the exercise intervention or control groups (Analysis 1.6).

\subsection{Glycaemic control at end of treatment (mean)}

Allocation to the control group was associated with a reduced blood glucose concentration at end of treatment compared with the exercise group (mean difference (MD) $0.28 \mathrm{mmol} / \mathrm{L}, 95 \% \mathrm{Cl} 0.04$ to 0.52 ; one RCT, 34 women). It is unclear if a MD of $0.28 \mathrm{mmol} / \mathrm{L}$ is of clinical significance (Analysis 1.7).

\subsection{Glycaemic control at end of treatment (fasting blood glucose concentration)}

Exercise was associated with a reduced fasting blood glucose concentration compared with control (average standardised mean difference (SMD) $-0.59,95 \% \mathrm{Cl}-1.07$ to 0.11 ; four RCTs, 363 women; $\mathrm{I}^{2}=73 \%, \mathrm{~T}^{2}=0.19$ ) (Analysis 1.8). The heterogeneity may be attributable to differences in the interventions.
1.9 Glycaemic control at end of treatment (postprandial blood glucose concentration)

Exercise was associated with a reduced postprandial blood glucose concentration compared with control (average SMD -0.85, 95\% CI -1.15 to -0.55 ; three RCTs, 344 women; $\mathrm{I}^{2}=34 \%, \mathrm{~T}^{2}=0.03$ ) (Analysis 1.9). The heterogeneity may be attributable to differences in the interventions.

\subsection{Glycaemic control at end of treatment (glycated haemoglobin (HbA1c))}

There was no clear evidence of a difference in glycated haemoglobin (HbA1c) between exercise and control groups (MD $-0.43 \mathrm{mmol} / \mathrm{mol}, 95 \% \mathrm{Cl}-0.51$ to 0.35 ; two RCTs, 320 women; $\mathrm{I}^{2}=$ $0 \%$; Analysis 1.10).

\subsection{Glycaemic control at end of treatment (glucose tolerance test)}

There was evidence of a reduced glucose tolerance test result at end of treatment for women in the exercise group compared with the control group (MD $-81.60 \mathrm{mg} / \mathrm{dl}, 95 \% \mathrm{Cl}-96.03$ to -67.17 ; one RCT, 19 women; Analysis 1.11).

\subsection{Weight gain in pregnancy}

There was no clear evidence of a difference between groups for weight gain in pregnancy (MD $-0.34 \mathrm{~kg}, 95 \% \mathrm{Cl}-1.25$ to 0.58 ; two RCTs, 104 women; $I^{2}=0 \%$; Analysis 1.12). The increase in weight differs substantially between the two studies (Analysis 1.12). We cannot find an explanation for this and both studies reported weight in $\mathrm{kg}$.

\subsection{Weight gain in pregnancy (excessive)}

There was no clear evidence of a difference between groups for excessive weight gain in pregnancy (RR $0.90,95 \% \mathrm{Cl} 0.47$ to 1.72 ; one RCT, 79 women; Analysis 1.13).

\subsection{Adherence to the intervention}

There was no clear evidence of a difference between groups for adherence to the intervention (RR 1.00, 95\% Cl 0.83 to 1.21; one RCT, 19 women; Analysis 1.14).

\subsection{Induction of labour}

There was no clear evidence of a difference between exercise and control groups for the risk of induction of labour (RR 1.38, 95\% $\mathrm{Cl} 0.71$ to 2.68; one RCT, 40 women; low-quality evidence; Analysis 1.15).

\subsection{Maternal mortality}

Two trials including a total of 48 women reported data on maternal mortality (Avery 1997; Jovanovic-Peterson 1989). There were no events in either the exercise intervention or control group (Analysis 1.16).

\subsection{Views of the intervention (favourable)}

One trial (40 women) reported data on favourable views of the intervention (Halse 2014). The MD was inestimable (Analysis 1.17).

\subsection{Postnatal weight retention or return to pre-pregnancy weight (maternal BMI (follow-up) kg/m2}

There was no clear evidence of a difference between groups for maternal BMI at follow-up (MD $0.11 \mathrm{~kg} / \mathrm{m}^{2}, 95 \% \mathrm{Cl}-1.04$ to 1.26 ; 
three RCTs, 254 women; $1^{2}=0 \%$; high-quality evidence; Analysis 1.18).

\section{Neonatal/infant}

\subsection{Stillbirth}

One trial reported stillbirth ( $n=29$; Avery 1997). There were no events in either the exercise intervention group or the control group (Analysis 1.19).

\subsection{Macrosomia}

There was no clear evidence of a difference in the risk of being born macrosomic between the exercise intervention and control groups (RR 0.69, 95\% Cl 0.35 to 1.35; five RCTs, 296 infants; $\mathrm{I}^{2}=0 \%$; Analysis 1.20).

\subsection{Gestational age at birth}

There was no clear evidence of a difference for gestational age at birth between exercise intervention and control groups (MD -0.01 weeks, $95 \% \mathrm{Cl}-0.40$ to 0.38 ; four RCTs, 167 infants; $\left.\right|^{2}=0 \%$; Analysis 1.21).

\subsection{Preterm birth}

There was no clear evidence of a difference between exercise intervention and control groups for the risk of preterm birth (RR 0.95, $95 \% \mathrm{Cl} 0.39$ to 2.36; five RCTs, 302 infants; $\mathrm{I}^{2}=0 \%$; Analysis 1.22).

\subsection{Five-minute Apgar score less than seven}

There was no clear evidence of a difference for the five-minute Apgar score less than seven between exercise intervention and control groups (RR $0.33,95 \% \mathrm{Cl} 0.01$ to 7.65 ; one RCT, 34 infants; Analysis 1.23).

\subsection{Birthweight}

There was no clear evidence of a difference between exercise intervention and control groups for birthweight (MD -61.50 g, 95\% $\mathrm{Cl}$-195.21 to 72.20; six RCTs, 192 infants; $\left.\right|^{2}=0 \%$; Analysis 1.24 ).

\subsection{Length at birth $(\mathrm{cm})$}

There was no clear evidence of a difference between exercise intervention and control groups for length at birth (MD $-1.70 \mathrm{~cm}$, $95 \% \mathrm{Cl}-3.41$ to 0.01 ; one RCT, 34 infants; Analysis 1.25).

\subsection{Neonatal hypoglycaemia}

There was no clear evidence of a difference between exercise and control groups (RR 2.00, $95 \% \mathrm{Cl} 0.20$ to 20.04; one RCT, 34 infants; low-quality evidence; Analysis 1.26).

\subsection{Respiratory distress syndrome}

There were no events of respiratory distress syndrome in either the exercise intervention or control groups reported in a single small trial of 34 infants (Bung 1991) (Analysis 1.27).

\subsection{Neonatal jaundice (hyperbilirubinaemia)}

There was no clear evidence of a difference between exercise intervention and control groups for hyperbilirubinaemia (RR 0.33 , $95 \% \mathrm{Cl} 0.01$ to 7.65 ; one RCT, 34 infants; Analysis 1.28).

\subsection{Hypocalcaemia}

There were no events of hypocalcaemia in either the exercise intervention or control groups reported in a single small trial of 34 infants (Bung 1991) (Analysis 1.29).

\subsection{Duration of hospital stay}

Duration of hospital stay more than four days was reported by Bo 2014. It is unclear if this is maternal, neonatal or both. The authors report $13 / 50$ for the diet only group, $9 / 51$ for the exercise only group, and $17 / 49$ for the behavioural group. No data for mean duration of hospital stay were provided.

\section{Secondary outcomes not reported in the included studies}

The following secondary, long-term, adulthood and health service use outcomes specified in this review were not included as prespecified trial outcomes in any of the included trials.

1. Mother - placental abruption, postpartum haemorrhage, postpartum infection, perineal trauma/tearing, breastfeeding at discharge, six weeks postpartum, six months or longer, sense of well-being and quality of life, behavioural changes associated with the intervention, relevant biomarker changes associated with the intervention.

2. Maternal long-term outcomes - postnatal depression, GDM in a subsequent pregnancy, type 2 diabetes, impaired glucose tolerance, cardiovascular health.

3. Neonatal/infant - neonatal death, small-for-gestational age, birth trauma (shoulder dystocia, bone fracture, nerve palsy), birthweight $z$ score, head circumference and $z$ score, length $z$ score, ponderal index, adiposity, polycythaemia, relevant biomarker changes associated with the intervention.

4. Later infant and childhood secondary outcomes - weight and $z$ scores, height and $z$ scores, head circumference and $z$ scores, adiposity, educational attainment, blood pressure, type 1 diabetes, type 2 diabetes, Impaired glucose tolerance, dyslipidaemia or metabolic syndrome.

5. Child as an adulthood - weight, height, adiposity, cardiovascular health, employment, education and social status/achievement, type 1 diabetes, type 2 diabetes, impaired glucose tolerance.

6. Health service use - number of antenatal visits or admissions, number of hospital or health professional visits, admission to neonatal intensive care unit/nursery, cost of maternal care, cost of offspring care, costs associated with the intervention, costs to families associated with the management provided, cost of dietary monitoring, costs to families - change of diet, extra antenatal visits, extra use of healthcare services (consultations, blood glucose monitoring, length and number of antenatal visits), women's view of treatment advice, duration of stay in neonatal intensive care unit or special care baby unit).

\section{DISCUSSION}

\section{Summary of main results}

We included 11 randomised controlled trials involving 638 women that compared exercise interventions with a control group in women with gestational diabetes.

For the mother: we found no clear evidence of a difference for the risk of pre-eclampsia, birth by caesarean section, the risk 
of induction of labour or maternal body mass index at followup. Data for development of type 2 diabetes, perineal trauma/ tearing and postnatal depression were not reported in the included studies (Summary of findings for the main comparison). Exercise interventions were associated with a reduced fasting (Analysis 1.8) and postprandial blood (Analysis 1.9) glucose concentration compared with the control group. However, caution is advised in interpreting these data due to heterogeneity, which is most likely due to the variation in the content and methods associated with the interventions themselves.

For the infant/child: we found no clear evidence of a difference for a composite outcome of neonatal mortality and morbidity or neonatal hypoglycaemia. There were no events of perinatal mortality reported. There were no data reported for large-for gestational age, adiposity, diabetes or neurosensory disability in childhood (Summary of findings 2 ).

Both short- and long-term outcomes of interest for this review were poorly reported in the included studies.

\section{Overall completeness and applicability of evidence}

There was a wide variation in the components of the exercise intervention, the duration of the intervention and whether the intervention was supervised or unsupervised. Short- and long-term outcomes of interest for this review for the mother and for the infant/child were poorly reported. The sample sizes of the included studies were small, ranging from a minimum of six women (Ramos 2015) to a maximum of 180 women (Youngwanichsetha 2014). All of the included studies were conducted in middle-or high-income countries. The data lack overall completeness and are unlikely to be applicable to all settings.

\section{Quality of the evidence}

We judged the overall risk of bias of the included studies to be unclear due to lack of methodological details. Using GRADE methodology, the quality of evidence for the selected outcomes ranged from high to low quality (Summary of findings for the main comparison; Summary of findings 2). The main reason for the downgrading of evidence was for risk of bias and imprecision. Sample sizes and event rates were low and data were often associated with wide confidence intervals.

\section{Potential biases in the review process}

We believe that every effort was made to attempt to minimise biases in the review process. We conducted a systematic search of the literature for randomised controlled trial evidence, we did not use any restrictions for language or publication date. Where necessary, we attempted to make contact with authors of primary studies to obtain additional methodological and/or outcome data.
We have adhered to Cochrane methodology for searching, data extraction and analysis.

\section{Agreements and disagreements with other studies or reviews}

A systematic review by Harrison 2016 reported a similar association between exercise interventions and lower fasting and postprandial blood glucose concentration compared with control. They had identified the same trials for inclusion as our review.

\section{AUTHORS' CONCLUSIONS}

\section{Implications for practice}

There is currently insufficient evidence to support or refute enrolling pregnant women with gestational diabetes into exercise programmes. However, even if exercise is not beneficial during pregnancy, this change in lifestyle may persist after birth and may help prevent the onset of type 2 diabetes and its long-term complications. Pregnant women with gestational diabetes who wish to enrol in an exercise programme may wish to discuss their choice with a health professional.

\section{Implications for research}

Further trials with larger sample sizes involving women with gestational diabetes are needed to evaluate this intervention, comparing different types of exercise intervention with control groups or with another exercise intervention and focusing on both short- and long-term outcomes for both the mother and the infant/ child (such as those listed in this review).

\section{ACKNOWLEDGEMENTS}

We acknowledge the contribution of Dr Rouiller, one of the authors of the original review (Ceysens 2006), who has since died.

We acknowledge the support from the Cochrane Pregnancy and Childbirth editorial team in Liverpool, the Australian and New Zealand Satellite of the Cochrane Pregnancy and Childbirth and the Liggins Institute, University of Auckland, New Zealand.

As part of the pre-publication editorial process, this review has been commented on by three peers (an editor and two referees who are external to the editorial team) and the Group's Statistical Adviser.

This project was supported by the National Institute for Health Research, via Cochrane Infrastructure and Cochrane Programme Grant funding to Cochrane Pregnancy and Childbirth. The views and opinions expressed therein are those of the authors and do not necessarily reflect those of the Systematic Reviews Programme, NIHR, NHS or the Department of Health. 


\section{R E F E R E N C E S}

\section{References to studies included in this review}

Adam 2014 \{published data only\}

Adam C, L'Abbe C, Lachapelle J, Ourabah S, Rakel A, De Guise M, et al. Impact of an individualized counselling on physical activity in women with gestational diabetes: Interim analysis of a randomized control trial. Endocrine Reviews 2014;35(3):SUN-1035.

\section{Avery 1997 \{published data only\}}

Avery MD, Leon AS, Kopher RA. Effects of a partially homebased exercise program for women with gestational diabetes. Obstetrics \& Gynecology 1997;89:10-5.

\section{Bambicini 2012 \{published data only\}}

Bambicini JT, Soares VCM, Zanetti MRD, Torloni MR, Ribeiro MC, Mattar R. Effects of aerobic and resistance exercises on glycemic levels of patients with gestational diabetes: Pilot study. International Journal of Gynecology and Obstetrics 2012;119(Suppl 3):S603.

\section{Bo 2014 \{published data only\}}

Bo S, Gambino R, Menato G, Canil S, Ponzo V, Pinach S, et al. Isoleucine-to-methionine substitution at residue 148 variant of PNPLA3 gene and metabolic outcomes in gestational diabetes. American Journal of Clinical Nutrition 2015;101(2):310-8.

* Bo S, Rosato R, Ciccone G, Canil S, Gambino R, Botto Poala C, et al. Simple lifestyle recommendations and the outcomes of gestational diabetes. A $2 \times 2$ factorial randomized trial. Diabetes, Obesity and Metabolism 2014;16(10):1032-5.

NCT01506310. Efficacy of behavioral therapy and exercise in gestational diabetes mellitus (GDM). clinicaltrials.gov/ct2/show/ NCT01506310 Date first received: 26 December 2011.

\section{Brankston 2004 \{published data only\}}

Brankston GN, Mitchell BF, Ryan EA, Okun NB. Resistance exercise decreases the need for insulin in overweight women with gestational diabetes mellitus. American Journal of Obstetrics and Gynecology 2004;190(1):188-93.

\section{Bung 1991 \{published data only\}}

Bung P, Artal R, Khodiguian N. Regular exercise therapy in disturbed carbohydrate metabolism during pregnancy - results of a prospective randomised longitudinal study. Geburtshilfe und Frauenheilkunde 1993;53:188-93.

* Bung P, Artal R, Khodiguian N, Kjos S. Exercise in gestational diabetes. An optional therapeutic approach?. Diabetes 1991;40(Suppl 2):182-5.

Bung P, Bung C, Artal R, Khodiguian N, Fallenstein F, Spatling L. Therapeutic exercise for insulin-requiring gestational diabetics: effects on the fetus - results of a randomized prospective longitudinal study. Journal of Perinatal Medicine 1993;21:125-37.

\section{de Barros 2010 \{published data only\}}

de Barros MC, Lopes MA, Francisco RP, Sapienza AD, Zugaib M. Resistance exercise and glycemic control in women with gestational diabetes mellitus. American Journal of Obstetrics and Gynecology 2010;203(6):556.e1-6.

Halse 2014 \{published data only\}

* Halse E, Wallman E, Newnham P, Guelfi J. Home-based exercise training improves capillary glucose profile in women with gestational diabetes. Medicine \& Science in Sports \& Exercise 2014;46(9):1702-9.

Halse RE, Wallman KE, Dimmock JA, Newnham JP, Guelfi KJ. Home-based exercise improves fitness and exercise attitude and intention in GDM women. Medicine and Science in Sports and Exercise 2015;47(8):1698-704.

Jovanovic-Peterson 1989 \{published data only\} Jovanovic-Peterson L, Durak EP, Peterson CM. Randomized trial of diet vs diet plus cardiovascular conditioning on glucose levels in gestational diabetes. American Journal of Obstetrics and Gynecology 1989;161:415-9.

Ramos 2015 \{published data only\} NCT01885234. Aerobic training in pregnant women with gestational diabetes and chronic hypertension. clinicaltrials.gov/ct2/show/NCT01885234 Date first received: 5 June 2013.

* Ramos JG, Bgeginski R, Opperman ML, Martins-Costa S, Delevatti R, Schuch R, et al. Effect of aerobic training in pregnant women diagnosed with gestational diabetes: $\mathrm{A}$ preliminary report. Pregnancy Hypertension 2015;5(1):105.

\section{Youngwanichsetha 2014 \{published data only\}}

Youngwanichsetha S, Phumdoung S, Ingkathawornwong T. The effects of mindfulness eating and yoga exercise on blood sugar levels of pregnant women with gestational diabetes mellitus. Applied Nursing Research 2014;27(4):227-30.

\section{References to studies excluded from this review}

Barakat 2013 \{published data only\}

Barakat R, Pelaez M, Lopez C, Lucia A, Ruiz JR. Exercise during pregnancy and gestational diabetes-related adverse effects: a randomised controlled trial. British Journal of Sports Medicine 2013;47:630-6.

Berry 2013 \{published data only\}

Berry DC, Neal M, Hall EG, Schwartz TA, Verbiest S, Bonuck K, et al. Rationale, design, and methodology for the optimizing outcomes in women with gestational diabetes mellitus and their infants study. BMC Pregnancy and Childbirth 2013;13:184-95.

Chen 1997 \{published data only\}

Chen B, Steiner JL, Holcomb WL. Effects of a short-term moderate exercise program on glucose tolerance in pregnancy. 
American Journal of Obstetrics and Gynecology 1997;176(1 Pt 2):S173.

\section{Deshpande 2013 \{published data only\}}

Deshpande CS, Rakhshani A, Nagarathna R, Ganpat TS, Kurpad A, Maskar R, et al. Yoga for high-risk pregnancy: a randomized controlled trial. Annals of Medical and Health Sciences Research 2013;3(3):341-4.

\section{Ehrlich 2016 \{published data only\}}

Ehrlich SF, Sternfeld B, Krefman AE, Hedderson MM, Brown SD, Mevi A. Moderate and vigorous intensity exercise during pregnancy and gestational weight gain in women with gestational diabetes. Maternal and Child Health Journal 2016;26(6):1247-57.

\section{Fieril 2015 \{published data only\}}

Fieril KP, Glantz A, Olsen MF. The efficacy of moderate-tovigorous resistance exercise during pregnancy: a randomized controlled trial. Acta Obstetricia et Gynecologica Scandinavica 2015;94:35-42.

\section{Garcia-Patterson 2001 \{published data only\}}

Garcia-Patterson A, Martin E, Ubeda J, Maria MA, de Leiva A, Corcoy R. Evaluation of light exercise in the treatment of gestational diabetes. Diabetes Care 2001;24:2006-7.

\section{Lesser 1996 \{published data only\}}

Lesser KB, Gruppuso PA, Terry RB, Carpenter MW. Exercise fails to improve postprandial glycemic excursion in women with gestational diabetes. Journal of Maternal-Fetal Medicine 1996;5:211-7.

\section{Melo 2008 \{published data only\}}

NCT00641550. Exercise and pregnancy: randomized clinical trial. clinicaltrials.gov/ct2/show/NCT00641550 Date first received: 17 March 2008.

\section{Moholdt 2013 \{published data only\}}

NCT01961401. Acute effects of moderate versus high intensity exercise on insulin sensitivity in pregnant women with and without gestational diabetes mellitus. clinicaltrials.gov/ct2/ show/NCT01961401 Date first received: 9 October 2013.

\section{Nobles 2015 \{published data only\}}

Nobles C, Marcus BH, Stanek EJ, Braun B, Whitcomb BW, Soloman CG. Effect of an exercise intervention on gestational diabetes mellitus. Obstetrics \& Gynecology 2015;125(5):1195-204.

\section{Ong 2009 \{published data only\}}

Ong MJ, Guelfi KJ, Hunter T, Wallman KE, Fournier PA, Newnham JP. Supervised home-based exercise may attenuate the decline of glucose tolerance in obese pregnant women. Diabetes \& Metabolism 2009;35:418-21.

\section{Yin 2014 \{published data only\}}

Yin Y, Li X, Tao T, Luo B, Liao S. Physical activity during pregnancy and the risk of gestational diabetes mellitus: a systematic review and meta-analysis of randomised controlled trials. British Journal of Sports Medicine 2014;48:290-5.

\section{References to studies awaiting assessment}

Frias 2012 \{published data only\}

NCT01748305. Moderate-to-vigorous physical activity for glycaemic control in patients with gestational diabetes mellitus. clinicaltrials.gov/ct2/show/NCT01748305 Date first received: 10 December 2012.

\section{References to ongoing studies}

da Silva 2013 \{published data only\}

NCT01940003. Effects of an aquatic physical exercise program on glycaemic control and perinatal outcomes of gestational diabetes: study protocol for a randomized controlled trial. clinicaltrials.gov/ct2/show/NCT01940003 Date first received: 23 August 2013.

da Silva JR Jr, Borges PS, Agra KF, Pontes IA, Alves JGB. Effects of an aquatic physical exercise program on glycemic control and perinatal outcomes of gestational diabetes: Study protocol for a randomized controlled trial. Trials 2013;14(1):390.

\section{Kokic 2014 \{published data only\}}

NCT02196571. The impact of structured aerobic and resistance exercise on the course and outcome of gestational diabetes mellitus. clinicaltrials.gov/ct2/show/NCT02196571 date first received: 19 July 2014.

\section{Shaw 2005 \{published data only\}}

Shaw J. The efficacy and feasibility of progressive strength training in the management of glucose control in women with gestational diabetes. anzctr.org.au/Trial/Registration/ TrialReview.aspx?id=436 Date first received: 7 September 2005.

\section{Additional references}

\section{ACOG 2013}

American College of Obstetricians and Gynecologists. ACOG Practice Bulletin. Clinical management guidelines for obstetrician-gynecologists. Obstetrics \& Gynecology 2013;122(2 Pt 1):406-16.

\section{ACOG 2015}

American College of Obstetrians and Gynecologists. Physical activity and exercise during pregnancy and the postpartum period. Committee Opinion Number 6502015.

\section{ACSM 2014}

American College of Sport Medicine. ACSM's Guidelines for Exercise Testing and Prescription. 9th Edition. Philadephia (PA): Wolters Kluwer/Lippincott Williams and Wilkins, 2014.

\section{Asano 2014}

Asano RY, Sales MM, Browne RA, Vila Nova Moraes JF, Coelho HJ Jnr, Moraes MR, et al. Acute effects of physical exercise in type 2 diabetes: a review. World Journal of Diabetes 2014;5(5):659-65. 


\section{Barbour 2007}

Barbour LA, McCurdy CE, Hernandez TL, Kirwan JP, Catalano PM, Friedman JE. Cellular mechanisms for insulin resistance in normal pregnancy and gestational diabetes. Diabetes Care 2007;30(Suppl 2):S111-S119.

\section{Bottalico 2007}

Bottalico JN. Recurrent gestational diabetes: risk factors, diagnosis, management, and implications. Seminars in Perinatology 2007;31(3):176-84.

\section{Catalano 2003}

Catalano PMA, Huston-Presley TL, Amini SB. Increased fetal adiposity: a very sensitive marker of abnormal in utero development. American Journal of Obstetrics and Gynecology 2003;189(6):1698-704

\section{Chamberlain 2013}

Chamberlain C, McNamara B, Williams E, Yore D, Oldenburg B, Oats $\mathrm{J}$, et al. Diabetes in pregnancy among indigenous women in Australia, Canada, New Zealand and the United States. Diabetes/Metabolism Research Reviews 2013;29(4):241-56.

\section{Chasan-Taber 2008}

Chasan-Taber L, Schmidt MD, Pekow P, Sternfeld B, Manson JE, Solomon CG, et al. Physical activity and gestational diabetes mellitus among Hispanic women. Journal of Women's Health 2008;17(6):999-1008.

\section{Chibalin 2000}

Chibalin AV, Yu M, Ryder JW, Song XM, Galuska D, Krook A, et al. Exercise-induced changes in expression and activity of proteins involved in insulin signal transduction in skeletal muscle: differential effects on insulin receptor substrates 1 and 2. Proceedings of the National Academy of Sciences of the United States of America 2000;97:38-43.

\section{Coustan 2010}

Coustan DR, Lowe LP, Metzger BE, Dyer AR, International Association of Diabetes and Pregnancy Study Groups. The hyperglycemia and adverse pregnancy outcome (HAPO) study: paving the way for new diagnostic criteria for gestational diabetes mellitus. American Journal of Obstetrics and Gynecology 2010;202(6):654.e1-654.e6.

\section{Crowther 2005}

Crowther CA, Hiller JE, Moss JR, McPhee AJ, Jeffries WS, Robinson JS, et al. Effect of treatment of gestational diabetes mellitus on pregnancy outcomes. New England Journal of Medicine 2005;352(24):2477-86.

\section{Cundy 2014}

Cundy T, Ackermann E, Ryan EA. Gestational diabetes: new criteria may triple the prevalence but effect on outcomes is unclear. BMJ 2014;348:g1567.

\section{Cypryk 2008}

Cypryk K, Szymczak W, Czupryniak L, Sobczak M, Lewinski A. Gestational diabetes mellitus - an analysis of risk factors. Endokrynologia Polska (Warszawa) 2008;59(5):393-7.

\section{da Silva 2013b}

da Silva JR Jr, Borges PS, Agra KF, Pontes IA, Alves JGB. Effects of an aquatic physical exercise program on glycemic control and perinatal outcomes of gestational diabetes: Study protocol for a randomized controlled trial. Trials 2013;14(1):390.

\section{Dela 1993}

Dela F, Handberg A, Mikines KJ, Vinten J, Galbo H. GLUT4 and insulin receptor binding and kinase activity in trained human muscle. Journal of Physiology 1993;469:615-24.

\section{Duran 2014}

Duran A, Saenz S, Torrejon M, Bordiu E, del Valle L, Galindo M, et al. Introduction of IADPSG criteria for the screening and diagnosis of gestational diabetes mellitus results in improved pregnancy outcomes at a lower cost in a large cohort of pregnant women: the St. Carlos gestational diabetes study. Diabetes Care 2014;37:2442-50.

\section{Esakoff 2009}

Esakoff TF, Cheng YW, Sparks TN, Caughey AB. The association between birthweight $4000 \mathrm{~g}$ or greater and perinatal outcomes in patients with and without gestational diabetes mellitus. American Journal of Obstetrics and Gynecology 2009;200(6):672.e1-672.e4.

\section{Ferrara 2007}

Ferrara A. Increasing prevalence of gestational diabetes mellitus: a public health perspective. Diabetes Care 2007;30(Suppl 2):S141-S146.

\section{Guerrero-Romero 2010}

Guerrero-Romero F, Aradillas-García C, Simental-Mendia LE, Monreal-Escalante E, de la Cruz Mendoza E, RodríguezMoran M. Birth weight, family history of diabetes, and metabolic syndrome in children and adolescents. Journal of Pediatrics 2010;156(5):719-23.

\section{HAPO 2008}

The HAPO Study Cooperative Research Group. Hyperglycemia and adverse pregnancy outcomes. New England Journal of Medicine 2008;358:1991-2002.

\section{Harder 2009}

Harder T, Roepke K, Diller N, Stechling Y, Dudenhausen JW, Plagemann A. Birth weight, early weight gain, and subsequent risk of type 1 diabetes: systematic review and meta-analysis. American Journal of Epidemiology 2009;169(12):1428-36.

\section{Harrison 2016}

Harrison AL, Shields N, Taylor NF, Frawley HC. Exercise improves glycaemic control in women diagnosed with gestational diabetes mellitus: A systematic review. Journal of Physiotherapy 2016;62(4):188-96.

\section{Hedderson 2010}

Hedderson MM, Gunderson EP, Ferrara A. Gestational weight gain and risk of gestational diabetes mellitus. Obstetrics \& Gynecology 2010;115(3):597-604. 


\section{Henriksen 2008}

Henriksen T. The macrosomic fetus: a challenge in current obstetrics. Acta Obstetricia et Gynecologica Scandinavica 2008;87(2):134-45.

\section{Higgins 2011}

Higgins JPT, Green S, editors. Cochrane Handbook for Systematic Reviews of Interventions Version 5.1.0 [updated March 2011]. The Cochrane Collaboration, 2011. Available from www.cochrane-handbook.org.

\section{Hjeltnes 1998}

Hjeltnes N, Galuska D, Bjornholm M, Aksnes AK, Lannem A, Zierath JR, et al. Exercise-induced overexpression of key regulatory proteins involved in glucose uptake and metabolism in tetraplegic persons: molecular mechanism for improved glucose homeostasis. FASEB Journal 1998;12:1701-12.

\section{IADPSG 2010}

International Association of Diabetes and Pregnancy Study Groups Consensus Panel, Metzger BE, Gabbe SG, Persson B, Buchanan TA, Catalano PA, Damm P, et al. International association of diabetes and pregnancy study groups recommendations on the diagnosis and classification of hyperglycemia in pregnancy. Diabetes Care 2010;33(3):676-82.

\section{Jastrow 2010}

Jastrow N, Roberge S, Gauthier RJ, Laroche L, Duperron L, Brassard N, et al. Effect of birth weight on adverse obstetric outcomes in vaginal birth after cesarean delivery. Obstetrics \& Gynecology 2010;115(2 Pt 1):338-43.

\section{Kim 2002}

Kim C, Newton KM, Knopp RH. Gestational diabetes and the incidence of type 2 diabetes: a systematic review. Diabetes Care 2002;25:1862-8.

\section{Kim 2010}

Kim SY, England L, Wilson HG, Bish C, Satten GA, Dietz P. Percentage of gestational diabetes attributable to overweight and obesity. American Journal of Public Health 2010;100(6):1047-52.

\section{Lain 2007}

Lain KY, Catalano PM. Metabolic changes in pregnancy. Clinical Obstetrics and Gynecology 2007;50(4):938-48.

\section{Landon 2009}

Landon MB, Spong CY, Thom E, Carpenter MW, Ramin SM, Casey B, et al. A multicenter, randomized trial of treatment for mild gestational diabetes. New England Journal of Medicine 2009;361(14):1339-48.

\section{Metzger 2008}

Metzger B, for The HAPO Study Cooperative Research Group. Hyperglycemia and adverse pregnancy outcomes. New England Journal of Medicine 2008;358:1991-2002.

\section{Nascimento 2012}

Nascimento SL, Surita FG, Cecatti JG. Physical exercise during pregnancy: a systematic review. Current Opinion in Obstetrics and Gynecology 2012;24(6):387-94.

\section{NICE 2015}

National Institute for Health and Clinical Excellence (NICE). Diabetes in Pregnancy: Management of Diabetes and its Complications from Pre-conception to the Postnatal Period. NICE clinical guideline NG3. London: NICE, 2015.

\section{Petry 2010}

Petry CJ. Gestational diabetes: risk factors and recent advances in its genetics and treatment. British Journal of Nutrition 2010;104(6):775-87.

\section{Pettitt 1985}

Petitt DJ, Bennett PH, Knowler WC, Baird HR, Aleck KA. Gestational diabetes mellitus and impaired glucose tolerance during pregnancy. Long-term effects on obesity and glucose tolerance in the offspring. Diabetes 1985;34(Suppl 2):119-22.

\section{Pettitt 1993}

Pettitt DJ, Nelson RG, Saad MF, Bennett PH, Knowler WC. Diabetes and obesity in the offspring of Pima Indian women with diabetes during pregnancy. Diabetes Care 1993;16(1):310-4.

\section{Reece 2009}

Reece EA, Leguizamon G, Wiznitzer A. Gestational diabetes: the need for a common ground. Lancet 2009;373(9677):1789-97.

\section{RevMan 2014 [Computer program]}

The Nordic Cochrane Centre, The Cochrane Collaboration. Review Manager (RevMan). Version 5.3. Copenhagen: The Nordic Cochrane Centre, The Cochrane Collaboration, 2014.

\section{Tran 2013}

Tran TS, Hirst JE, Do MA, Morris JM, Jeffrey HE. Early prediction of gestational diabetes mellitus in Vietnam: clinical impact of currently recommended diagnostic criteria. Diabetes Care 2013;36(3):618-24.

\section{Tuomilehto 2001}

Tuomilehto J, Lindstrom J, Eriksson JG, Valle TT, Hamalainen H, Ilanne-Parikka $P$, et al. Prevention of type 2 diabetes mellitus by changes in lifestyle among subjects with impaired glucose tolerance. New England Journal of Medicine 2001;344(18):1343-50.

\section{WHO 1999}

World Health Organization. Definition, Diagnosis and Classification of Diabetes Mellitus and its Complications. Report of a WHO Consultation. Part 1. Geneva, Switzerland: WHO, 1999.

\section{WHO 2014}

World Health Organization. WHO Diagnostic Criteria and Classification of Hyperglycaemia First Detected in Pregnancy. Report WHO/NMH/MND/13.2. Geneva, Switzerland: WHO, 2014. 


\section{References to other published versions of this review}

\section{Ceysens 2006}

Ceysens G, Roullier D, Boulvain M. Exercise for diabetic pregnant women. Cochrane Database of Systematic Reviews 2006, Issue 3. [DOI: 10.1002/14651858.CD004225.pub2]

\section{Ceysens 2016}

Ceysens G, Brown J, Boulvain M. Exercise for pregnant women with gestational diabetes for improving maternal and fetal outcomes. Cochrane Database of Systematic Reviews 2016, Issue 5. [DOI: 10.1002/14651858.CD012202]

* Indicates the major publication for the study

\section{CHARACTERISTICS OF STUDIES}

Characteristics of included studies [ordered by study ID]

Adam 2014

\begin{tabular}{ll} 
Methods & Parallel randomised controlled trial. \\
\hline Participants & 79 women randomised. \\
Inclusion criteria: pregnant women diagnosed with GDM. & Exclusion criteria: not described. \\
& Setting: Montreal, Canada. \\
& Timing: no details. \\
& Exercise group - individualised follow-up by kinesiologist ( $\mathrm{n}=40)$ \\
Interventions & versus \\
control group - general counselling about physical activity $(\mathrm{n}=39)$. \\
\hline Primary outcome was the use of insulin. \\
$\begin{array}{l}\text { Secondary outcomes included excessive gestational weight gain according to the IOM guidelines, eval- } \\
\text { uation of medical intervention (non stress test and induction) and a composite outcome of maternal } \\
\text { and fetal complications (hypertension, pre-eclampsia, caesarean section, assisted delivery, macroso- } \\
\text { mia, prematurity, neonatal unit admission). }\end{array}$
\end{tabular}

Notes

There was also a third "control" group. However, these women were not randomly assigned to receive 'no advice' about physical activity, they were matched for age, BMI at term, and GDM diagnosis to women in the trial. Data for this group have not been included in this review.

Funding source: no details.

Declarations of interest: statement that there are no conflicts of interest.

\section{Risk of bias}

\begin{tabular}{lll}
\hline Bias & Authors' judgement & Support for judgement \\
\hline $\begin{array}{l}\text { Random sequence genera- } \\
\text { tion (selection bias) }\end{array}$ & Unclear risk & "randomly assigned" no other information. \\
\hline $\begin{array}{l}\text { Allocation concealment } \\
\text { (selection bias) }\end{array}$ & Unclear risk & No details. \\
\hline $\begin{array}{l}\text { Blinding of participants } \\
\text { and personnel (perfor- } \\
\text { mance bias) } \\
\text { All outcomes }\end{array}$ & Unclear risk & No details. \\
\hline \hline
\end{tabular}


Adam 2014 (Continued)

Blinding of outcome as-
sessment (detection bias) $\quad$ Unclear risk No details.

All outcomes

\begin{tabular}{lll}
\hline $\begin{array}{l}\text { Incomplete outcome data } \\
\text { (attrition bias) } \\
\text { All outcomes }\end{array}$ & Unclear risk & No details as to whether all participants completed the trial. \\
\hline $\begin{array}{l}\text { Selective reporting (re- } \\
\text { porting bias) }\end{array}$ & Unclear risk & $\begin{array}{l}\text { The study was assessed from a brief conference abstract, without access to the } \\
\text { study protocol. }\end{array}$ \\
\hline
\end{tabular}

Other bias Unclear risk The report states that "characteristics were similar at baseline".

There is no power calculation, but the authors comment that the study could be under-powered to show differences.

\section{Avery 1997}

\begin{tabular}{ll}
\hline Methods $\quad$ Parallel randomised controlled trial. \\
\hline
\end{tabular}

Participants 33 women randomised.

Inclusion criteria: physician or certified nurse-midwife diagnosis of GDM, 34 weeks' gestation or less, no other important medical or obstetric complications, ability to read and write English, age 18-40 years, no current regular exercise regimen for continuous 30-minute periods more than twice per week.

Exclusion criteria: no details, although "19 women were ineligible for medical reasons" and "three subjects in the control group were withdrawn for medical reasons" (p12). 3 women were excluded because exercise was recommended to them by the care provider.

Setting: USA, large mid-western health maintenance organisation.

Timing: no details.

Interventions

Exercise group - exercise for 30 minutes 3 to 4 times weekly for the remainder of the pregnancy. 5 minutes warm up, 5 minutes cool down, 20 minutes cycle ergometer or walking at $70 \%$ of estimated maximal heart rate. 2 exercise sessions were in the presence of the investigator, with maternal and fetal monitoring. Once or twice a week, the women exercised unsupervised $(n=16)$.

versus

control group - continued dietary therapy and usual physical activity level. They were asked not to change their current amount of activity. They were telephoned weekly by the investigator to monitor progress in the study and were asked to record any exercise $(n=17)$.

Outcomes Daily fasting and postprandial blood glucose levels, $\mathrm{HbA}_{1} \mathrm{C}$, incidence of exogenous insulin therapy, incidence of newborn hypoglycaemia.

Notes

Funding: National Institute of Nursing Research, National Institute of Health NR06568-01A1; the American Diabetes Association, MN Affiliate; the March of Dimes, Greater Twin Cities Chapter; Boehringer Manheim Corporation; the Clinical Research and Education Fund, Group Health Foundation.

Funding source: National Institute of Nursing Research, National Institutes of Health, American Diabetes Association, March of Dimes, Greater Twin Cities Chapter, Boerhinger Manheim Corporation, Clinial Research and Education Fund.

Declarations of interest: no details. 
Avery 1997 (Continued)

Risk of bias

\begin{tabular}{lll}
\hline Bias & Authors' judgement & Support for judgement \\
\hline $\begin{array}{l}\text { Random sequence genera- } \\
\text { tion (selection bias) }\end{array}$ & Low risk & $\begin{array}{l}\text { "Group assignment was determined using a random-numbers table by the } \\
\text { block randomisation procedure". }\end{array}$ \\
\hline $\begin{array}{l}\text { Allocation concealment } \\
\text { (selection bias) }\end{array}$ & Unclear risk & No details. \\
\hline $\begin{array}{l}\text { Blinding of participants } \\
\begin{array}{l}\text { and personnel (perfor- } \\
\text { mance bias) } \\
\text { All outcomes }\end{array}\end{array}$ & High risk & "subjects were not blinded as to the nature of the study intervention". \\
\hline
\end{tabular}

Blinding of outcome as- Unclear risk No details.

sessment (detection bias)

All outcomes

\section{Incomplete outcome data High risk} (attrition bias)

All outcomes

\begin{abstract}
The number of eligible women was 144, however 19 were ineligible for medical reasons, 21 were beyond 34 weeks' gestation, 68 declined, and exercise was recommended to 3 by the care provider. Withdrawals - exercise group $n=16$ ( 1 woman subsequently dropped out); control group $n=17$ ( 3 women were subsequently withdrawn for medical reasons).

"several subjects gave birth before the follow-up exercise test", however the number of women included in the measures at the end is unclear.

Home blood glucose levels are reported for 10/15 women in the exercise group, and 12/14 women in the control group. It is unclear why the other women's results are missing.
\end{abstract}

\begin{tabular}{lll}
\hline $\begin{array}{l}\text { Selective reporting (re- } \\
\text { porting bias) }\end{array}$ & Unclear risk & This study was assessed from a published report, without a protocol available. \\
\hline Other bias & Unclear risk & $\begin{array}{l}\text { Baseline characteristics were mostly similar, however parity was higher in the } \\
\text { exercise group. The trial authors are aware that the trial is underpowered to } \\
\text { detect differences in blood glucose values or } \mathrm{HbA}_{1} \mathrm{C} .\end{array}$ \\
\hline
\end{tabular}

Bambicini 2012

\begin{tabular}{ll}
\hline Methods & Parallel randomised 3-arm trial. \\
\hline Participants & 17 women randomised. \\
& Inclusion criteria: pregnant women with GDM, 27 to 37 weeks' gestation. \\
& Exclusion criteria: not described. \\
& Setting: Sao Paulo, Brazil. \\
& Timing: no details. \\
& Exercise group 1: aerobic activity: 30 minutes brisk walking $(n=6)$. \\
Interventions & Exercise group 2: resistance exercises: 30 minutes circuit workout with elastic-band exercises (n=5) \\
& versus
\end{tabular}


Bambicini 2012 (Continued)

control group: remained seated for 30 minutes listening to explanations about Shantala exercises for the baby $(n=6)$.

\begin{tabular}{|c|c|c|}
\hline Outcomes & \multicolumn{2}{|c|}{ Capillary blood glucose before, at the end of session and 1 hour after. } \\
\hline Notes & \multicolumn{2}{|c|}{$\begin{array}{l}\text { Funding source: no details. } \\
\text { Declarations of interest: no details. }\end{array}$} \\
\hline \multicolumn{3}{|l|}{ Risk of bias } \\
\hline Bias & Authors' judgement & Support for judgement \\
\hline $\begin{array}{l}\text { Random sequence genera- } \\
\text { tion (selection bias) }\end{array}$ & Unclear risk & "randomized" no other details. \\
\hline $\begin{array}{l}\text { Allocation concealment } \\
\text { (selection bias) }\end{array}$ & Unclear risk & No details. \\
\hline $\begin{array}{l}\text { Blinding of participants } \\
\text { and personnel (perfor- } \\
\text { mance bias) } \\
\text { All outcomes }\end{array}$ & Unclear risk & No details. \\
\hline $\begin{array}{l}\text { Blinding of outcome as- } \\
\text { sessment (detection bias) } \\
\text { All outcomes }\end{array}$ & Unclear risk & No details. \\
\hline $\begin{array}{l}\text { Incomplete outcome data } \\
\text { (attrition bias) } \\
\text { All outcomes }\end{array}$ & Unclear risk & No details. \\
\hline $\begin{array}{l}\text { Selective reporting (re- } \\
\text { porting bias) }\end{array}$ & Unclear risk & Not described. Assessed from a brief abstract, without the trial protocol. \\
\hline Other bias & Unclear risk & Very little detail of methodology reported. \\
\hline
\end{tabular}

\section{Bo 2014}

\begin{tabular}{ll}
\hline Methods & $2 \times 2$ factorial randomised controlled trial. \\
\hline Participants & 200 women randomised. \\
& $\begin{array}{l}\text { Inclusion criteria: pregnant women, age 18-50, 24-26th weeks of gestation, GDM diagnosis based on a } \\
75 \mathrm{~g} \text { OGTT, singleton pregnancy. }\end{array}$
\end{tabular}

Exclusion criteria: $\mathrm{BMI}>40 \mathrm{~kg} / \mathrm{m}^{2}$, any known diseases, medications or obstetrical absolute/relative contraindications to exercise.

Setting: Sant'Anna Hospital, Torino, Italy.

Timing: July 2009-February 2012.

All women were given an individually-prescribed diet (carbohydrates $48 \%$ to $50 \%$, proteins $18 \%$ to
$20 \%$, fats $30 \%$ to $35 \%$, fibre $20 \mathrm{~g}$ to $25 \mathrm{~g} /$ day, no alcohol).
In addition:


Bo 2014 (Continued)

Group E: advised to briskly walk at least 20 minutes/day. $\mathrm{N}=51$.

Group B: individually oral/written recommendations for helping with healthy dietary choices (i.e. lowering carbohydrate intake, strategies for out-of-home eating, healthy cooking and food shopping and related behavioural suggestions) and debunking false myths about diet in pregnancy. $\mathrm{N}=49$.

Group BE brisk walk and dietary advice $\mathrm{n}=50$.

Group D (control group): individually-prescribed dietary recommendations only $n=50$.

All women were monitored by weekly phone calls and visited every 2 weeks to monitor adverse events and protocol adherence. Participants self-monitored capillary blood glucose concentrations 4-6 times per day with a glucometer.

$\begin{array}{ll}\text { Outcomes } & \text { Fasting glucose values, high-density lipoprotein (HDL)-cholesterol, triglycerides, insulin, Homeosta- } \\ \text { sis-Model-Assessment-Insulin Resistance (HOMA-IR), high-sensitivity C-reactive protein (CRP), glycated } \\ \text { haemoglobin (HbAlc), postprandial glucose, maternal/neonatal complications. }\end{array}$

Notes $\quad$ Funding source: Regione Piemonte 2009.

Declarations of interest: the authors report no conflicts of interest.

\section{Risk of bias}

\begin{tabular}{|c|c|c|}
\hline Bias & Authors' judgement & Support for judgement \\
\hline $\begin{array}{l}\text { Random sequence genera- } \\
\text { tion (selection bias) }\end{array}$ & Low risk & $\begin{array}{l}\text { "Randomization was stratified by baseline body mass index (BMI) and METs, } \\
\text { and was implemented through a website (www.epiclin.it)". }\end{array}$ \\
\hline $\begin{array}{l}\text { Allocation concealment } \\
\text { (selection bias) }\end{array}$ & Unclear risk & No details provided on method used to conceal allocation. \\
\hline $\begin{array}{l}\text { Blinding of participants } \\
\text { and personnel (perfor- } \\
\text { mance bias) } \\
\text { All outcomes }\end{array}$ & Unclear risk & $\begin{array}{l}\text { It was not feasible to blind women to the intervention. However, "The dieti- } \\
\text { cians, the obstetricians who reported maternal/neonatal complications, and } \\
\text { the laboratory personnel were blinded to the group assignment". }\end{array}$ \\
\hline $\begin{array}{l}\text { Blinding of outcome as- } \\
\text { sessment (detection bias) } \\
\text { All outcomes }\end{array}$ & Low risk & $\begin{array}{l}\text { "It is possible that women in the exercise group could have over-reported exer- } \\
\text { cise or declared healthier nutritional habit. However, all the outcomes, which } \\
\text { were blindly measured, were consistent with the declared lifestyle changes". } \\
\text { Outcome assessment was done by dieticians, obstetricians and laboratory } \\
\text { personnel who were blinded to group allocation. }\end{array}$ \\
\hline
\end{tabular}

Incomplete outcome data Low risk The authors state that "All participants completed the study".
(attrition bias)

All outcomes

\begin{tabular}{|c|c|c|}
\hline $\begin{array}{l}\text { Selective reporting (re- } \\
\text { porting bias) }\end{array}$ & Low risk & $\begin{array}{l}\text { The protocol was available for this trial. } \\
\text { All prespecified outcomes except infant birthweight were reported. }\end{array}$ \\
\hline Other bias & Low risk & $\begin{array}{l}\text { Baseline characteristics appear to be similar across groups. The sample size } \\
\text { was calculated to have } 95 \% \text { statistical power to detect at least a } 10 \% \text { reduc- } \\
\text { tion in fasting glucose by exercise. The authors acknowledge that the study } \\
\text { is underpowered to find small differences in the incidence of adverse mater- } \\
\text { nal/neonatal outcomes. }\end{array}$ \\
\hline
\end{tabular}


Brankston 2004

\begin{tabular}{ll}
\hline Methods & Parallel randomised controlled trial. \\
\hline Participants & Possibly 38 women randomised. \\
& $\begin{array}{l}\text { Inclusion criteria: otherwise healthy pregnant women with GDM, between age } 20 \text { and } 40 \text { years, ges- } \\
\text { tational age between } 26 \text { and } 32 \text { weeks', BMI below } 40 \mathrm{~kg} / \mathrm{m}^{2}, \text { nonsmokers, who were not involved in a } \\
\text { regular exercise program. }\end{array}$
\end{tabular}
regular exercise program.

Exclusion criteria: no details.

Setting: Alberta, Canada. Diabetic Outpatient Clinics at the Royal Alexandra and Grey Nuns Hospitals in Edmonton.

Timing: not stated.

Interventions

Exercise group: progressive physical conditioning program. 3 supervised introductory sessions, and weekly contact with supervisor. Instructed to perform resistance training circuit-type exercises 3 times per week. Women were instructed to exercise at a level that felt "somewhat hard", and were taught to monitor their heart rate to ensure that it did not rise above 140 beats/min during exercise. All exercise sessions were recorded in a log book $(n=16)$

versus

control group: diet alone. Standard diabetic diet advice: $40 \%$ carbohydrate, $20 \%$ protein, $40 \%$ fat, calculated at 24 to $30 \mathrm{kcal} / \mathrm{kg}$ per day on the basis of the woman's ideal pre-pregnant body weight. Women were asked not to begin a structured exercise program for the remainder of the pregnancy $(\mathrm{n}=$ 16).

Primary outcome: requirement for insulin.
$\begin{aligned} & \text { Secondary outcomes: latency to insulin treatment, amount of insulin required, gestational age at birth, } \\ & \text { birthweight. }\end{aligned}$

Notes Funding source: no details.

Declarations of interest: no details.

\section{Risk of bias}

\begin{tabular}{lll}
\hline Bias & Authors' judgement & Support for judgement \\
\hline $\begin{array}{l}\text { Random sequence genera- } \\
\text { tion (selection bias) }\end{array}$ & Low risk & Random numbers table used. \\
\hline $\begin{array}{l}\text { Allocation concealment } \\
\text { (selection bias) }\end{array}$ & Low risk & Sequentially numbered opaque envelopes. \\
\hline $\begin{array}{l}\text { Blinding of participants } \\
\text { and personnel (perfor- } \\
\text { mance bias) } \\
\text { All outcomes }\end{array}$ & High risk & No blinding. \\
\hline
\end{tabular}

\begin{tabular}{lll}
\hline $\begin{array}{l}\text { Blinding of outcome as- } \\
\text { sessment (detection bias) } \\
\text { All outcomes }\end{array}$ & Unclear risk & No details. \\
\hline $\begin{array}{l}\text { Incomplete outcome data } \\
\text { (attrition bias) }\end{array}$ & Unclear risk & $\begin{array}{l}38 \text { women randomised. However physicians advised against the program for } 3 \\
\text { women because of pregnancy-induced hypertension, and } 2 \text { women who were } \\
\text { randomised to exercise did not enter the program. } 1 \text { woman dropped out of } \\
\text { the study due to time constraints: it does not say which group she was ran- }\end{array}$ \\
\hline
\end{tabular}


domised to, but exercise would demand more time commitment so probably this group). "four women in each group did not record their blood glucose measurements adequately" so these data are missing from blood glucose levels.

\begin{tabular}{|c|c|c|}
\hline $\begin{array}{l}\text { Selective reporting (re- } \\
\text { porting bias) }\end{array}$ & Unclear risk & $\begin{array}{l}\text { The protocol was not available for this trial, so it was assessed from only the } \\
\text { published report. Several outcomes are reported in the text as "no significant } \\
\text { differences" but without providing the number of women/infants (gestational } \\
\text { age at delivery, rate of caesarean deliveries, birthweight). }\end{array}$ \\
\hline
\end{tabular}

Other bias Unclear risk The report states that the analyses were done by intention to treat, however 6 women who were probably randomised to the exercise group were not included in the analyses.

The groups had similar baseline physical characteristics, although the diet-alone group had a significantly higher mean pre-pregnant body mass (weight) than the diet plus exercise group.

\section{Bung 1991}

\begin{tabular}{ll}
\hline Methods & Parallel randomised controlled trial. \\
\hline Participants & 41 women randomised. \\
& $\begin{array}{l}\text { Inclusion criteria: pathological results in a OGTT and persisting fasting blood glucose values }>105, \\
\text { but }<130 \mathrm{mg} / \mathrm{dl} \text { after a failed } 1 \text { week ADA diet trial ( } 24 \text { to } 30 \mathrm{kcal} / \mathrm{kg} / \text { day); following the clinical protocol } \\
\text { these women would then require Insulin therapy. No contraindications to exercise, before } 33 \text { weeks' } \\
\text { pregnancy (to allow at least } 4 \text { weeks of exercise). }\end{array}$
\end{tabular}

Exclusion criteria: other medical or obstetrical complications of pregnancy; women at risk for premature labour.

Setting: high risk obstetrical clinic of Los Angeles County/University of Southern California Women's Hospital.

Timing: May - November 1990.

Interventions

Exercise group - exercise and diet. Instructed to conduct a non-sedentary lifestyle, and attend the exercise laboratory 3 times a week to exercise under medical supervision. 45 minutes with $2 \times 5$-minute breaks, on a recumbent bicycle, at $50 \%$ of their last determined maximum aerobic capacity (classed as moderate exercise) $(n=21)$

versus

Control group - insulin therapy and diet $(n=20)$.

Outcomes Heart rate and uterine activity. Clinical data, pregnancy complications, maternal and neonatal out-
come variables.

Notes $\quad$ Funding source: no details.

Declarations of interest: no details.

\section{Risk of bias}

Bias Authors' judgement Support for judgement


Bung 1991 (Continued)

Random sequence genera- Unclear risk Double-stratified randomisation, but no information on sequence generation. tion (selection bias)

\begin{tabular}{lll}
\hline $\begin{array}{l}\text { Allocation concealment } \\
\text { (selection bias) }\end{array}$ & Unclear risk & No details. \\
\hline $\begin{array}{l}\text { Blinding of participants } \\
\text { and personnel (perfor- } \\
\text { mance bias) }\end{array}$ & Unclear risk & No details. \\
All outcomes & \\
\hline
\end{tabular}

Blinding of outcome as- Unclear risk No details.

sessment (detection bias)

All outcomes

\section{Incomplete outcome data High risk} (attrition bias)

All outcomes
$17 / 21$ women in the exercise group completed the study. 4 women were excluded for: pPROM, non-compliance with exercises, moving away, and withdrew. 17/20 women in the control group completed the study. 3 women did not return to the clinic and were lost to follow-up. Some of this attrition may be related to the intervention, but these women were not included in the analyses.

\begin{tabular}{lll}
\hline $\begin{array}{l}\text { Selective reporting (re- } \\
\text { porting bias) }\end{array}$ & Unclear risk & Assessed from published reports without access to the protocol. \\
\hline Other bias & Unclear risk & $\begin{array}{l}\text { There were small discrepancies between reports, for example birthweight and } \\
\text { number of babies with Apgar }<7 \text { at } 5 \text { minutes. }\end{array}$ \\
\hline
\end{tabular}

\section{de Barros 2010}

Methods Parallel randomised controlled trial.

\section{Participants}

\section{4 women}

Inclusion criteria: pregnant women with a diagnosis of GDM, sedentary according to the International Physical Activity Questionnaire (IPAQ), nonsmokers, age 18-45 years, no physical factor or disease limiting exercise, singleton pregnancy, absence of fetal malformation upon ultrasound, gestational age 24-34 weeks', no risk factors for preterm delivery.

Exclusion criteria: clinical or obstetric complications contraindicating exercise during pregnancy and loss to follow-up.

Setting: Obstetric clinic of the University Hospital, University of Sao Paulo School of Medicine, Brazil.

Timing: October 2006-November 2008.

Interventions

Exercise group - resistance exercise program with an elastic band. Women exercised 3 times a week, for 30-40 minutes, on non-consecutive days, twice a week at home and once in the clinic under supervision. Women were instructed to maintain an exercise intensity of 5 or 6 on an exertion scale, which is "somewhat heavy" exercise perception. Exercises were adapted by the researcher at the weekly clinic to maintain this intensity. Women started the program about 90 minutes after eating and after measuring capillary glycaemia. If capillary glucose levels were between $100 \mathrm{mg} / \mathrm{dL}$ and $250 \mathrm{mg} / \mathrm{dL}$, women did the program, otherwise they waited until the next day $(n=32)$

versus 
de Barros 2010 (Continued)

control group - no change to prenatal routine care, weekly outpatient visits. Occasional questions about whether they had started any physical activity. Instructed not to start any new type of physical activity after randomisation $(n=32)$.

$\begin{array}{ll}\text { Outcomes } & \text { Requirement for insulin, amount of insulin required, latency to insulin requirement (weeks), mean glu- } \\ \text { cose levels, percentage of weeks spent within the target glucose range, maternal BMI at birth, pregnan- } \\ \text { cy weight gain, gestational age at delivery, birthweight. }\end{array}$

Notes Sample size was calculated as 30 women in each group to show reduction in insulin requirement.

Funding source: Coodenacao de Aperfeicoamento de Pessoal de Nivel Superior.

Declarations of interest: no details.

\section{Risk of bias}

\begin{tabular}{|c|c|c|}
\hline Bias & Authors' judgement & Support for judgement \\
\hline $\begin{array}{l}\text { Random sequence genera- } \\
\text { tion (selection bias) }\end{array}$ & Low risk & $\begin{array}{l}\text { "Women admitted to the study were randomized using a computer-generated } \\
\text { random series produced by a person not related to the protocol" }\end{array}$ \\
\hline $\begin{array}{l}\text { Allocation concealment } \\
\text { (selection bias) }\end{array}$ & Low risk & Sequential sealed opaque envelopes. \\
\hline $\begin{array}{l}\text { Blinding of participants } \\
\text { and personnel (perfor- } \\
\text { mance bias) } \\
\text { All outcomes }\end{array}$ & High risk & $\begin{array}{l}\text { Women were not blinded, and the main researcher knew their allocation. "The } \\
\text { obstetricians responsible for clinical and prenatal care and data recording was } \\
\text { unaware to which group the patients belonged, and only the main researcher } \\
\text { questioned the patients with respect to the exercise practice" }\end{array}$ \\
\hline $\begin{array}{l}\text { Blinding of outcome as- } \\
\text { sessment (detection bias) } \\
\text { All outcomes }\end{array}$ & Low risk & The obstetricians recording data were blinded to group allocation. \\
\hline $\begin{array}{l}\text { Incomplete outcome data } \\
\text { (attrition bias) } \\
\text { All outcomes }\end{array}$ & Low risk & $\begin{array}{l}\text { After randomisation, } 1 \text { woman withdrew because of lack of time to perform } \\
\text { the exercise program, and another started using metformin for glycaemic con- } \\
\text { trol. These women were included in the analyses. }\end{array}$ \\
\hline $\begin{array}{l}\text { Selective reporting (re- } \\
\text { porting bias) }\end{array}$ & Unclear risk & $\begin{array}{l}\text { This trial was assessed from a published report, without access to the proto- } \\
\text { col. }\end{array}$ \\
\hline Other bias & Low risk & No evidence of other bias. \\
\hline
\end{tabular}

Halse 2014

\begin{tabular}{ll}
\hline Methods $\quad$ Parallel randomised controlled trial. \\
\hline
\end{tabular}

Participants 40 women randomised.

Inclusion criteria: pregnant women, within 1 week of GDM diagnosis, singleton pregnancy, between 26 and 30 weeks' gestation, normal 18 week anatomy scan, $\mathrm{BMI} \leq 45 \mathrm{~kg} / \mathrm{m}^{2}$, non-exercise program, medically cleared for exercise participation.

Exclusion criteria: less than 18 years of age, unable to understand the implications of participation, on any medications at the time of recruitment, low-lying placenta, pre-existing diabetes (type 1 or 2), or cardiac disease.

Setting: King Edward Memorial Hospital, Perth, Western Australia, Australia. 
Halse 2014 (Continued)

Timing: no details.

Interventions Exercise group: experimental intervention: home-based exercise program involving 5 sessions per week continued until week 34 of gestation. 3 sessions per week were supervised, 2 were unsupervised, using an upright stationary cycle ergometer. Sessions were 25-30 minutes in week 1 , increasing to 40-45 minutes by week $4(n=20)$.

versus

control group: continued with their usual physical activity regimen for the duration of the intervention.

Both groups: assessment of glycaemic control and counselling by a diabetes educator and dietician. Daily fasting and 120 minutes postprandial glucose levels after breakfast, lunch and dinner. Food and drink diary.

Outcomes $\quad$ Aerobic fitness, maternal weight gain, obstetric and neonatal outcomes.

Notes Funding source: University of Western Australia, Women's and Infants Research Foundation, National Health and Medical Research Council.

Declarations of interest: publication states there were no personal or financial conflicts of interest.

\section{Risk of bias}

\begin{tabular}{|c|c|c|}
\hline Bias & Authors' judgement & Support for judgement \\
\hline $\begin{array}{l}\text { Random sequence genera- } \\
\text { tion (selection bias) }\end{array}$ & Unclear risk & "randomized", no description of sequence generation. \\
\hline $\begin{array}{l}\text { Allocation concealment } \\
\text { (selection bias) }\end{array}$ & Low risk & $\begin{array}{l}\text { "Concealed, sequentially numbered opaque envelopes selected by each par- } \\
\text { ticipant". }\end{array}$ \\
\hline $\begin{array}{l}\text { Blinding of participants } \\
\text { and personnel (perfor- } \\
\text { mance bias) } \\
\text { All outcomes }\end{array}$ & Unclear risk & No details. \\
\hline $\begin{array}{l}\text { Blinding of outcome as- } \\
\text { sessment (detection bias) } \\
\text { All outcomes }\end{array}$ & Unclear risk & No details. \\
\hline $\begin{array}{l}\text { Incomplete outcome data } \\
\text { (attrition bias) } \\
\text { All outcomes }\end{array}$ & Unclear risk & $\begin{array}{l}\text { No attrition is described, however the mode of delivery for control group adds } \\
\text { up to } 19 \text {, not } 20 \text {. }\end{array}$ \\
\hline $\begin{array}{l}\text { Selective reporting (re- } \\
\text { porting bias) }\end{array}$ & Unclear risk & This study was assessed from published reports, without access to a protocol. \\
\hline Other bias & Low risk & $\begin{array}{l}\text { Sample size was calculated to detect differences in blood glucose based on } \\
\text { previous study and pilot data. }\end{array}$ \\
\hline
\end{tabular}

Jovanovic-Peterson 1989

\begin{tabular}{ll}
\hline Methods & Parallel randomised controlled trial. \\
\hline Participants & 39 women randomised.
\end{tabular}


Jovanovic-Peterson 1989 (Continued)

Inclusion criteria: pregnant women with gestational diabetes diagnosed according to standard protocol. The study appears to have started at 28 weeks' gestation.

Exclusion criteria: maternal morbidity ( 1 woman with placenta praevia was excluded from the study).

Setting: USA.

Timing: not stated.

Interventions

Exercise group: supervised arm ergometer training, 20 minutes, 3 times a week for 6 weeks, plus diet ( 24 to $30 \mathrm{kcal} / \mathrm{kg} / 24$ hours; $20 \%$ protein, $40 \%$ carbohydrate, $40 \%$ fat). Target heart rate: (220-age in years) $\times 70 \%$ unless $>140 \mathrm{bpm}$, then target was $140 \mathrm{bpm}(\mathrm{n}=20)$

versus

control group: diet alone ( 24 to $30 \mathrm{kcal} / \mathrm{kg} / 24$ hours; $20 \%$ protein, $40 \%$ carbohydrate, $40 \%$ fat), divided into 3 meals and 3 snacks. Women did not participate in any structured exercise program $(n=19)$.

\begin{tabular}{ll}
\hline Outcomes & Blood glucose, glycosylated $\mathrm{Hb}$. \\
\hline Notes & Funding source: no details. \\
& Declarations of interest: no details.
\end{tabular}

\section{Risk of bias}

\begin{tabular}{|c|c|c|}
\hline Bias & Authors' judgement & Support for judgement \\
\hline $\begin{array}{l}\text { Random sequence genera- } \\
\text { tion (selection bias) }\end{array}$ & Unclear risk & "women were randomized into two groups by drawing a number". \\
\hline $\begin{array}{l}\text { Allocation concealment } \\
\text { (selection bias) }\end{array}$ & Unclear risk & No details. \\
\hline $\begin{array}{l}\text { Blinding of participants } \\
\text { and personnel (perfor- } \\
\text { mance bias) } \\
\text { All outcomes }\end{array}$ & Unclear risk & No details. \\
\hline $\begin{array}{l}\text { Blinding of outcome as- } \\
\text { sessment (detection bias) } \\
\text { All outcomes }\end{array}$ & Unclear risk & No details. \\
\hline $\begin{array}{l}\text { Incomplete outcome data } \\
\text { (attrition bias) } \\
\text { All outcomes }\end{array}$ & Low risk & $\begin{array}{l}\text { "one woman was dropped from the study because she was found to have pla- } \\
\text { centa previa", the woman appears to have been excluded before randomisa- } \\
\text { tion, and otherwise all women are accounted for. }\end{array}$ \\
\hline $\begin{array}{l}\text { Selective reporting (re- } \\
\text { porting bias) }\end{array}$ & Unclear risk & $\begin{array}{l}\text { This study was assessed from a published report without access to the proto- } \\
\text { col. }\end{array}$ \\
\hline Other bias & Unclear risk & $\begin{array}{l}\text { There is incomplete reporting of methodology, possibly due to publication in } \\
\text { 1989. The diet group had lower peak } 1 \text { hour plasma glucose on } 100 \text { g glucose } \\
\text { tolerance test at the start of the study. }\end{array}$ \\
\hline
\end{tabular}

Ramos 2015

Methods Parallel-arm, randomised controlled trial.


Ramos 2015 (Continued)

Participants $\quad 6$ women randomised (interim report from an ongoing trial)

Inclusion: pregnant women with gestational diabetes, over 20 years old, gestational age 20-27 weeks, singleton pregnancy, no orthopaedic limitations, non-smoker, medical clearance for exercise.

Exclusion: pre-eclampsia, fetal malformations, intrauterine fetal death.

Setting: prenatal clinics, Hospital de Clinicas de Porto Alegre, Brazil.

Timing: not stated.

Interventions $\quad$ Exercise group: low-intensity aerobic training in cycle-ergometer for 50 minutes per session, 3 times a week, for 10 weeks $(n=2)$

versus

control group: relaxation and stretching for 50 minutes per session, once a week for 10 weeks $(n=4)$.

Outcomes

(from protocol on clinicaltrials.gov NCT01885234) Glycated haemoglobin (HbA1c), homeostasis model assessment (HOMA), first ventilatory threshold, type of delivery, weight and length of newborn.

Notes

Funding source: no details.

Declarations of interest: publication lists no conflicts of interest.

\section{Risk of bias}

\begin{tabular}{lll}
\hline Bias & Authors' judgement & Support for judgement \\
\hline $\begin{array}{l}\text { Random sequence genera- } \\
\text { tion (selection bias) }\end{array}$ & Unclear risk & $\begin{array}{l}\text { States "randomised" however, no details provided of method used to generate } \\
\text { the random sequence. }\end{array}$ \\
\hline $\begin{array}{l}\text { Allocation concealment } \\
\text { (selection bias) }\end{array}$ & Unclear risk & No description of method used to conceal allocation. \\
\hline
\end{tabular}

Blinding of participants Unclear risk Not described, but unlikely due to the nature of the intervention.

and personnel (perfor-

mance bias)

All outcomes

Blinding of outcome as- Unclear risk Protocol states single blind (investigator), but no further details provided.

sessment (detection bias)

All outcomes

Incomplete outcome data Unclear risk Study is ongoing.
(attrition bias)

(attrition bias)

All outcomes

\begin{tabular}{|c|c|c|}
\hline $\begin{array}{l}\text { Selective reporting (re- } \\
\text { porting bias) }\end{array}$ & Unclear risk & $\begin{array}{l}\text { Assessed from protocol and very brief interim abstract; not all prespecified } \\
\text { outcomes were reported at this stage. }\end{array}$ \\
\hline
\end{tabular}

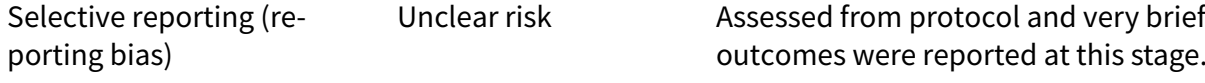

Other bias Unclear risk Insufficient information at this stage.

Methods Parallel-arm, randomised controlled trial.


Youngwanichsetha 2014 (Continued)
Participants
180 women.

Inclusion: pregnant women diagnosed with GDM A1, 24-30 weeks gestational age, fasting blood glucose concentration less than $105 \mathrm{mg} / \mathrm{dL}$, postprandial blood glucose concentration less than $120 \mathrm{mg} /$ $\mathrm{dL}$, not receiving insulin therapy for glycaemic control, no serious complications such as gestational hypertension, pre-eclampsia, preterm labour or other serious health problems.

Exclusion: blood glucose concentration higher than $120 \mathrm{mg} / \mathrm{L}$ and therefore receiving insulin therapy for glycaemic control.

Setting: tertiary hospital in southern Thailand, which is the referral centre for diabetes care.

Timing: not stated.

Exercise group: trained to perform mindfulness eating and yoga exercise in 250 minute sessions. Then
encouraged to continue mindfulness eating and yoga exercise at home for 15 to 20 minutes, 5 times a
week for 8 weeks. Encouraged and monitored by the research team every week by phone and at face to
face appointments $(n=90)$
versus
control group: standard diabetes care $(n=90)$.

\begin{tabular}{ll}
\hline Outcomes & Fasting and postprandial blood glucose concentrations, glysated haemoglobin (HbA1c). \\
\hline Notes & Funding source: no details. \\
& Declarations of interest: no details. \\
\hline
\end{tabular}

\section{Risk of bias}

\begin{tabular}{|c|c|c|}
\hline Bias & Authors' judgement & Support for judgement \\
\hline $\begin{array}{l}\text { Random sequence genera- } \\
\text { tion (selection bias) }\end{array}$ & Unclear risk & No information provided on method used to generate random sequence. \\
\hline $\begin{array}{l}\text { Allocation concealment } \\
\text { (selection bias) }\end{array}$ & Unclear risk & Opaque envelopes used. No information provided on numbering sequence. \\
\hline $\begin{array}{l}\text { Blinding of participants } \\
\text { and personnel (perfor- } \\
\text { mance bias) } \\
\text { All outcomes }\end{array}$ & Unclear risk & Not described as blinded. Unlikely due to nature of intervention. \\
\hline $\begin{array}{l}\text { Blinding of outcome as- } \\
\text { sessment (detection bias) } \\
\text { All outcomes }\end{array}$ & Unclear risk & No mention of blinding of outcome assessors. \\
\hline $\begin{array}{l}\text { Incomplete outcome data } \\
\text { (attrition bias) } \\
\text { All outcomes }\end{array}$ & Unclear risk & $\begin{array}{l}90 \text { women were randomised to each group. } 5 \text { women from each group did not } \\
\text { complete the study or were lost to follow-up. }\end{array}$ \\
\hline $\begin{array}{l}\text { Selective reporting (re- } \\
\text { porting bias) }\end{array}$ & Unclear risk & $\begin{array}{l}\text { This study was assessed from a published report without access to the proto- } \\
\text { col, however outcomes specified in the publication were reported on. }\end{array}$ \\
\hline Other bias & Unclear risk & Unclear \\
\hline
\end{tabular}

BMI: body mass index bpm: beats per minute 
GDM: gestational diabetes mellitus

$\mathrm{Hb}$ : haemoglobin

OGTT: oral glucose tolerance test

pPROM: preterm premature rupture of membranes

\section{Characteristics of excluded studies [ordered by study ID]}

\begin{tabular}{|c|c|}
\hline Study & Reason for exclusion \\
\hline Barakat 2013 & Ineligible population: examines the effect of exercise on the prevention of GDM. \\
\hline Berry 2013 & $\begin{array}{l}\text { Ineligible intervention: the exercise component of the intervention commences at } 6 \text { weeks post- } \\
\text { partum. }\end{array}$ \\
\hline Chen 1997 & $\begin{array}{l}\text { Ineligible population: the participants have an abnormal oral glucose challenge test, but are not di- } \\
\text { agnosed with GDM. }\end{array}$ \\
\hline Deshpande 2013 & $\begin{array}{l}\text { Ineligible population: participants are women with "high risk pregnancy" including women with di- } \\
\text { abetes at the time of trial entry. }\end{array}$ \\
\hline Ehrlich 2016 & Ineligible trial design: prospective cohort study - not randomised. \\
\hline Fieril 2015 & Ineligible population: participants were healthy women without GDM. \\
\hline Garcia-Patterson 2001 & Ineligible trial design: not randomised. \\
\hline Lesser 1996 & Ineligible trial design: cross-over trial. \\
\hline Melo 2008 & Ineligible population: healthy participants. \\
\hline Moholdt 2013 & Ineligible trial design: cross-over trial. \\
\hline Nobles 2015 & Ineligible population: examines the effect of exercise in prevention of GDM. \\
\hline Ong 2009 & Ineligible population: participants do not have a diagnosis of GDM. \\
\hline Yin 2014 & Ineligible trial/population: systematic review on effect of physical activity on prevention of GDM. \\
\hline
\end{tabular}

GDM: gestational diabetes mellitus

Characteristics of studies awaiting assessment [ordered by study ID]

Frias 2012

\begin{tabular}{ll}
\hline Methods & Interventional treatment trial. \\
\hline Participants & Women, 18 years and older, newly diagnosed with GDM. \\
& Women with pre-existing diabetes are excluded. \\
\hline
\end{tabular}

Interventions

Intervention group: instructed on moderate-to-vigorous intensity exercise.

Control group: routine diet and exercise counselling.

Outcomes

Need for medication for diabetes

Birthweight 
Frias 2012 (Continued)

HbA1c at delivery

Mode of delivery

Notes

ClinicalTrials.gov stated this trial has been terminated due to recruitment issues. Attempts will be made to contact the responsible party for further information.

GDM: gestational diabetes mellitus

Characteristics of ongoing studies [ordered by study ID]

da Silva 2013

Trial name or title gestational diabetes.

Effects of an aquatic physical exercise program on glycaemic control and perinatal outcomes of

\begin{tabular}{|c|c|}
\hline Methods & Parallel-arm randomised controlled trial. \\
\hline Participants & $\begin{array}{l}\text { Instituto de Medicina Integral Prof. Fernando Figueira (IMIP, Recife, Brazil. } \\
\text { Pregnant women recently diagnosed with GDM by OGTT between } 24 \text { and } 28 \text { weeks' gestation using } \\
\text { IADPSG criteria. }\end{array}$ \\
\hline Interventions & $\begin{array}{l}\text { Comparison group - usual care consisting of standard dietary and exercise advice. } \\
\text { Intervention group - in addition to standard dietary and exercise advice, participants in the inter- } \\
\text { vention group will take part in aquatic exercises such as walking, walking backwards, swimming } \\
\text { laps, jogging, step climbing and strength exercises in a temperature maintained swimming pool for } \\
45 \text { minutes, } 3 \text { times a week, conducted from GDM diagnosis until the end of the third trimester. }\end{array}$ \\
\hline Outcomes & $\begin{array}{l}\text { Primary - glucose control. } \\
\text { Secondary - weight gain in pregnancy, systolic and diastolic blood pressure, pre-eclampsia, urinary } \\
\text { tract infections, vaginal infections, intrauterine growth restriction, preterm birth, caesarean sec- } \\
\text { tion, birth injury, macrosomia, maternal or neonatal intensive care admission. }\end{array}$ \\
\hline Starting date & Recruitment between August 2013 to March 2014. \\
\hline Contact information & joaoguilherme@imip.org.br \\
\hline Notes & $\begin{array}{l}\text { Reference for protocol: da Silva 2013b } \\
\text { Clinicaltrials.gov identifier: NCT01940003. }\end{array}$ \\
\hline
\end{tabular}

Kokic 2014

\begin{tabular}{ll}
\hline Trial name or title & Structured aerobic and resistance exercise and gestational diabetes. \\
\hline Methods & Parallel-arm randomised controlled trial. \\
\hline Participants & $\begin{array}{l}\text { Association for Functional Rehabiliations, Recreation and Applied Kinesiology Impulse, Zagreb, } \\
\text { Croatia. }\end{array}$ \\
& Pregnant women between the ages of 20 and 40, with established diagnosis of GDM. \\
\hline
\end{tabular}

Interventions Comparison group - standard antenatal care.


Kokic 2014 (Continued)

Intervention group - participation in a 50-minute structured exercise program twice a week consisting of aerobic, resistance and stretching and relaxation exercises, conducted from GDM diagnosis until the end of pregnancy.

\begin{tabular}{ll}
\hline Outcomes & $\begin{array}{l}\text { Primary - number of women with complications during pregnancy, labour and delivery, blood glu- } \\
\text { cose levels, need for insulin and oral hypoglycaemic drugs, caesarean section and other operative } \\
\text { delivery methods, other adverse occurrences during pregnancy. } \\
\text { Secondary - macrosomia, weight gain in pregnancy, body mass and fat percentage, lower back } \\
\text { pain, physical activity in pregnancy (questionnaire). }\end{array}$ \\
\hline Starting date & Janurary 2014 - December 2014. \\
\hline Contact information & Iva Sklempe Kokic. \\
\hline Notes & Clinicaltrials.gov identifier: NCT02196571. \\
\hline
\end{tabular}

\section{Shaw 2005}

\begin{tabular}{ll}
\hline Trial name or title & Strength training in gestational diabetes mellitus. \\
\hline Methods & Parallel-arm randomised controlled trial. \\
\hline Participants & $\begin{array}{l}\text { International Diabetes Insitute, Melbourne, Australia. } \\
\text { Pregnant women between the ages of } 18 \text { and } 40 \text { years, diagnosed with GDM. }\end{array}$ \\
\hline Interventions & $\begin{array}{l}\text { Comparison group - usual care. } \\
\text { Intervention group - supervised 45-minute strength training program twice a week from diagnosis } \\
\text { of GDM to birth. }\end{array}$ \\
\hline Outcomes & $\begin{array}{l}\text { Primary - changes in fasting glucose concentrations. } \\
\text { Secondary - changes in HbA1c, use of insulin, time until use of insulin, insulin resistance, blood } \\
\text { pressure, muscle strength. }\end{array}$ \\
\hline Starting date & Retrospectively registered - start date March 2005. \\
\hline Contact information & jshaw@idi.org.au \\
\hline Notes & ANZCTR identifier: ACTRN12605000378628. \\
\hline
\end{tabular}

GDM: gestational diabetes mellitus

OGTT: oral glucose tolerance test

\section{DATA AND ANALYSES}


Comparison 1. Exercise versus control

\begin{tabular}{|c|c|c|c|c|}
\hline Outcome or subgroup title & No. of studies & $\begin{array}{l}\text { No. of partici- } \\
\text { pants }\end{array}$ & Statistical method & Effect size \\
\hline $\begin{array}{l}1 \text { Hypertensive disorders of preg- } \\
\text { nancy (pre-eclampsia) }\end{array}$ & 2 & 48 & Risk Ratio (M-H, Fixed, 95\% Cl) & $0.31[0.01,7.09]$ \\
\hline 2 Caesarean section & 5 & 316 & Risk Ratio (M-H, Fixed, 95\% Cl) & $0.86[0.63,1.16]$ \\
\hline $\begin{array}{l}3 \text { Perinatal mortality (stillbirth and } \\
\text { neonatal mortality) }\end{array}$ & 1 & 19 & Risk Ratio (M-H, Fixed, 95\% Cl) & $0.0[0.0,0.0]$ \\
\hline $\begin{array}{l}4 \text { Mortality and morbidity compos- } \\
\text { ite (variously defined by trials, e.g. } \\
\text { perinatal or infant death, shoulder } \\
\text { dystocia, bone fracture or nerve pal- } \\
\text { sy) }\end{array}$ & 2 & 169 & Risk Ratio (M-H, Fixed, 95\% Cl) & $0.56[0.12,2.61]$ \\
\hline $\begin{array}{l}5 \text { Use of additional pharmacothera- } \\
\text { py }\end{array}$ & 7 & 413 & Risk Ratio (M-H, Fixed, 95\% Cl) & $0.76[0.54,1.08]$ \\
\hline 6 Maternal hypoglycaemia & 1 & 34 & Risk Ratio (M-H, Fixed, 95\% Cl) & $0.0[0.0,0.0]$ \\
\hline $\begin{array}{l}7 \text { Glycaemic control end of treat- } \\
\text { ment (Mean) }\end{array}$ & 1 & 34 & $\begin{array}{l}\text { Mean Difference (IV, Fixed, 95\% } \\
\mathrm{Cl} \text { ) }\end{array}$ & $0.28[0.04,0.52]$ \\
\hline $\begin{array}{l}8 \text { Glycaemic control end of treat- } \\
\text { ment (Fasting blood glucose con- } \\
\text { centration) }\end{array}$ & 4 & 363 & $\begin{array}{l}\text { Std. Mean Difference (IV, Ran- } \\
\text { dom, } 95 \% \mathrm{CI} \text { ) }\end{array}$ & $-0.59[-1.07,-0.11]$ \\
\hline $\begin{array}{l}9 \text { Glycaemic control end of treat- } \\
\text { ment (Postprandial blood glucose } \\
\text { concentration) }\end{array}$ & 3 & 344 & $\begin{array}{l}\text { Std. Mean Difference (IV, Ran- } \\
\text { dom, } 95 \% \mathrm{CI} \text { ) }\end{array}$ & $-0.85[-1.15,-0.55]$ \\
\hline $\begin{array}{l}10 \text { Glycaemic control end of treat- } \\
\text { ment (HbA1c) }\end{array}$ & 2 & 320 & $\begin{array}{l}\text { Mean Difference (IV, Fixed, 95\% } \\
\mathrm{Cl} \text { ) }\end{array}$ & $-0.43[-0.51,-0.35]$ \\
\hline $\begin{array}{l}11 \text { Glycaemic control end of treat- } \\
\text { ment (Glucose tolerance test) }\end{array}$ & 1 & 19 & $\begin{array}{l}\text { Mean Difference (IV, Fixed, 95\% } \\
\mathrm{Cl} \text { ) }\end{array}$ & $\begin{array}{l}-81.6[-96.03 \\
-67.17]\end{array}$ \\
\hline 12 Weight gain in pregnancy & 2 & 104 & $\begin{array}{l}\text { Mean Difference (IV, Fixed, 95\% } \\
\mathrm{CI})\end{array}$ & $-0.34[-1.25,0.58]$ \\
\hline $\begin{array}{l}13 \text { Weight gain in pregnancy (Exces- } \\
\text { sive) }\end{array}$ & 1 & 79 & Risk Ratio (M-H, Fixed, 95\% Cl) & $0.9[0.47,1.72]$ \\
\hline 14 Adherence to the intervention & 1 & 19 & Risk Ratio (M-H, Fixed, 95\% Cl) & $1.0[0.83,1.21]$ \\
\hline 15 Induction of labour & 1 & 40 & Risk Ratio (M-H, Fixed, 95\% Cl) & $1.38[0.71,2.68]$ \\
\hline 16 Maternal mortality & 2 & 48 & Risk Ratio (M-H, Fixed, 95\% Cl) & $0.0[0.0,0.0]$ \\
\hline $\begin{array}{l}17 \text { Views of the intervention } \\
\text { (favourable) }\end{array}$ & 1 & 40 & $\begin{array}{l}\text { Mean Difference (IV, Fixed, 95\% } \\
\mathrm{Cl} \text { ) }\end{array}$ & $0.0[0.0,0.0]$ \\
\hline $\begin{array}{l}18 \text { Postnatal weight retention or re- } \\
\text { turn to pre-pregnancy weight }\end{array}$ & 3 & 254 & $\begin{array}{l}\text { Mean Difference (IV, Fixed, 95\% } \\
\mathrm{Cl} \text { ) }\end{array}$ & $0.11[-1.04,1.26]$ \\
\hline
\end{tabular}




\begin{tabular}{|c|c|c|c|c|}
\hline Outcome or subgroup title & No. of studies & $\begin{array}{l}\text { No. of partici- } \\
\text { pants }\end{array}$ & Statistical method & Effect size \\
\hline 18.1 Maternal BMI (follow-up) kg/m2 & 3 & 254 & $\begin{array}{l}\text { Mean Difference (IV, Fixed, 95\% } \\
\text { Cl) }\end{array}$ & $0.11[-1.04,1.26]$ \\
\hline 19 Stillbirth & 1 & 29 & Risk Ratio (M-H, Fixed, 95\% Cl) & $0.0[0.0,0.0]$ \\
\hline 20 Macrosomia & 5 & 296 & Risk Ratio (M-H, Fixed, 95\% Cl) & $0.69[0.35,1.35]$ \\
\hline 21 Gestational age at birth & 4 & 167 & $\begin{array}{l}\text { Mean Difference (IV, Fixed, 95\% } \\
\text { CI) }\end{array}$ & $-0.01[-0.40,0.38]$ \\
\hline 22 Preterm birth & 5 & 302 & Risk Ratio (M-H, Fixed, 95\% Cl) & $0.95[0.39,2.36]$ \\
\hline 23 Five-minute Apgar < seven & 1 & 34 & Risk Ratio (M-H, Fixed, 95\% Cl) & $0.33[0.01,7.65]$ \\
\hline 24 Birthweight & 6 & 192 & $\begin{array}{l}\text { Mean Difference (IV, Fixed, 95\% } \\
\text { CI) }\end{array}$ & $\begin{array}{l}-61.50[-195.21 \\
72.20]\end{array}$ \\
\hline 25 Length $(\mathrm{cm})$ (at birth) & 1 & 34 & $\begin{array}{l}\text { Mean Difference (IV, Fixed, 95\% } \\
\text { CI) }\end{array}$ & $-1.70[-3.41,0.01]$ \\
\hline 26 Neonatal hypoglycaemia & 1 & 34 & Risk Ratio (M-H, Fixed, 95\% Cl) & $2.0[0.20,20.04]$ \\
\hline 27 Respiratory distress syndrome & 1 & 34 & Risk Ratio (M-H, Fixed, 95\% Cl) & $0.0[0.0,0.0]$ \\
\hline $\begin{array}{l}28 \text { Neonatal jaundice (hyperbilirubi- } \\
\text { naemia) }\end{array}$ & 1 & 34 & Risk Ratio (M-H, Fixed, 95\% Cl) & $0.33[0.01,7.65]$ \\
\hline 29 Hypocalcaemia & 1 & 34 & Risk Ratio (M-H, Fixed, 95\% Cl) & $0.0[0.0,0.0]$ \\
\hline
\end{tabular}

\section{Analysis 1.1. Comparison 1 Exercise versus control, Outcome} 1 Hypertensive disorders of pregnancy (pre-eclampsia).

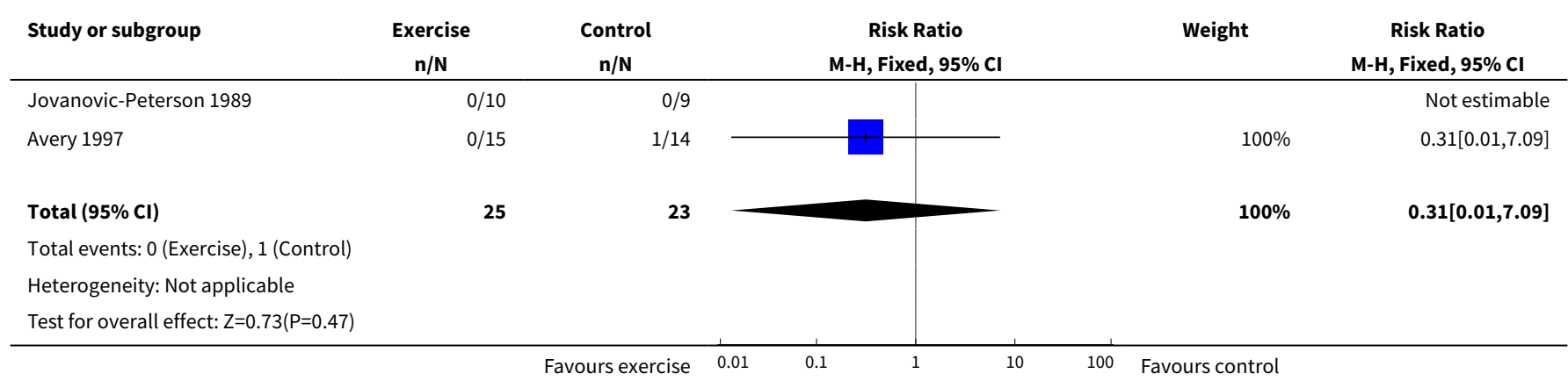


Analysis 1.2. Comparison 1 Exercise versus control, Outcome 2 Caesarean section.

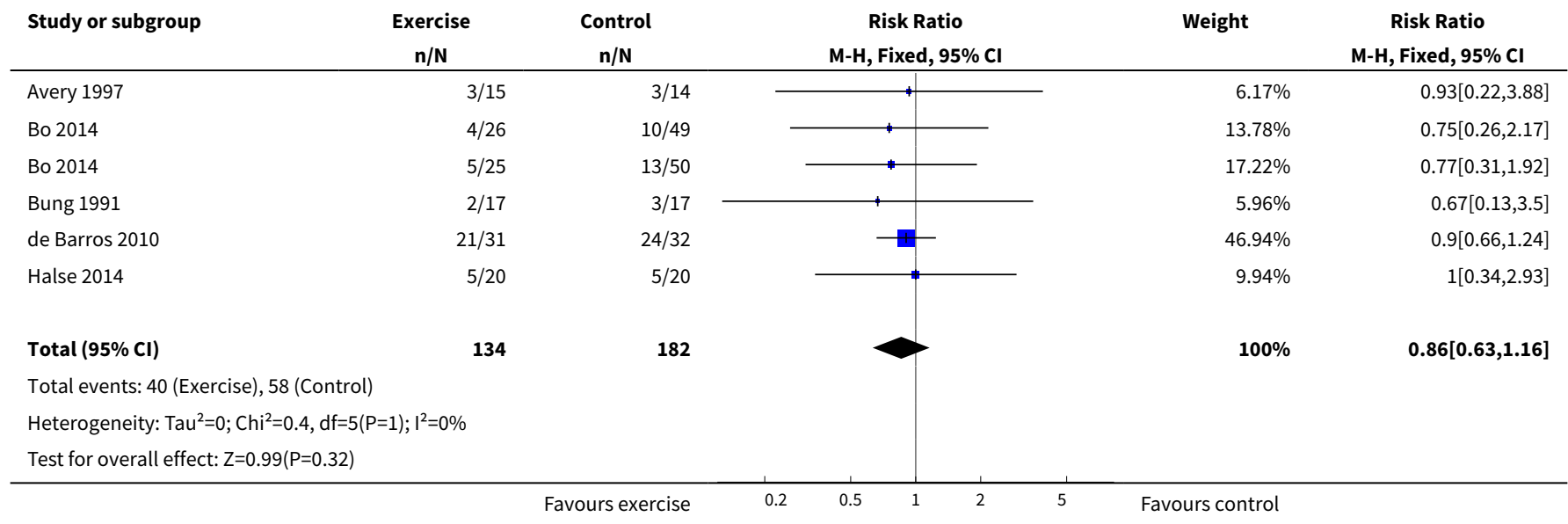

Analysis 1.3. Comparison 1 Exercise versus control, Outcome 3 Perinatal mortality (stillbirth and neonatal mortality).

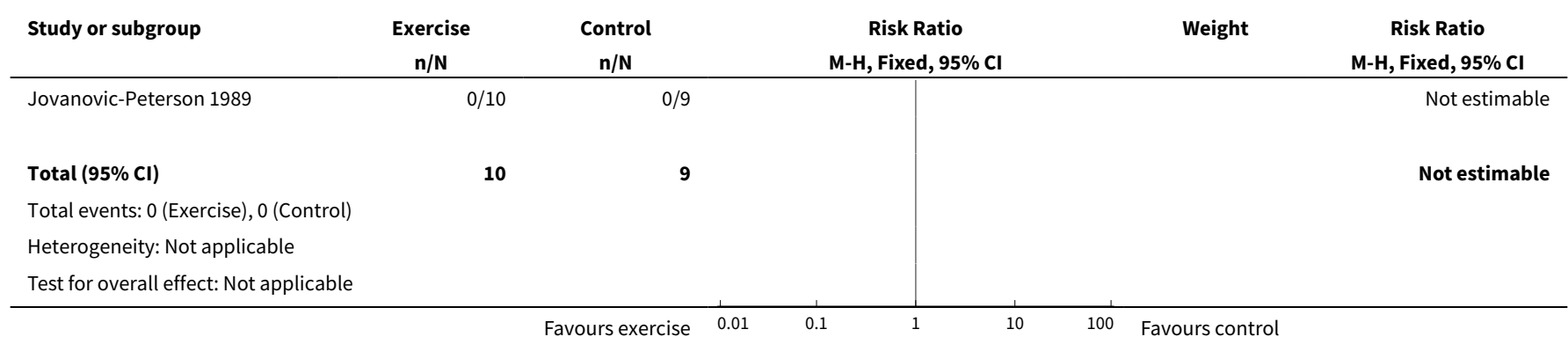

Analysis 1.4. Comparison 1 Exercise versus control, Outcome 4 Mortality and morbidity composite (variously defined by trials, e.g. perinatal or infant death, shoulder dystocia, bone fracture or nerve palsy).

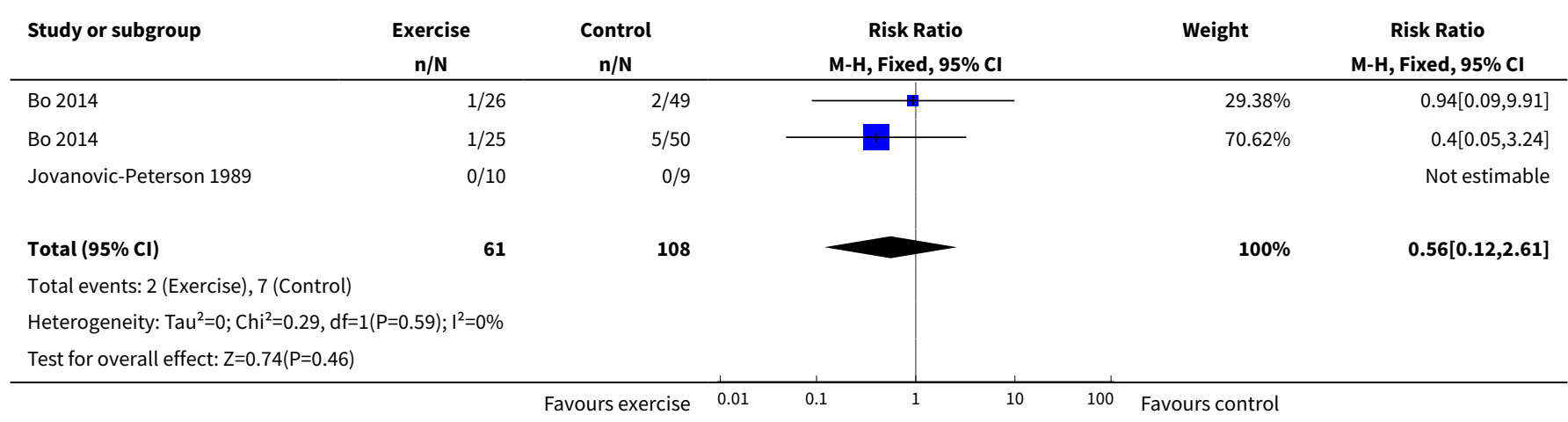


Analysis 1.5. Comparison 1 Exercise versus control, Outcome 5 Use of additional pharmacotherapy.

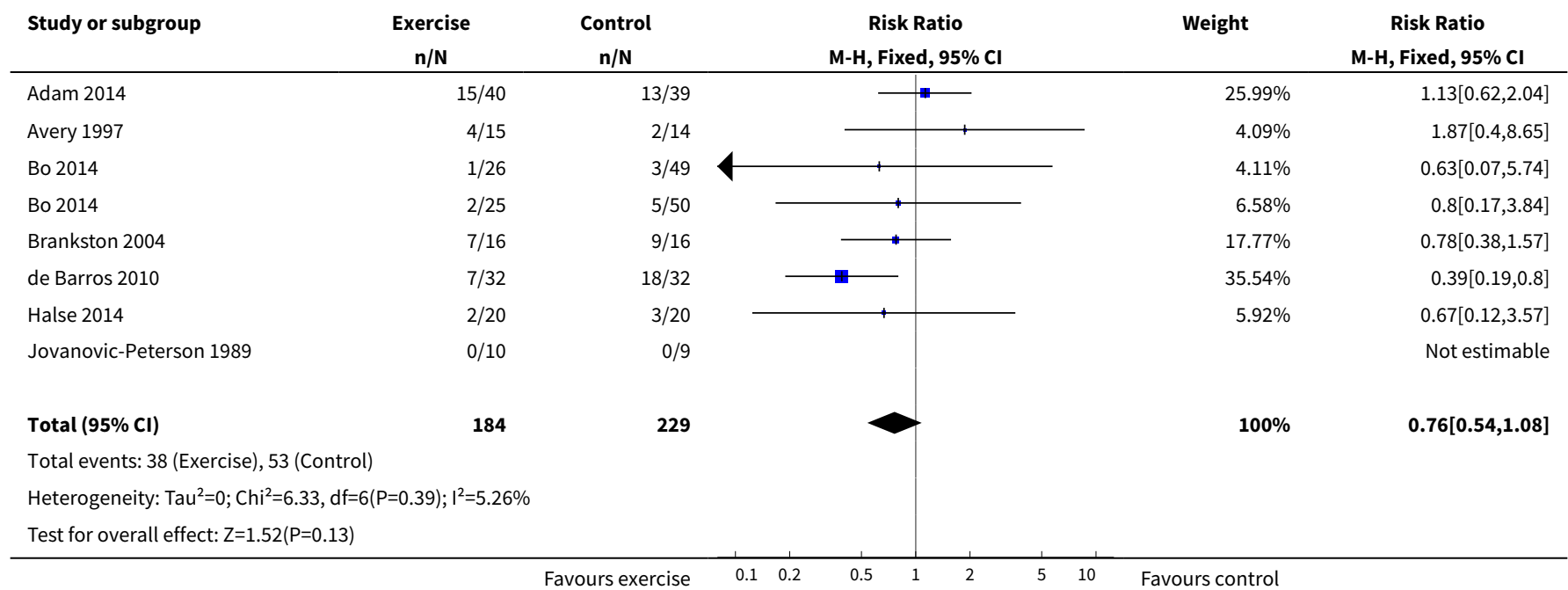

Analysis 1.6. Comparison 1 Exercise versus control, Outcome 6 Maternal hypoglycaemia.

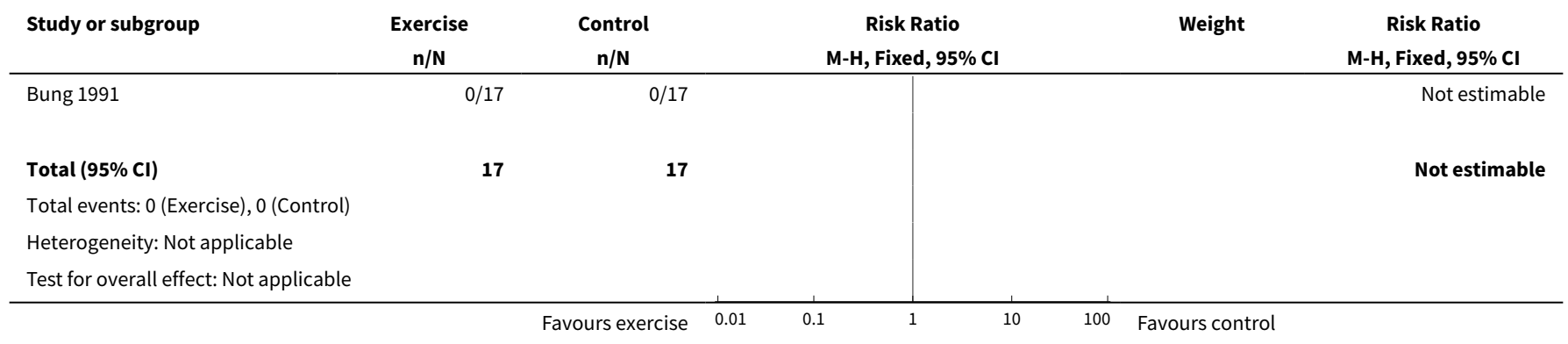

\section{Analysis 1.7. Comparison 1 Exercise versus control, Outcome 7 Glycaemic control end of treatment (Mean).}

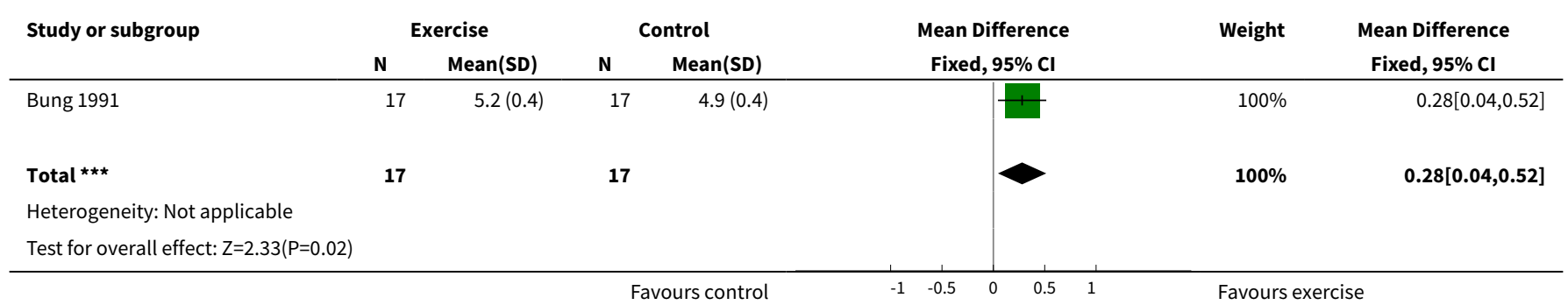


Analysis 1.8. Comparison 1 Exercise versus control, Outcome 8 Glycaemic control end of treatment (Fasting blood glucose concentration).

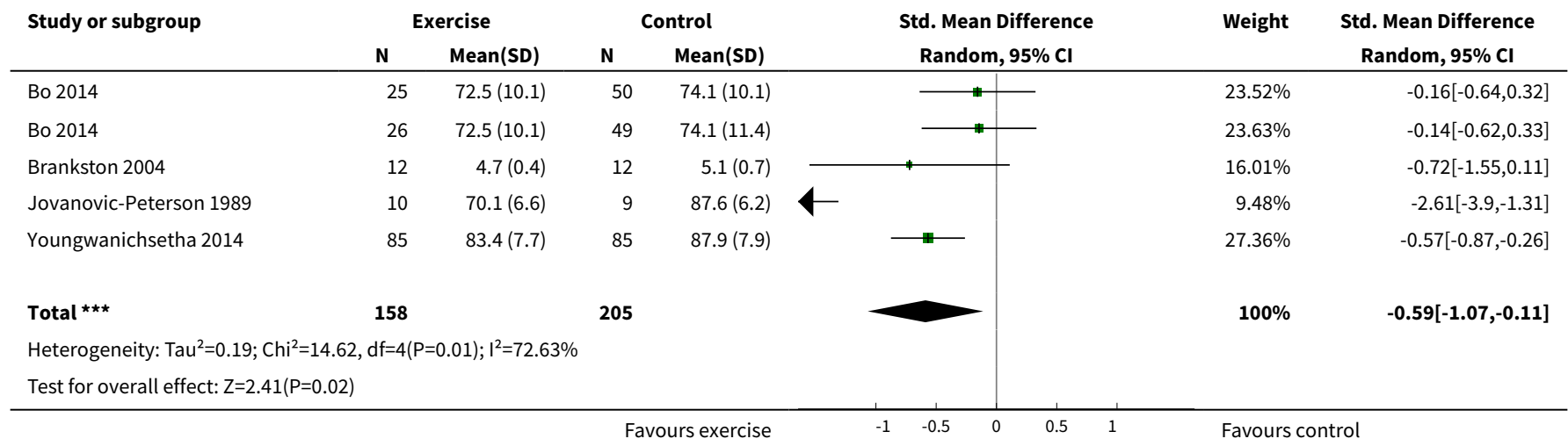

Analysis 1.9. Comparison 1 Exercise versus control, Outcome 9 Glycaemic control end of treatment (Postprandial blood glucose concentration).

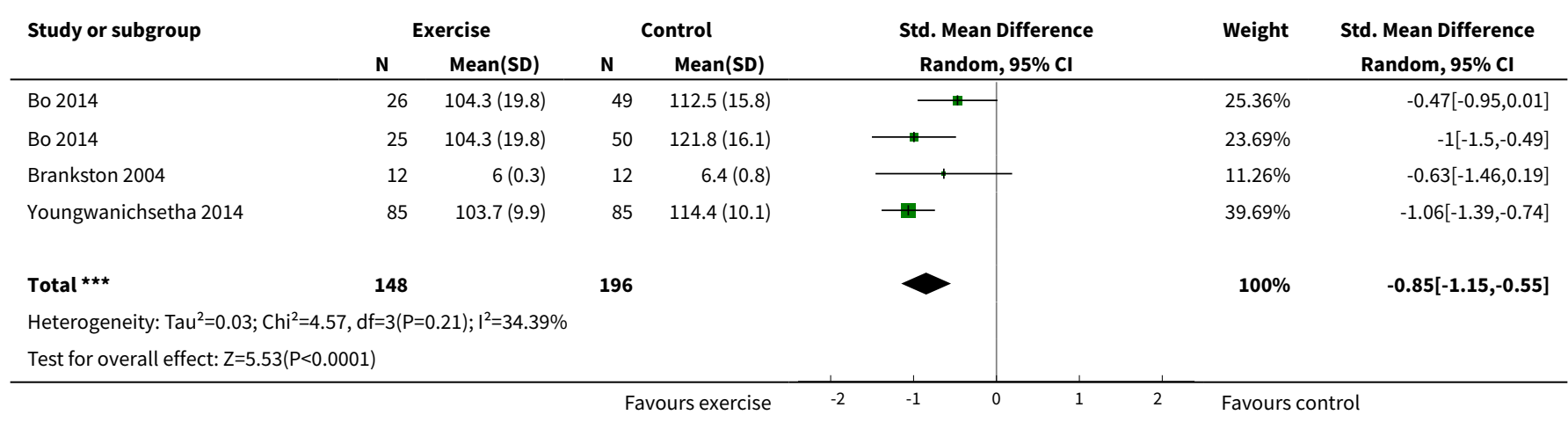

Analysis 1.10. Comparison 1 Exercise versus control, Outcome 10 Glycaemic control end of treatment (HbA1c).

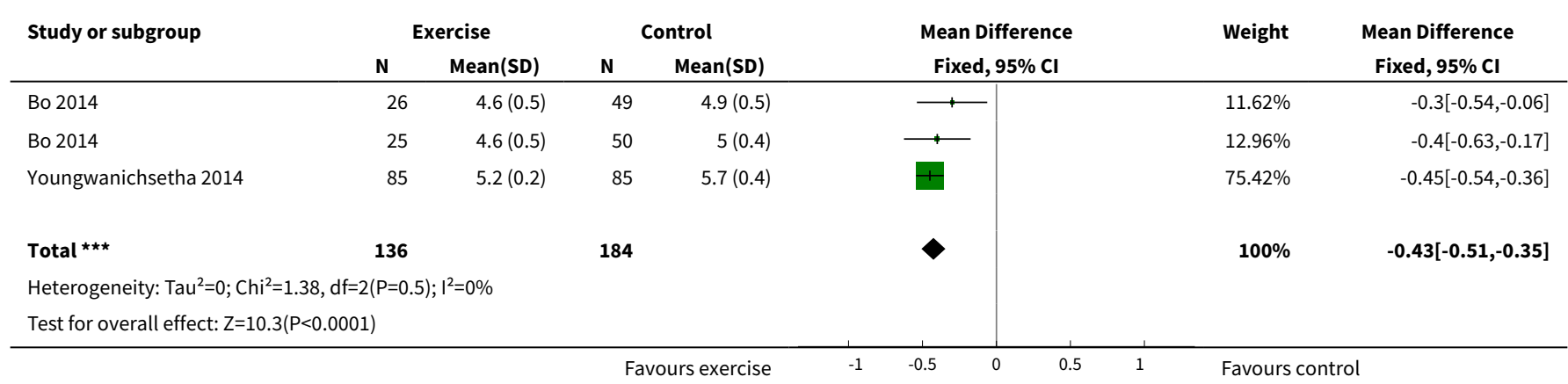


Analysis 1.11. Comparison 1 Exercise versus control, Outcome

11 Glycaemic control end of treatment (Glucose tolerance test).

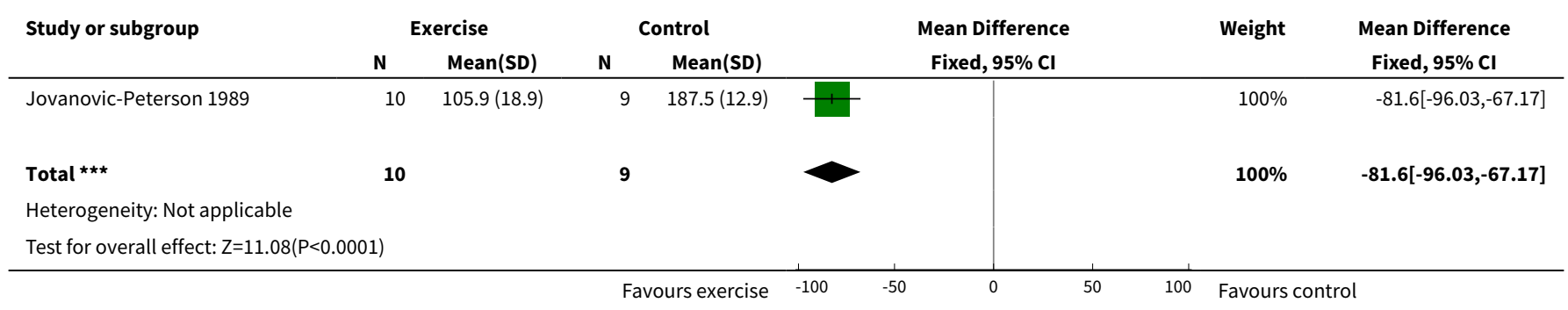

Analysis 1.12. Comparison 1 Exercise versus control, Outcome 12 Weight gain in pregnancy.

\begin{tabular}{|c|c|c|c|c|c|c|c|}
\hline \multirow{3}{*}{$\begin{array}{l}\text { Study or subgroup } \\
\text { de Barros } 2010\end{array}$} & \multicolumn{2}{|c|}{ Exercise } & \multicolumn{2}{|c|}{ Control } & \multirow{2}{*}{$\begin{array}{c}\text { Mean Difference } \\
\text { Fixed, 95\% Cl }\end{array}$} & \multirow[t]{2}{*}{ Weight } & \multirow{2}{*}{$\begin{array}{c}\text { Mean Difference } \\
\text { Fixed, } 95 \% \mathrm{Cl}\end{array}$} \\
\hline & $\mathbf{N}$ & Mean(SD) & $\mathbf{N}$ & Mean(SD) & & & \\
\hline & 32 & $11.3(5.6)$ & 32 & $12.6(5.3)$ & & $11.67 \%$ & $-1.36[-4.04,1.32]$ \\
\hline Halse 2014 & 20 & $0.8(1.3)$ & 20 & $1(1.8)$ & & $88.33 \%$ & $-0.2[-1.17,0.77]$ \\
\hline Total $\star \star \star$ & 52 & & 52 & & & $100 \%$ & $-0.34[-1.25,0.58]$ \\
\hline \multicolumn{8}{|c|}{ Heterogeneity: $\operatorname{Tau}^{2}=0 ; \mathrm{Chi}^{2}=0.64, \mathrm{df}=1(\mathrm{P}=0.42) ; \mathrm{I}^{2}=0 \%$} \\
\hline
\end{tabular}

Analysis 1.13. Comparison 1 Exercise versus control, Outcome 13 Weight gain in pregnancy (Excessive).

\begin{tabular}{|c|c|c|c|c|c|}
\hline Study or subgroup & $\begin{array}{l}\text { Exercise } \\
n / N\end{array}$ & $\begin{array}{c}\text { Control } \\
n / N\end{array}$ & $\begin{array}{c}\text { Risk Ratio } \\
\text { M-H, Fixed, 95\% CI }\end{array}$ & Weight & $\begin{array}{c}\text { Risk Ratio } \\
\text { M-H, Fixed, 95\% CI }\end{array}$ \\
\hline Adam 2014 & $12 / 40$ & $13 / 39$ & & $100 \%$ & $0.9[0.47,1.72]$ \\
\hline Total $(95 \% \mathrm{Cl})$ & 40 & 39 & & $100 \%$ & $0.9[0.47,1.72]$ \\
\hline \multicolumn{6}{|c|}{ Total events: 12 (Exercise), 13 (Control) } \\
\hline \multicolumn{6}{|c|}{ Heterogeneity: Not applicable } \\
\hline
\end{tabular}

Analysis 1.14. Comparison 1 Exercise versus control, Outcome 14 Adherence to the intervention.

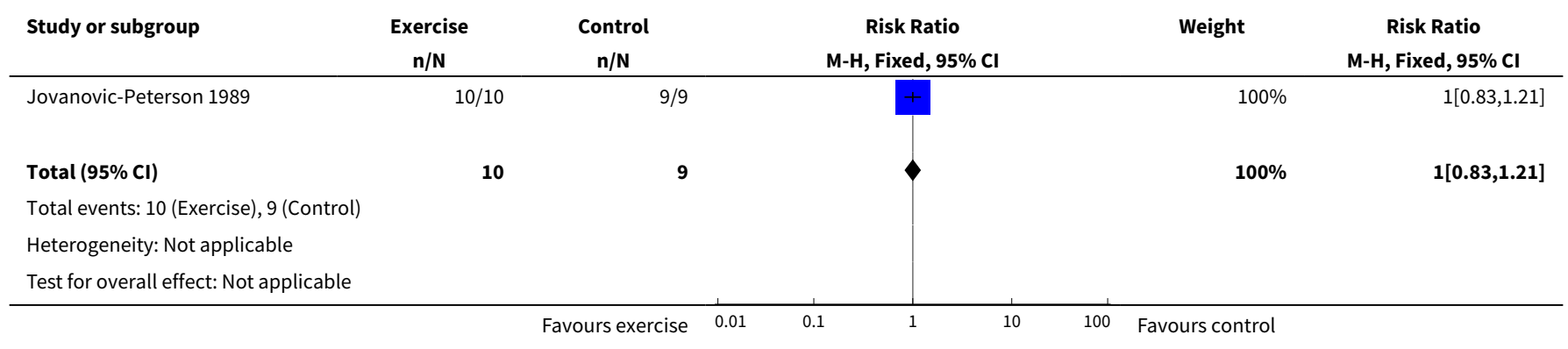


Analysis 1.15. Comparison 1 Exercise versus control, Outcome 15 Induction of labour.

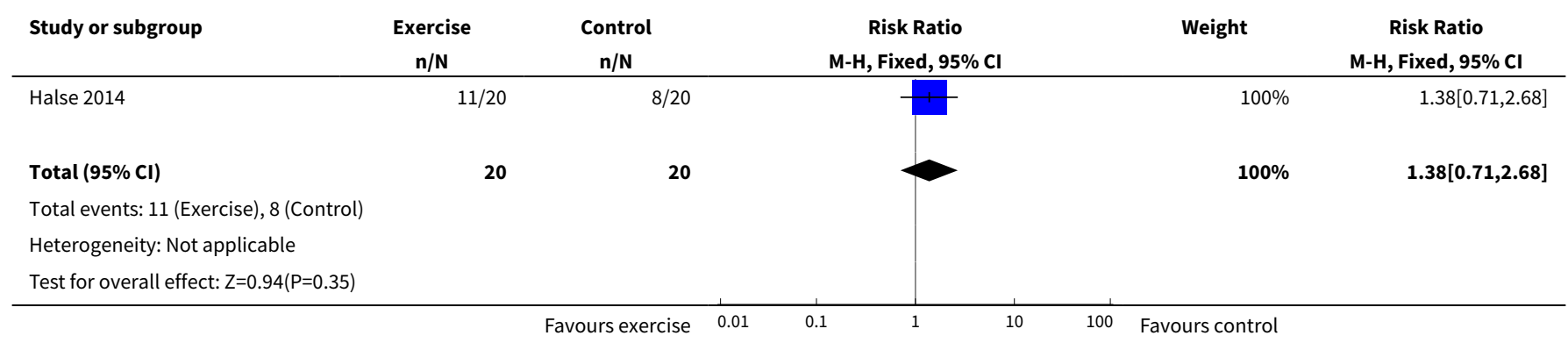

Analysis 1.16. Comparison 1 Exercise versus control, Outcome 16 Maternal mortality.

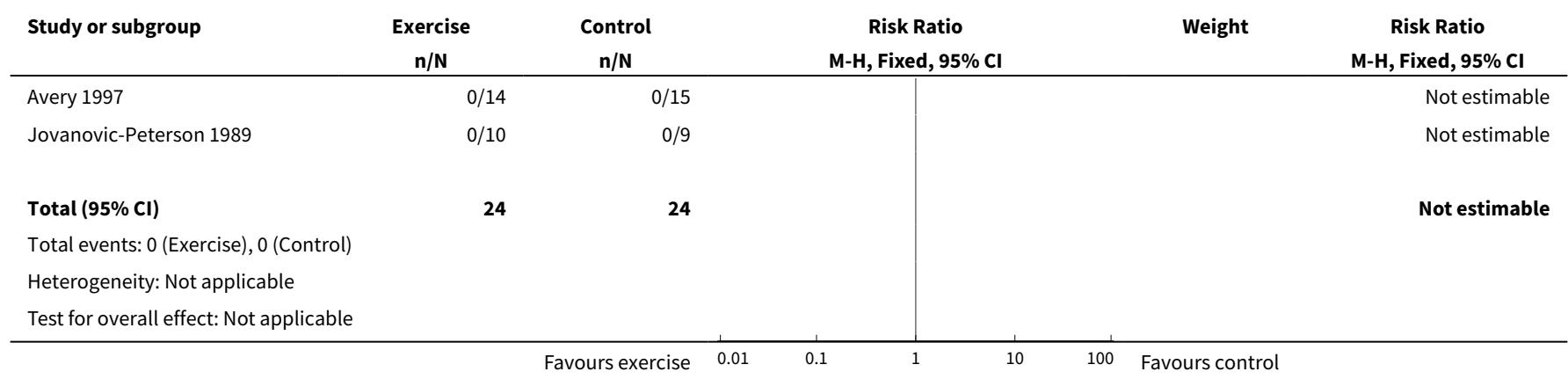

Analysis 1.17. Comparison 1 Exercise versus control, Outcome 17 Views of the intervention (favourable).

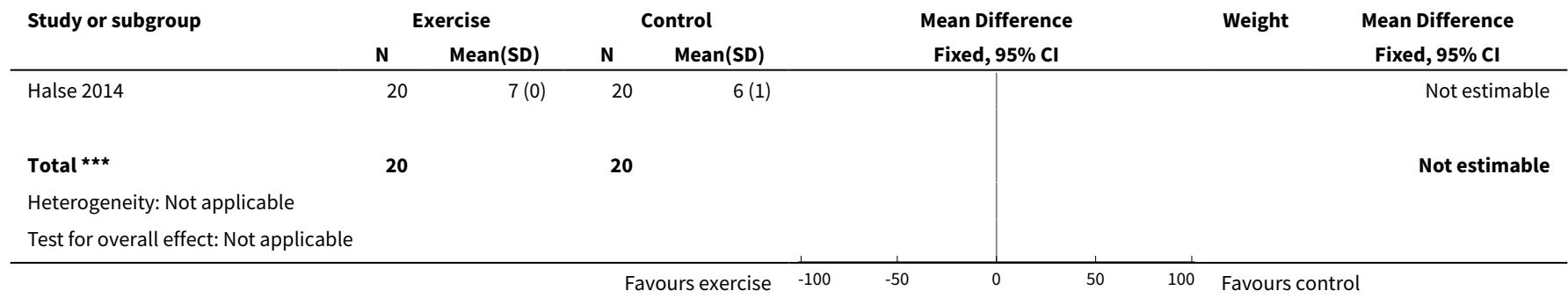

Analysis 1.18. Comparison 1 Exercise versus control, Outcome 18 Postnatal weight retention or return to pre-pregnancy weight.

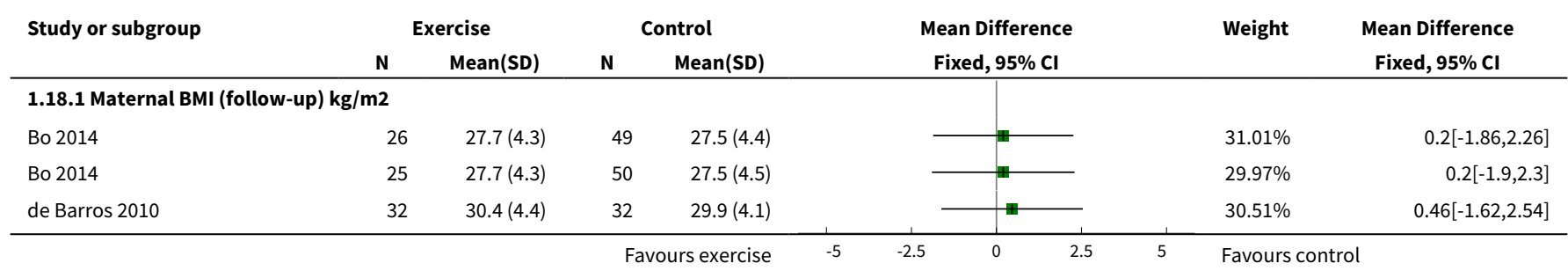




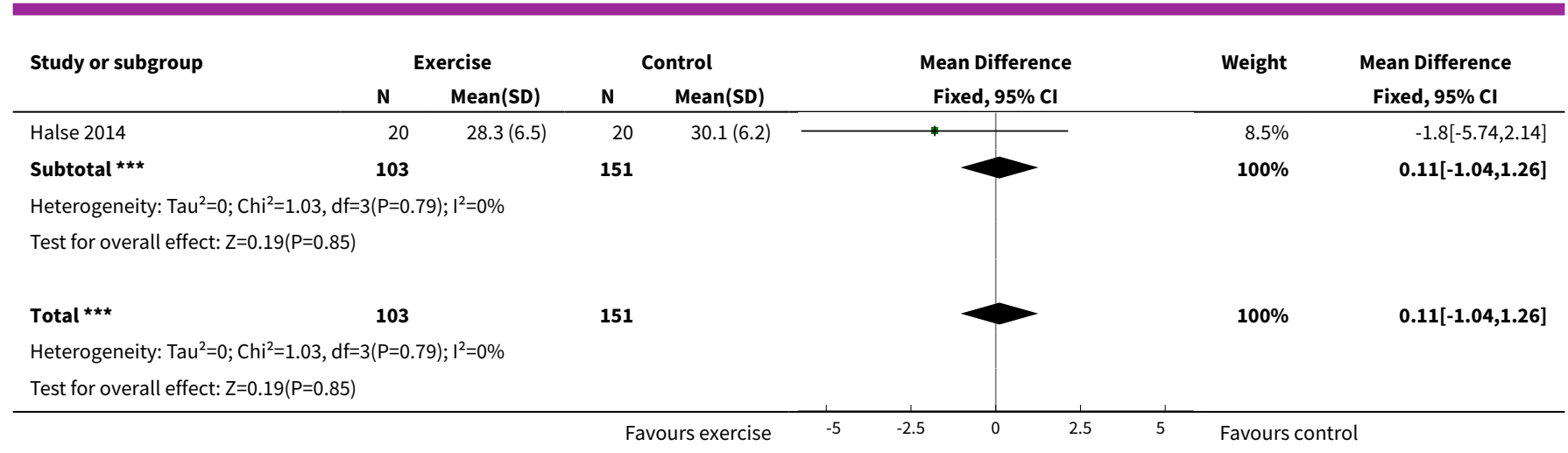

Analysis 1.19. Comparison 1 Exercise versus control, Outcome 19 Stillbirth.

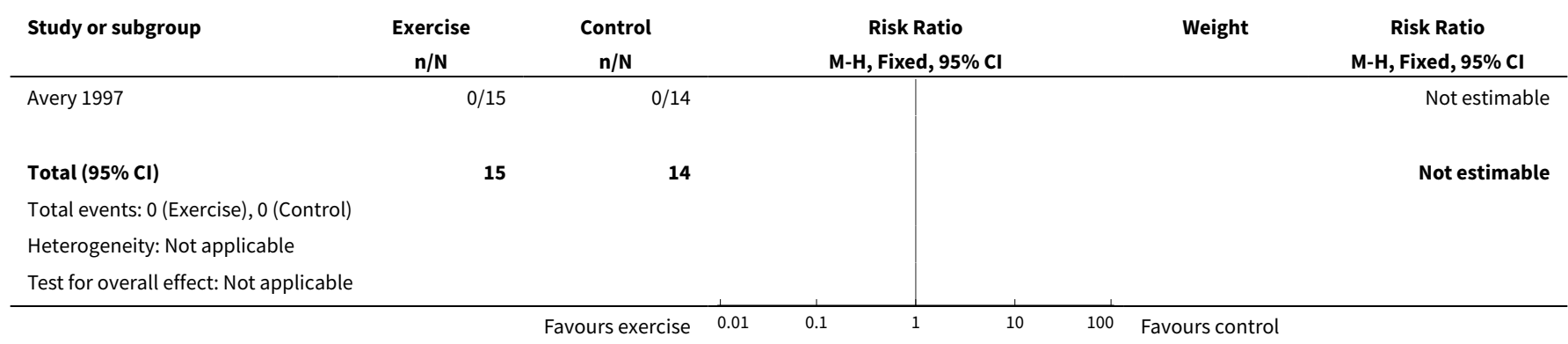

Analysis 1.20. Comparison 1 Exercise versus control, Outcome 20 Macrosomia.

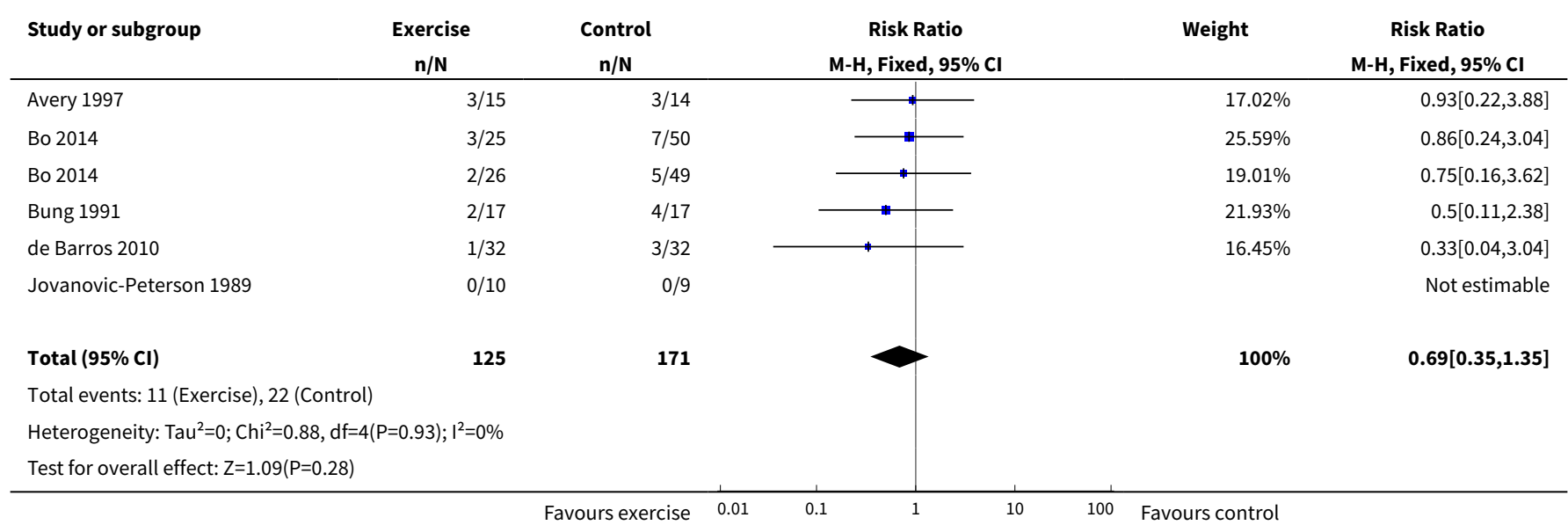

Analysis 1.21. Comparison 1 Exercise versus control, Outcome 21 Gestational age at birth.

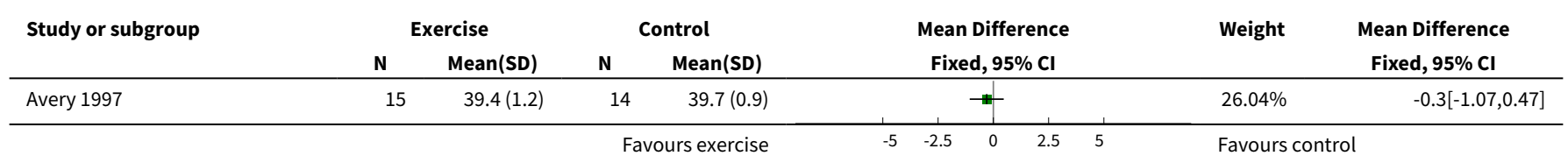




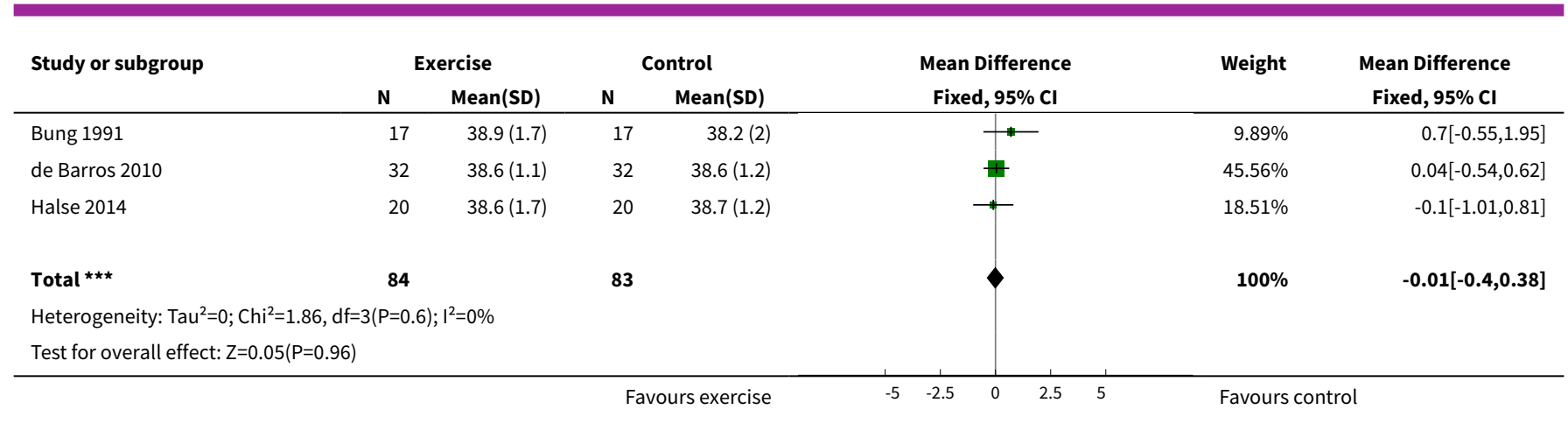

Analysis 1.22. Comparison 1 Exercise versus control, Outcome 22 Preterm birth.

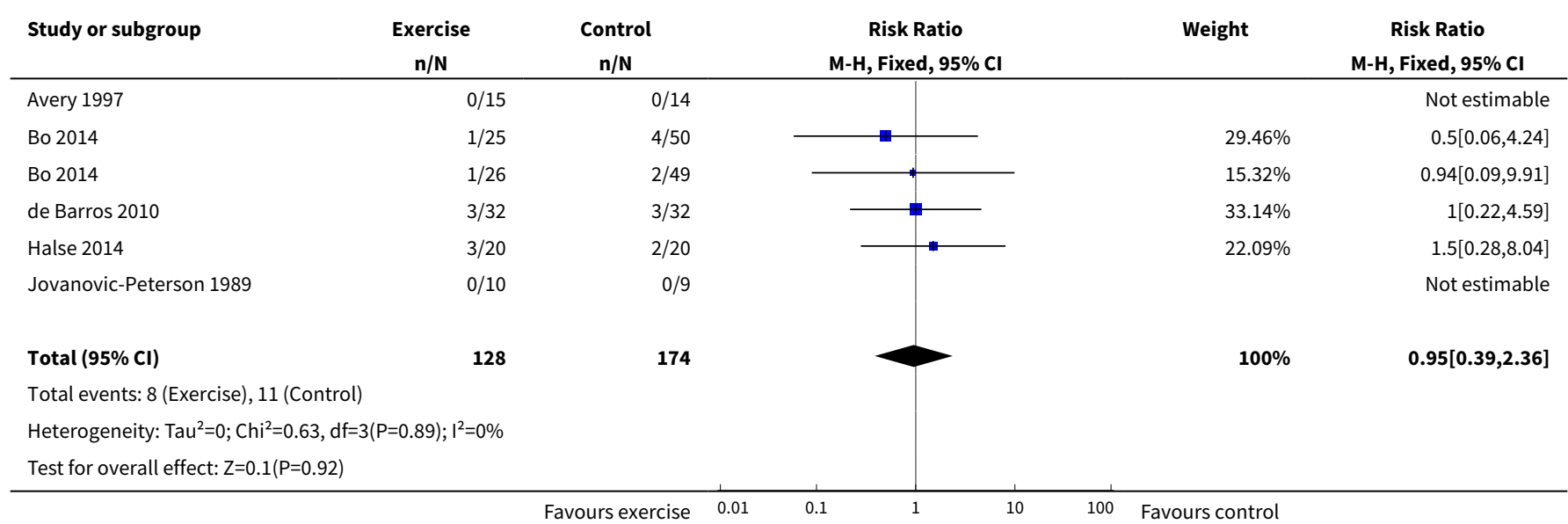

Analysis 1.23. Comparison 1 Exercise versus control, Outcome 23 Five-minute Apgar < seven.

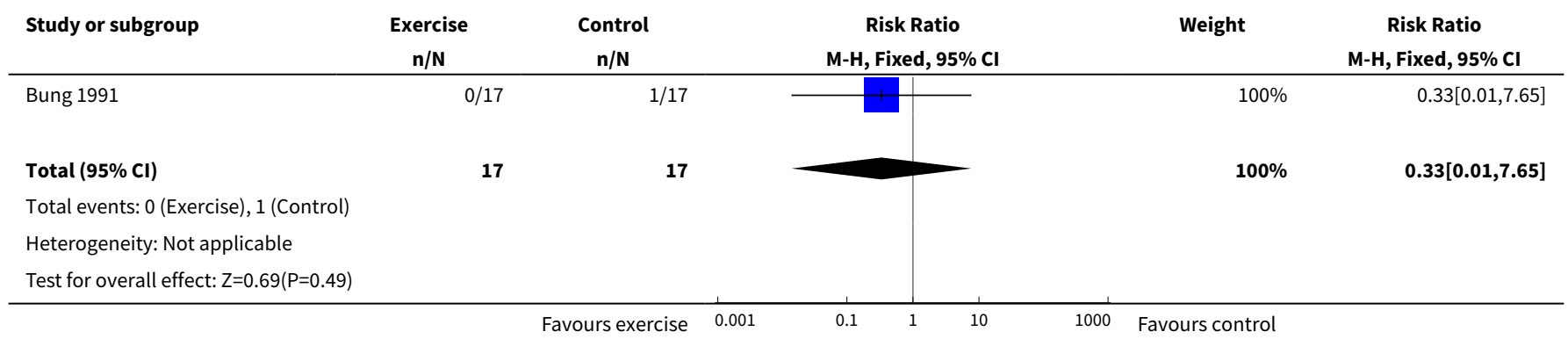

Analysis 1.24. Comparison 1 Exercise versus control, Outcome 24 Birthweight.

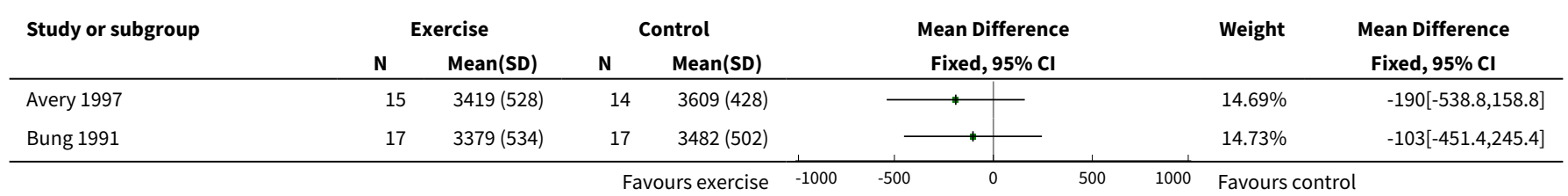




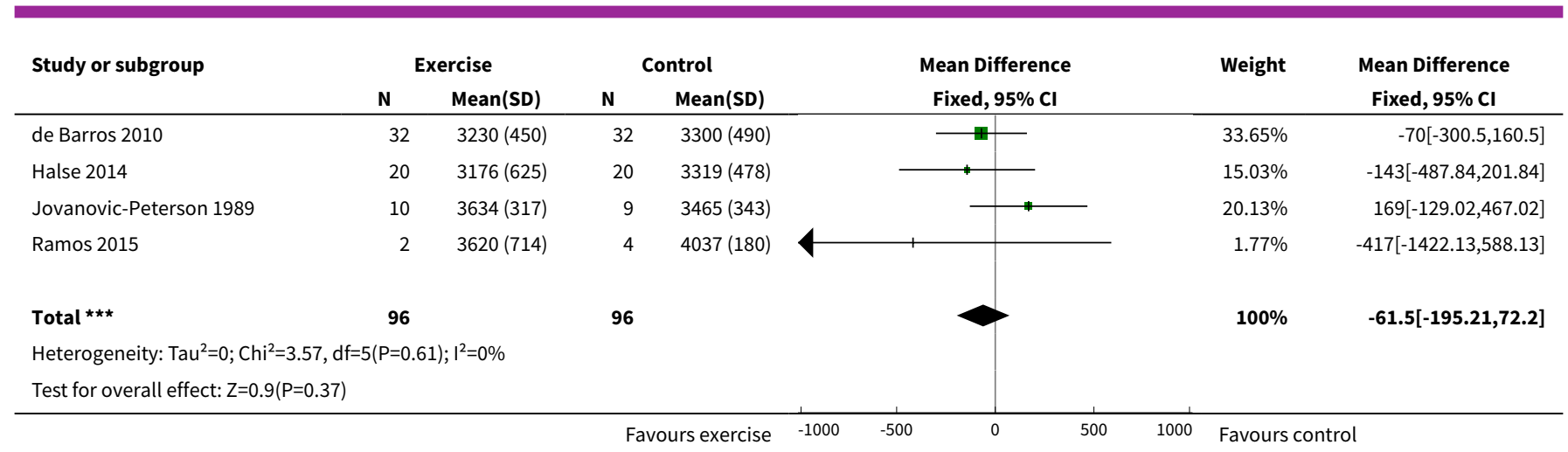

Analysis 1.25. Comparison 1 Exercise versus control, Outcome 25 Length (cm) (at birth).

\begin{tabular}{|c|c|c|c|c|c|c|c|}
\hline \multirow[t]{2}{*}{ Study or subgroup } & \multicolumn{2}{|c|}{ Exercise } & \multicolumn{2}{|c|}{ Control } & \multirow{2}{*}{$\begin{array}{c}\text { Mean Difference } \\
\text { Fixed, } 95 \% \mathrm{Cl}\end{array}$} & \multirow[t]{2}{*}{ Weight } & \multirow{2}{*}{$\begin{array}{c}\text { Mean Difference } \\
\text { Fixed, } 95 \% \mathrm{Cl}\end{array}$} \\
\hline & $\mathbf{N}$ & Mean(SD) & $\mathbf{N}$ & Mean(SD) & & & \\
\hline Bung 1991 & 17 & $49.3(2)$ & 17 & $51(3)$ & + & $100 \%$ & $-1.7[-3.41,0.01]$ \\
\hline 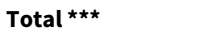 & 17 & & 17 & & 1 & $100 \%$ & $-1.7[-3.41,0.01]$ \\
\hline \multicolumn{8}{|c|}{ Heterogeneity: Not applicable } \\
\hline \multicolumn{8}{|c|}{ Test for overall effect: $\mathrm{Z}=1.94(\mathrm{P}=0.05)$} \\
\hline & & & & urs exercise $\quad-100$ & -50 & Favours & \\
\hline
\end{tabular}

Analysis 1.26. Comparison 1 Exercise versus control, Outcome 26 Neonatal hypoglycaemia.

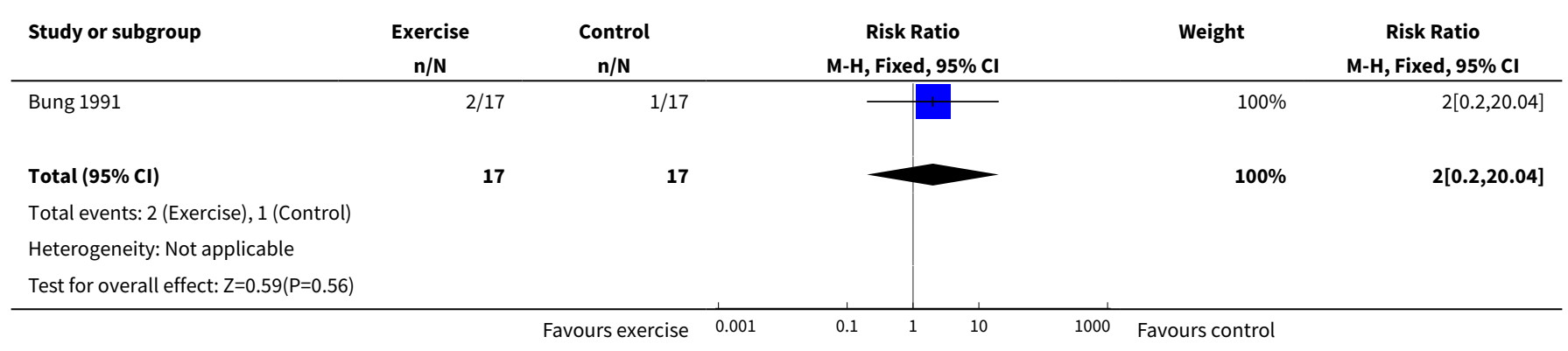

Analysis 1.27. Comparison 1 Exercise versus control, Outcome 27 Respiratory distress syndrome.

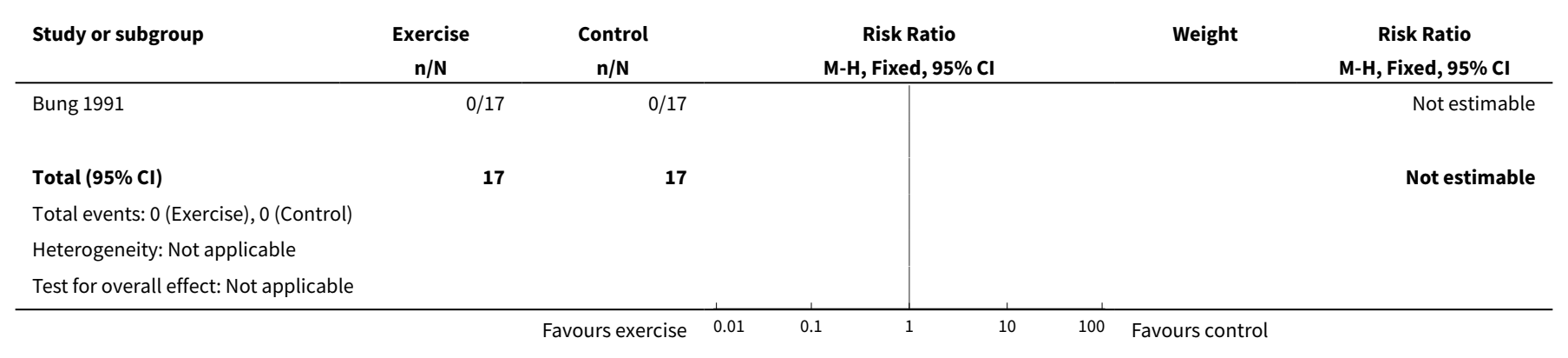


Analysis 1.28. Comparison 1 Exercise versus control, Outcome 28 Neonatal jaundice (hyperbilirubinaemia).

\begin{tabular}{|c|c|c|c|c|c|}
\hline Study or subgroup & $\begin{array}{c}\text { Exercise } \\
\mathrm{n} / \mathrm{N}\end{array}$ & $\begin{array}{c}\text { Control } \\
\mathrm{n} / \mathrm{N}\end{array}$ & $\begin{array}{c}\text { Risk Ratio } \\
\text { M-H, Fixed, } 95 \% \text { Cl }\end{array}$ & Weight & $\begin{array}{c}\text { Risk Ratio } \\
\text { M-H, Fixed, } 95 \% \mathrm{Cl}\end{array}$ \\
\hline Bung 1991 & $0 / 17$ & $1 / 17$ & $=$ & $100 \%$ & $0.33[0.01,7.65]$ \\
\hline Total $(95 \% \mathrm{Cl})$ & 17 & 17 & & $100 \%$ & $0.33[0.01,7.65]$ \\
\hline \multicolumn{6}{|c|}{ Total events: 0 (Exercise), 1 (Control) } \\
\hline \multicolumn{6}{|c|}{ Heterogeneity: Not applicable } \\
\hline Test for overall effect & & & & & \\
\hline
\end{tabular}

Analysis 1.29. Comparison 1 Exercise versus control, Outcome 29 Hypocalcaemia.

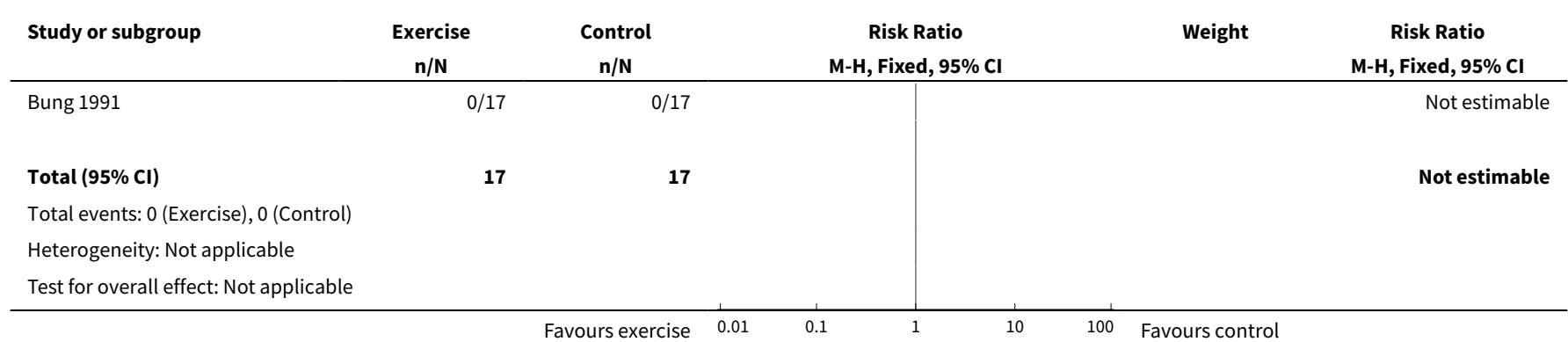

\section{APPENDICES}

\section{Appendix 1. Search terms for ICTRP and ClinicalTrials.gov}

exercise AND GDM

exercise AND gestational diabetes

exercise AND diabetes AND pregnancy

\section{CONTRIBUTIONS OF AUTHORS}

Dr Julie Brown guarantees this review. Dr Gilles Ceysens and Dr Michel Boulvain prepared the original (Ceysens 2006) review upon which this review is based. For this review, Dr Brown joined the team to provide methodological support to update the review, which was split into two new reviews on: exercise for pregnant women with gestational diabetes, and exercise for pregnant women with pre-existing diabetes. A new protocol (Ceysens 2016) was developed to inform this review.

\section{DECLARATIONS OF INTEREST}

Dr Gilles Ceysens - none known.

Dr Julie Brown - none known.

Dr Michel Boulvain received research funding from Centre de Recherche Clinique (Advanced researcher grant scheme (2007-2010)) to study exercise in pregnancy. One of the studies was a randomised controlled trial evaluating the effects of exercise in women with gestational diabetes. This study may be eligible for inclusion in this review - Michel Boulvain will not be involved in any decisions relating to the inclusion of his own study in this review. All tasks relating to that study (assessment for inclusion, risk of bias, data extraction) will be carried out by the other members of the review team who were not directly involved in the trial. In 2012, he was invited to speak at the DIP 2012 Congress on gestational diabetes and was reimbursed for travel and accommodation. 


\section{SOURCESOF SUPPORT}

\section{Internal sources}

- Liggins Institute, University of Auckland, New Zealand.

Support for infrastructure to develop this protocol and update the review was received from the Liggins Institute, University of Auckland.

\section{External sources}

- National Institute for Health Research (NIHR), UK. NIHR Cochrane Programme Grant Project: 13/89/05 - Pregnancy and childbirth systematic reviews to support clinical guidelines, UK

\section{DIFFERENCES BETWEEN PROTOCOL AND REVIEW}

There are some differences between our published protocol (Ceysens 2016) and this full review.

Dr Julie Brown has now taken over the role of contact person and guarantor for this review.

Methods/types of outcomes - we edited the outcome 'Large for gestational age' to include the criterion '( $\geq 4 \mathrm{~kg})$ '.

Methods/Assessment of the quality of the body of evidence using the GRADE approach - for consistency, we edited some outcome names to match the list of outcomes in the main methods. This relates to the following outcomes.

\section{Maternal}

1. 'Hypertensive disorders of pregnancy' has now been edited to 'Hypertensive disorders of pregnancy (as reported by trialists, including pre-eclampsia, pregnancy-induced hypertension, eclampsia)'

2. 'Perineal trauma' has now been edited to 'Perineal trauma/tearing'

3. 'Return to pre-pregnancy weight' has now been edited to 'Postnatal weight retention or return to pre-pregnancy weight'

\section{Child (as a fetus, neonatal child or adult)}

1. 'Perinatal mortality' has been edited to 'Perinatal mortality (stillbirth and neonatal mortality)'

2. 'Composite outcome of serious neonatal outcomes' has been edited to 'Mortality and morbidity composite (variously defined by trials, e.g. perinatal or infant death, shoulder dystocia, bone fracture or nerve palsy)'

3. We clarified that 'Diabetes' could be either type 1 or type 2 and could relate to later infant, childhood or for the child as an adult

4. We clarified that 'Adiposity' could relate to the neonate, later during infancy, childhood or for the child as an adult

\section{Methods to be utilised in future updates, as appropriate}

\section{Data collection and analysis}

\section{Unit of analysis issues}

\section{Multiple-arm studies}

We will avoid 'double-counting' of participants by combining group to create a single pair-wise comparison, if possible. In this version of the review it was not possible to do this so we split the 'shared' group into two or more groups with smaller sample sizes to include two or more reasonably independent comparisons.

\section{Sensitivity analysis}

Planned sensitivity analyses were not carried out because we did not observe substantial heterogeneity in our analysis and did not include cluster-randomised controlled trials. We will perform planned sensitivity analyses for the review's primary outcomes in future updates, if appropriate.

\section{Subgroup analysis and investigation of heterogeneity}

Planned subgroup analyses were not carried out due to insufficient data - these will be performed in future updates, if appropriate. 


\section{N D EX TERMS}

\section{Medical Subject Headings (MeSH)}

Body Mass Index; Cesarean Section; Diabetes, Gestational [^therapy]; Dystocia [epidemiology]; Exercise Therapy [ ${ }^{\star}$ methods]; Hypoglycemia [epidemiology]; Labor, Induced [statistics \& numerical data]; Perinatal Mortality; Pre-Eclampsia [epidemiology]; Randomized Controlled Trials as Topic

\section{MeSH check words}

Adult; Female; Humans; Infant; Infant, Newborn; Pregnancy 